\author{
UNIVERSIDADE DE SÃO PAULO \\ FACULDADE DE CIÊNCIAS FARMACÊUTICAS DE RIBEIRÃO PRETO
}

Análise comparativa entre galectinas-1 humana e de camundongo sob os aspectos biológico e molecular 
FACULDADE DE CIÊNCIAS FARMACÊUTICAS DE RIBEIRÃO PRETO

\title{
Análise comparativa entre galectinas-1 humana e de camundongo sob os aspectos biológico e molecular
}

\author{
Dissertação de Mestrado apresentada ao \\ Programa de Pós-Graduação em \\ Biociências Aplicadas à Farmácia para \\ obtenção do Título de Mestre em Ciências \\ Área de Concentração: Biociências \\ Aplicadas à Farmácia.
}

Orientada: Amanda Cristina Trabuco

Orientador: Prof. Dr. Marcelo Dias Baruffi

Versão corrigida da Dissertação de Mestrado apresentada ao Programa de PósGraduação em Biociências Aplicadas À Farmácia em 12/08/2013. A versão original encontra-se disponível na Faculdade de Ciências Farmacêuticas de Ribeirão Preto/USP 
AUTORIZO A REPRODUÇÃO E DIVULGAÇÃO TOTAL OU PARCIAL DESTE TRABALHO, POR QUALQÜER MEIO CONVENCIONAL OU ELETRÔNICO, PARA FINS DE ESTUDO E PESQUISA, DESDE QUE CITADA A FONTE.

Trabuco, Amanda Cristina

Análise comparativa entre galectinas-1 humana e de camundongo sob os aspectos biológico e molecular, Ribeirão Preto, 2013.

79p. : il.; $30 \mathrm{~cm}$.

Dissertação de Mestrado, apresentada à Faculdade de Ciências Farmacêuticas de Ribeirão Preto/USP - Área de concentração: Biociências Aplicadas à Farmácia.

Orientador: Dias-Baruffi, Marcelo.

1. Galectina-1 de camundongo. 2. Galectina-1 humana. 3. Cristalografia. 4. Glycan array. 5. Hemaglutinação, 6. Mac-1. 7. Fosfatidilserina. 


\section{FOLHA DE APROVAÇÃO}

Nome do aluno: Amanda Cristina Trabuco

Título do trabalho: Análise comparativa entre galectinas-1 humana e de camundongo sob os aspectos biológico e molecular

Dissertação de Mestrado apresentada ao Programa de Pós-Graduação em Biociências Aplicadas à Farmácia para obtenção do Título de Mestre em Ciências

Área de Concentração: Biociências Aplicadas à Farmácia.

Orientador: Prof. Dr. Marcelo Dias Baruffi

Aprovado em:

Banca Examinadora

Prof. Dr.

Instituição:

Assinatura:

Prof. Dr.

Instituição:

Assinatura:

Prof. Dr.

Instituição: Assinatura: 
Dedicatóría 
Dedico este trabalho aos mens pais Ovidio Eduardo e Durvatina e a mens irmãos Edson Eduardo e Alessandra. Este trabalho é resultado do carinho, compreensão e dedicação de cada um de vocês. Vocês são minha vida e mew amor por vocês não cabe em palavras. 
Agradecimentos 


\section{A Deus}

Pela minha vida, pela saúde e capacidade para desenvolver esse trabalho e por permitir que pessoas maravilhosas estivessem em meu caminho para me apoiar em todas as situações.

Ao Prof. Dr. Marcelo Dias Baruffi

Pela orientação, apoio, amizade, carinho e dedicação, tornando possível o desenvolvimento desse trabalho, assim como pelos ensinamentos tanto no âmbito profissional quanto pessoal.

Aos técnicos e amigos Francine Bianchini, Lílian Cataldi Rodrigues e Rubens Eduardo da Silva

Pelo apoio durante a execução das técnicas laboratoriais. Obrigada pela dedicação e carinho.

\section{Aos amigos do laboratório de Glicoimunologia}

Thalita Bachelli Riul, Camillo Del Cistia Andrade, Renata Tomé Alves, Vanessa Leiria Campo e Marise Lopes pela amizade, ótima convivência e pelo apoio durante as atividades desse trabalho.

\section{À Prof. Dra. Maria Regina Torqueti e às amigas do laboratório de Citologia Clínica}

Amanda Natalina Faria e Bianca Stocco pela amizade e apoio no desenvolvimento desse trabalho.

\section{Ao Laboratório de Cristalografia de Proteínas}

Maria Cristina Nonato e Joane Kathelen Rustiguel, pela orientação e auxílio, de extrema importância em parte desse trabalho e também pelo excelente convívio.

Ao Grupo de Biofísica Molecular Sérgio Mascarenhas, Instituto de Física de São Carlos da Universidade de São Paulo

Dr. Antônio José da Costa Filho e Patricia Suemy Kumagai, pelas análises por dicroísmo circular.

Ao Departamento de Bioquímica da Emory University School of Medicine Dr. Sean Robinson Stowell, Dr. Richard D. Cummings e Connie Arthur, pela colaboração que permitiu realizar os ensaios de glycan array.

Núcleo de Pesquisa em Produtos Naturais e Sintéticos da Faculdade de Ciências Farmacêuticas de Ribeirão Preto da Universidade de São Paulo Prof. Dr. Norberto Peporine Lopes e Denise Brentan, pelo auxílio nas análises por espectrometria de massas.

Aos amigos com os quais trabalhei em outros projetos

Karina Alves de Toledo, Willian Abraham da Silveira, Natália Sakura Koyama, Helen Figueiredo Fumagalli, Eleni José Linjardi, Marlise Bonetti Agostinho Montes, Jennifer Michiko Chauca, os quais colaboraram com o meu crescimento pessoal e profissional. Muito obrigada pelo carinho e pela amizade. 


\section{A Luís Guilherme Pereira Feitosa}

Por compartilhar os momentos de alegria e me ajudar nos momentos de dificuldade durante este período. Muito obrigada pelo grande apoio, dedicação e carinho.

\section{À Faculdade de Ciências Farmacêuticas de Ribeirão Preto}

Pela excelente formação profissional e pessoal que me proporcionou, permitindo o acesso à informação e pesquisa através de excelentes profissionais e amigos.

Ao Conselho Nacional de Desenvolvimento Científico e Tecnológico (CNPq) e à Fundação de Amparo à Pesquisa do Estado de São Paulo (FAPESP)

Pelo auxílio financeiro que tornou possível a execução desse trabalho.

A todos que tornaram possível o desenvolvimento e conclusão do presente trabalho 
Epigrafe 
"A ciência nunca resolve um problema sem criar pelo menos outros dez." George Bernard Shaw 


\section{RESUMO}

TRABUCO, A. C. Análise comparativa entre galectinas-1 humana e de camundongo sob os aspectos biológico e molecular. 2013. 79f. Dissertação. Faculdade de Ciências Farmacêuticas de Ribeirão Preto - Universidade de São Paulo, Ribeirão Preto, 2013.

A galectina-1 (Gal-1) é uma lectina homodimérica multifuncional capaz de reconhecer e se ligar a beta-galactosídeos por meio de um domínio denominado carbohydrate recognition domain (CRD). A Gal-1 humana (Gal-1h) e a Gal-1 de camundongo (Gal-1c) mantêm $88,15 \%$ de homologia e, apesar de não existirem mutações em aminoácidos-chave do CRD, há substituições próximas a esses resíduos. Considerando as implicações dessas diferenças em estrutura e função, e que é comum a utilização de modelos murinos para estudar a função Gal-1, o presente trabalho objetiva analisar comparativamente a Gal-1c e a Gal-1h por meio de ensaios de cristalização e determinação estrutural da Gal-1c, além da avaliação comparativa da atividade lectínica da Gal-1h e da Gal-1c por glycan array e hemaglutinação. Também foi avaliada a capacidade de ambas as Gal-1 em induzir a exposição de fosfatidilserina (FS) em neutrófilos ativados provenientes de medula de camundongos normais ou deficientes de $\beta$-2 integrina (Mac-1), de modo a investigar se a interação Gal-1/Mac-1 estaria envolvida nesse processo. Preparações homogêneas e ativas de Gal-1c e Gal-1h foram utilizadas nos ensaios. Os cristais de Gal-1c foram obtidos em 20\% de polietilenoglicol 3350 e 0,2 M de fluoreto de amônio. Os dados de difração de raios $X$ foram coletados e processados, obtendose uma estrutura com resolução de $2,4 \AA$. Observou-se que substituições de aminoácidos entre a Gal-1c e a Gal-1h estão localizadas em regiões expostas ao solvente, próximas do CRD e distantes da interface de dimerização. A análise comparativa entre Gal-1c e Gal-1h mostrou que estas substituições conferem a Gal1c um caráter mais polar, com consequente aumento da distribuição de volume molecular. Nos ensaios de hemaglutinação, pode-se observar que é necessária uma concentração 2 vezes maior de Gal-1c para aglutinar eritrócitos humanos, de carneiro e de coelho na mesma proporção que a Gal-1h. Por meio do glycan array, pode-se determinar o perfil de ligação a glicanas de ambas as Gal-1. As duas Gal-1 apresentam afinidade por glicanas ramificadas contendo galactose terminal, e a Gal$1 \mathrm{~h}$ apresentou maior intensidade de ligação às glicanas quando comparada à Gal1c. Preparações de Gal-1c e Gal-1h induzem níveis semelhantes de exposição de FS na superfície de neutrófilos deficientes ou não de Mac-1, sugerindo que a interação Gal-1/Mac-1 não esteja envolvida no processo de exposição de FS na superfície de neutrófilos ativados. Assim, a diferença sequencial entre a Gal-1c e a Gal-1h é capaz de gerar diferenças estruturais consideráveis que implicam no reconhecimento diferencial de glicanas, o que, entretanto, não se reflete na capacidade de indução de FS na superfície de neutrófilos ativados. Além disso, a interação Gal-1/Mac-1 parece não participar desse processo, o que pode indicar que o papel da Gal-1 no turnover de neutrófilos, via reconhecimento fagocítico, seja um processo complexo e independente dessa interação.

Palavras-chave: galectina-1, cristalografia, glycan array, hemaglutinação, Mac-1, fosfatidilserina. 


\begin{abstract}
TRABUCO, A. C. Comparative analysis of the biochemistry and biology of human and mouse galectin-1. 2013. 79f. Dissertation. Faculdade de Ciências Farmacêuticas de Ribeirão Preto - Universidade de São Paulo, Ribeirão Preto, 2013.
\end{abstract}

Galectin-1 (Gal-1) is a homodimeric and multifunctional lectin that recognizes and binds to beta-galactoside by a carbohydrate recognition domain (CRD). Human Gal-1 (hGal-1) and mouse Gal-1 (mGal-1) are $88.15 \%$ identical, and although there are no mutations in key amino acids within the CRD, there are differences in the amino acids sequence near the CRD. Given the potential of these differences to alter overall structure and function, and the common utilization of murine models to study Gal-1 function, we sought to directly compare key biochemical features of hGal and mGal-1. Thus, we performed crystallization and structure determination assays of mGal-1, and determined the carbohydrate binding specificy of mGal-1 and hGal-1 using a glycan array and using hemagglutination assay. We also evaluated the ability of both Gal-1 to induce exposure of phosphatidylserine (PS) in activated neutrophils from the bone marrow of normal or $\beta-2$ integrin (Mac-1) deficient mice, in order to investigate the involvement of Gal-1/Mac-1 interaction in this process. To accomplish this, homogeneous and active preparations of hGal-1 and mGal-1 were used in the study. mGal-1 crystals were obtained in $20 \%$ polyethylene glycol 3350 and $0.2 \mathrm{M}$ ammonium fluoride. Data from X-ray diffraction were collected and processed, yielding a structure with a final resolution of $2.4 \AA$. The amino acid substitutions found between mGal-1 and hGal-1 are detected on the solvent-exposed surfaces where the CRDs are located and not on the proteins dimerization surfaces. A comparative structural analysis between mGal-1 and hGal-1 shows that these amino acid substitutions confer to mGal-1 a greater number of ionizable residues, polar character, appearance of the acid regions clustered, and a slight increase of volume distribution. In hemagglutination assays, twice the concentration of mGal-1 was required to cause equivalent agglutination of human, sheep or rabbit erythrocytes as hGal-1. Glycan array analysis demonstrated that both galectins have affinity for branched glycans containing terminal galactose residues. However, hGal-1 appeared to display higher levels of binding that mGal-1. Preparations of mGal-1 and hGal-1 induced similar levels of PS exposure on normal or Mac-1 deficient neutrophils, suggesting that the interaction Gal-1/Mac-1 is not involved in this process. Thus, hGal-1 and mGal-1 appear to possess considerable differences in glycan recognition that likely reflects subtle difference in amino acid sequence. Furthermore, the interaction Gal-1/Mac-1 do not appear to participate in this PS exposure process, which suggest that other Gal-1 receptors are likely important in this process.

Keywords: galectin-1, crystallography, glycan array, hemagglutination, Mac-1, phosphatidylserine. 


\section{RESUMEN}

TRABUCO, A. C. Análisis comparativo de las galectinas-1 humana y de ratón en aspectos biológicos y moleculares. 2013. 79f. Disertación. Faculdade de Ciências Farmacêuticas de Ribeirão Preto - Universidade de São Paulo, Ribeirão Preto, 2013.

La galectina-1 (Gal-1) es una lectina homodimérica y multifuncional capaz de reconocer y unirse a la beta-galactosidasa a través de una región denominado carbohydrate recognition domain (CRD). La Gal-1 humana (Gal-1h) y la Gal-1 de ratón (Gal-1c) mantienen $88,15 \%$ de homología, y aunque no hay mutaciones en los principales aminoácidos en el CRD, hay sustituciones próximas a estos aminoácidos. Teniendo en cuenta las implicaciones de estas diferencias en la estructura y función, y es común el uso de modelos de ratón para estudiar la función de Gal-1, este estudio tiene como objetivo analizar comparativamente la Gal-1c y Gal-1h. Para ello, se realizaron ensayos de cristalización y determinación de la estructura de Gal-1c, y la evaluación comparativa de la actividad de lectina de Gal$1 \mathrm{~h}$ y Gal-1c en glicanos de mamíferos por glycan array y hemaglutinación. También se evaluó la capacidad de ambos Gal-1 para inducir la exposición de la fosfatidilserina (FS) en los neutrófilos activados a partir de la médula ósea de ratones normales o deficientes de $\beta-2$ integrina (Mac-1), con el fin de investigar si la interacción Gal-1/Mac-1 está involucrado en este proceso. Se utilizaron preparaciones homogéneas y activas de Gal1-c y Gal-1h en las pruebas. Los cristales de Gal-1c se obtuvieron en polietilenglicol 3350 al 20\% y 0,2 M de fluoruro de amonio. Los datos de difracción de rayos $X$ se colectarón y procesaron, produciendo una estructura con una resolución de 2,4 A. Las substituciones de aminoácidos entre la Gal-1c y la Gal-1h están en regiones expuestas al solvente, próximas al CRD y distantes de la interfase de dimerización. El análisis estructural comparativo entre la Gal-1c y la Gal-1h mostro que estas substituciones confieren a la Gal-1c un caracter más polar, con el consiguiente aumento en la distribución de volumen molecular. En ensayos de hemaglutinación, se puede observar que es necesario dos veces mayor concentración de Gal-1c para aglutinar eritrocitos humanos, cordero y conejo en la misma proporción que la Gal-1h. A través de los ensayos de glycan array, se puede determinar el perfil de ligación a glucanos de ambas Gal-1. Ambos galectinas tienen una afinidad para glicanos que contienen ramificación de galactosa terminal y la Gal-1h tiene una mayor intensidad de ligación a glucanos en comparación con Gal-1c. Preparaciones de Gal-1c y Gal-1h inducen niveles similares de exposición de FS en la superficie de los neutrófilos deficientes o normales de Mac-1, lo que sugiere que la interacción Gal-1/Mac-1 no esta involucrado en el proceso de exposición de la FS en la superficie de los neutrófilos activados. Por lo tanto, la diferencia secuencial Gal-Gal-1c y Gal-1h es capaz de generar considerables diferencias estructurales que implican en el reconocimiento diferencial de glucanos, que, sin embargo, no se refleja en la capacidad de inducir la FS en la superficie de los neutrófilos activados. Además, la interacción Gal-1/Mac-1 no parece participar en este proceso, lo que puede indicar que la función de Gal-1 en la renovación de neutrófilos a través del reconocimiento de fagocitos, es un proceso complejo y es independiente de la interacción.

Palabras clave: galectina-1, cristalografía, Glycan array, hemaglutinación, Mac-1, fosfatidilserina. 


\section{Lista de figuras}

Figura 1. Comparação entre a sequência de aminoácidos da Gal-1c e da Gal-1h. Verde e sublinhado: aminoácidos que diferem nas duas lectinas. Vermelho: aminoácidos relacionados com o grau de oxirredução da Gal-1 (C2, H45 e H53) e importantes para a propriedade lectínica. Os aminoácidos compreendidos entre resíduos de número 43 e 79 compõem o domínio de reconhecimento de carboidratos (CRD) (WILSON et al., 1989, VARKI et al., 2009).

Figura 2. Representação esquemática da preparação de um arranjo de glicanas (glycan array) para a análise da capacidade de reconhecimento de carboidratos das galectinas e outras proteínas ligantes de glicanas (modificado de HEINBURGMOLINARO, 2011).

Figura 3. Esquema representativo do processo de isolamento de neutrófilos medulares de camundongos.

Figura 4. Perfil de eluição de Gal-1h (a) e Gal-1c (b) em coluna de agarose-lactose com o tampão de eluição contendo lactose $100 \mathrm{mM}$ e 2-ME $14 \mathrm{mM}$, em PBS. Observa-se que para ambas as proteínas o início do pico de eluição se dá após a passagem de aproximadamente 3,5-4 $\mathrm{mL}$ de tampão de eluição pela coluna, sendo finalizado após a passagem de $7 \mathrm{~mL}$. .23

Figura 5.SDS-PAGE 12,5\%, mostrando as frações correspondentes ao pico de eluição de Gal-1h (a) e Gal-1c (b) em coluna de agarose-lactose. Obtiveram-se bandas de peso molecular aproximado de $15 \mathrm{kDa}$ (setas) correspondente ao peso molecular esperado tanto para Gal-1c quanto para Gal-1h. M: Marcador de peso molecular; F6, F7, F8, F9, F10, F11, F12 e F13: Frações cromatográficas. .............23 Figura 6. Espectro de massas (MALDI-TOF) obtido para Gal-1c...........................24 Figura 7. Espectros de Dicroísmo Circular (DC) para Gal-1c na ausência de ligante (a), na presença de lactose (b), e na presença de sucrose (c). Curva de melting $(216 \mathrm{~nm})$ para Gal-1c na presença e na ausência de ligantes (lactose e sucrose) (d).

Figura 8. Representação gráfica da elevação do título de anticorpos anti-Gal-1c em coelho após hiperimunização com Gal-1c conforme protocolo descrito por HARLOW \& LANE (1988) 
Figura 9. SDS-PAGE $12 \%$ de alíquotas da resina Affi-Gel 15 contendo Gal-1c imobilizada. Resina pré eluição: alíquota da resina não submetida ao tratamento com baixo $\mathrm{pH}$; Resina pós eluição: alíquota de resina submetida a $\mathrm{pH}$ 2,5; F1, F5, F10 e F15: Frações da "pré eluição" realizada para verificar o grau de acoplamento da Gal-1c à Affi-Gel 15. 28

Figura 10. Immunoblotting das frações de Gal-1c, Gal-1h, Affi-Gel 15 acoplada com Gal-1c pré e pós-tratamento ácido, e frações provenientes da "pré-eluição" da resina (F1, F5, F10 e F15). 29

Figura 11. Cristais de Gal-1c em Fluoreto de amônio 0,2M e 20\% de PEG 3350.....31 Figura 12. Padrão de difração observado para o cristal de mGal-1. Os dados foram coletados na linha MX-2 do LNLS. ...................................................... 32

Figura 13. Tetrâmetro encontrado na unidade assimétrica do cristal de Gal-1c. ......35

Figura 14. Modelo tridimensional da galectina-1 de camundongo. ........................36 Figura 15. Alinhamento sequencial entre a galectina-1 de camundongo (Mgal-1) e a galectina-1 humana (Hgal-1) 36

Figura 16. Representação esquemática das substituições (em amarelo) encontradas na Gal-1c em relação a Gal-1h. As substituições estão localizadas próximas à região do CRD (representada em rosa), mas distante da interface de dimerização. 38 Figura 17. Distribuição do potencial eletrostático para a Gal-1c e Gal-1h (PDB $1 \mathrm{GZW})$. As regiões em vermelho representam regiões negativamente carregadas. 39 Figura 18. SDS-PAGE 12\% das preparações de Gal-1c e Gal-1h utilizadas nos ensaios de hemaglutinação.

Figura 19. Ensaio de aglutinação com o uso de Gal-1h e Gal-1c e de hemácias: a) humanas; b) de carneiro; c) de coelho. 43

Figura 20. Ensaio de aglutinação de hemácias de coelho. 44

Figura 21. Ensaio de aglutinação de hemácias humanas. .45

Figura 22. Ensaio de aglutinação de hemácias de camundongo. 45

Figura 23. Ensaio de aglutinação de hemácias de carneiro. .45

Figura 24. Análise da intensidade da aglutinação de hemácias humanas após incubação com Gal-1c e Gal-1h. C-: Controle negativo.

Figura 25. Intensidade de ligação de Gal-1c às glicanas imobilizadas em fase sólida (Mammalian Printed Array version 5.0). .49 
Figura 26. Intensidade de ligação de Gal-1h às glicanas imobilizadas em fase sólida (Mammalian Printed Array version 5.0). .50

Figura 27. Glicanas correspondentes aos picos de maior intensidade de fluorescência em todas as concentrações testadas de Gal-1c. 52

Figura 28. Glicanas correspondentes aos picos de maior intensidade de fluorescência em todas as concentrações testadas de Gal-1h. 53

Figura 29. Análise comparativa entre Gal-1c e Gal-1h quanto à capacidade de ligação às glicanas correspondentes aos picos de fluorescência. .56

Figura 30. Representação esquemática das glicanas a que ambas as Gal-1 se ligam com maior afinidade. As estruturas foram construídas no programa GlycoworkBench 2.1 (CERONI et al., 2008). .58

Figura 31. Representação esquemática das glicanas sulfatadas às quais a Gal-1h se liga com maior afinidade. As estruturas foram construídas no programa GlycoworkBench 2.1 (CERONI et al., 2008). .59

Figura 32. Representação esquemática das glicanas sialiladas a que ambas as Gal1 se ligam, com intensidades próximas, a baixas concentrações. As estruturas foram construídas no programa GlycoworkBench 2.1 (CERONI et al., 2008).

Figura 33. Imunofenotipagem de neutrófilos WT ativados por marcação com antiLY6C, anti-LY6G e anti-CD11b. .63

Figura 34. Imunofenotipagem de neutrófilos deficientes de Mac-1 ativados por marcação com anti-LY6C, anti-LY6G e anti-CD11b.

Figura 35. Representação gráfica dos resultados obtidos por citometria de fluxo, utilizando como variáveis o tratamento (Gal-1h, Gal-1c e etoposídeo) e marcação positiva para Anexina (Anexina $\mathrm{V}_{+}$) e negativa para $\mathrm{PI}(\mathrm{PI}-)$ em dois diferentes grupos (neutrófilos provenientes de camundongos com expressão normal e neutrófilos provenientes de camundongos com expressão reduzida de Mac-1). Os resultados expressos são representativos de 3 experimentos independentes. $O$ tratamento estatístico utilizado para comparação entre os diferentes grupos experimentais foi a análise de variância (ANOVA) "two-way", seguido do pós-teste de Bonferroni com o uso do programa GraphPad Prism (versão 4 Prism, GraphPad, USA). 


\section{Lista de tabelas}

Tabela 1. Dados Cristalográficos do cristal de Gal-1c.....................................33

Tabela 2. Dados de refinamento para o modelo cristalográfico para a estrutura da

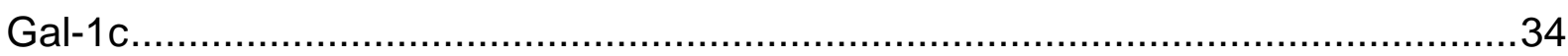

Tabela 3. Correspondência entre os números arbitrários utilizados para representar cada glicana e a sequência de carboidratos presente em cada glicana. .54 


\section{Lista de Abreviaturas}

2ME - b-mercaptoetanol

ANOVA - Analysis of variance (Análise de variância entre grupos)

$C D$ - Cluster of Differentiation

CRD - Carbohydrate Recognition Domain (domínio de reconhecimento de carboidrato)

DAMPs - damage associated molecular patterns (padrões moleculares associados a dano celular)

DC - Dicroísmo Circular

DHB - ácido 2,5-dihidroxibenzóico

ELISA - Enzyme Linked Immuno Sorbent Assay (ensaio imunoenzimático)

FACS - Fluorescence-activated cell sorting (seleção celular ativada por fluorescência)

FITC - Fluorescein Isotiocianate (isotiocianato de fluoresceína)

fMLP - Formyl-Methionyl-Leucyl-Phenylalanine (f-Met-Leu-Phe)

FS - fosfatidilserina

Gal-1c - Galectina-1 de camundongo

Gal-1h - Galectina-1 humana

Gal-8C - Domínio carboxiterminal da galectina-8

HBSS - Hank's Balanced Salt Solution

HEPES - (4-(2-hydroxyethyl)-1-piperazineethanesulfonic acid))

IgG - Imunoglobulina $G$

IPTG - Isopropil b-D-tiogalacto-piranosídeo

LAD-1 - leukocyte adhesion deficiency I

LFA-1 - lymphocyte function-associated antigen-1

Mac-1 - alpha M beta 2 integrina ou CD11b/CD18

mRNA - messenger Ribonucleic acid (ácido ribonucléico mensageiro)

NF-kB - Fator de transcrição

PAMPs - Patogen Associated Molecular Patterns (padrões moleculares associados a patógenos)

PBS - Phosphate Buffered Saline (solução salina-fosfato tamponada)

PEG - Polietilenoglicol

PRRs - Pattern Recognition Receptors (receptores de reconhecimento de padrão) 
rmGal-1 $\alpha$ - Recombinant mouse galectin-1 alpha

SDS-PAGE - Sodium dodecyl-sulfate polyacrylamide gel electrophoresis (Eletroforese em gel de poliacrilamida)

Proteínas SR - Proteínas ligantes de RNA que contém um domínio rico em Arginina e Serina

Th - T helper

Tm - Temperatura de melting

TNF - Tumor Necrosis Factor (fator de necrose tumoral)

URF - Unidades relativas de fluorescência

UA - Unidade Assimétrica

WT - wild type (selvagem) 


\section{Sumário}

RESUMO

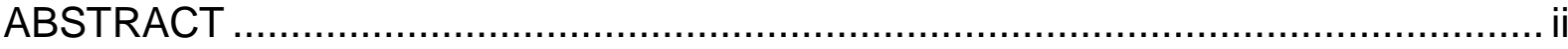

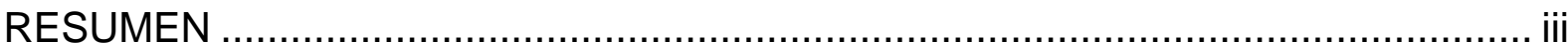

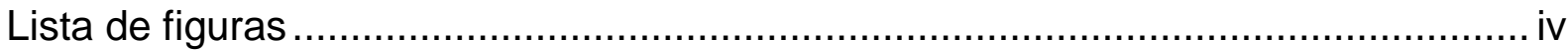

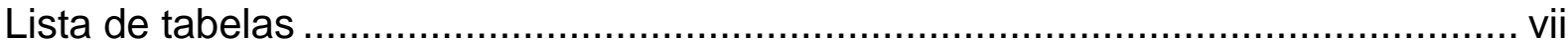

Lista de Abreviaturas................................................................................... viii

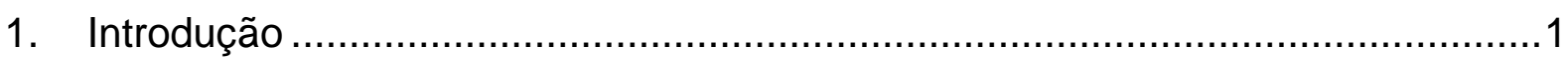

1.1. Galectina-1 - Aspectos Gerais .............................................................

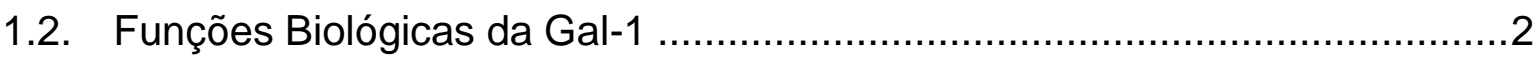

1.3. Atuação da Gal-1 na Resposta Imune ................................................

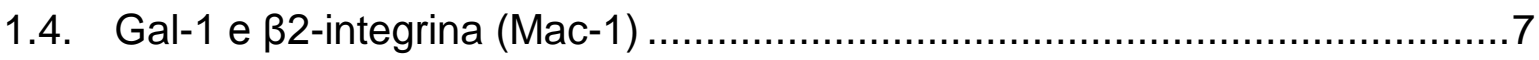

2. Justificativa

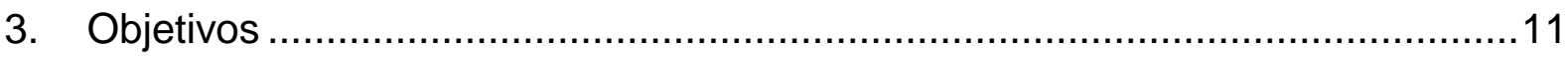

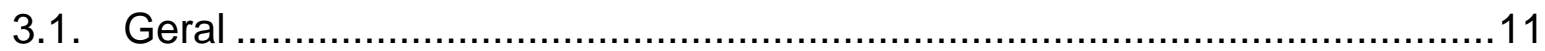

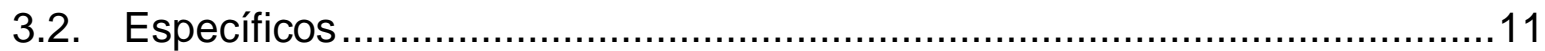

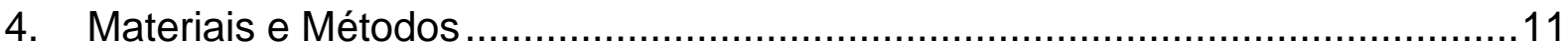

4.1. Obtenção e purificação da galectina-1 recombinante de camundongo ........11

4.2. Obtenção e purificação de galectina-1 recombinante humana ....................13

4.3. Caracterização molecular da Gal-1c ………......................................13

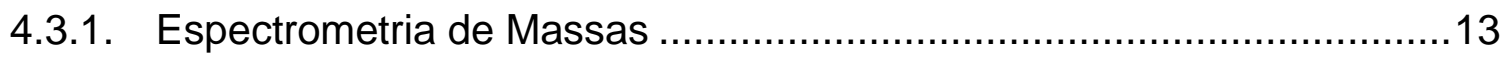

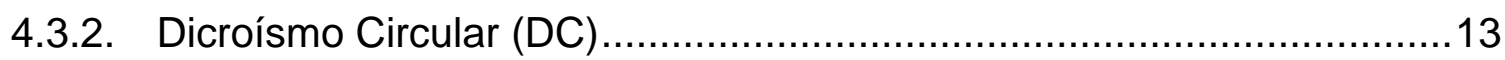

4.4. Obtenção de soro imune de coelho contendo anticorpos anti-Gal-1c..........14 
4.5. Determinação da estrutura cristalográfica da galectina-1 de camundongo...15

4.5.1. Cristalização 15

4.5.2. Coleta e processamento de dados ............................................. 16

4.5.3. Faseamento e refinamento ........................................................... 16

4.6. Ensaio de hemaglutinação ..............................................................17

4.7. Análise da capacidade de reconhecimento de glicoconjugados ................18

4.8. Avaliação da exposição de fosfatidilserina (FS) nas superfícies de neutrófilos 20

4.8.1. Separação de neutrófilos de camundongos C57BL/6 que expressam níveis normais e reduzidos de Mac-1 .20

4.8.2. Avaliação da exposição de fosfatidilserina (FS) nas superfícies de neutrófilos através da metodologia de citometria de fluxo 21

5. Análise dos resultados 22

6. Resultados e Discussão 22

6.1. Obtenção e purificação de Gal-1c e Gal-1h .22

6.2. Caracterização molecular da Gal-1c .24

6.2.1. Espectrometria de Massas 24

6.2.2. Obtenção dos Espectros de Dicroísmo Circular (DC). 24

6.3. Obtenção do soro imune de coelho contendo anticorpos anti-Gal-1c. 27

6.4. Determinação da estrutura cristalográfica da Gal-1c 30

6.4.1. Caracterização cristalográfica. .30

6.4.2. Estrutura global. .35 
6.4.3. Galectina humana $\times$ Galectina de camundongo .36

6.5. Ensaios de Hemaglutinação 41

6.6. Análise da capacidade de reconhecimento de glicoconjugados .48

6.7. Avaliação da exposição de fosfatidilserina (FS) nas superfícies de neutrófilos ativados e ensaio de fagocitose. 62

6.7.1. Separação de neutrófilos de camundongos C57BL/6 que expressam níveis normais e reduzidos de Mac-1 e Imunofenotipagem 62

6.7.2. Avaliação da exposição de fosfatidilserina (FS) nas superfícies de neutrófilos através da metodologia de citometria de fluxo .64

7. Conclusões .66

8. Referências .67 


\section{Introdução}

\subsection{Galectina-1 - Aspectos Gerais}

As galectinas são lectinas solúveis com alta afinidade por $\beta$-galactosídeos. Apesar de suas funções não serem completamente entendidas, sabe-se que elas são proteínas multifuncionais e estão envolvidas em diversos eventos celulares importantes (BARONDES et al., 1994; RABINOVICH, 1999; CAMBY et al., 2006 e VARKI et al., 2009, SCHATTNER \& RABINOVICH, 2013). A família das galectinas apresenta domínios altamente conservados durante a evolução, sendo um deles a região denominada domínio de reconhecimento de carboidratos (carbohydrate recognition domain - CRD) (VARKI et al., 2009). Sabe-se que as galectinas podem reconhecer carboidratos com afinidades distintas principalmente devido à conformação de seus CRDs (BIAN et al., 2011), a qual, por sua vez, é determinada pela sequência de aminoácidos de cada uma dessas lectinas.

A galectina-1 (Gal-1) é uma proteína homodimérica (BARONDES et al., 1994; CHO AND CUMMINGS, 1995) amplamente expressa em uma grande variedade de tecidos, tanto normais quanto patológicos. A Gal-1 humana (Gal-1h) é codificada pelo gene LGALS1, localizado no cromossomo 22q12. O transcrito de 0,4 kb (GenBank: NM_002305) resulta do splicing de quatro éxons, codificando uma proteína de 135 aminoácidos (GenPept : NP_002296, SwissProt: P09382) (CAMBY et al., 2006; COOPER \& BARONDES, 1999). A Gal-1h apresenta topologia molecular do tipo "jelly-roll" composta por duas folhas- $\beta$ anti-paralelas, padrão estrutural típico das galectinas (LOPEZ-LUCENDO et al., 2004). Monômeros de Gal1 , de aproximadamente $14,5 \mathrm{kDa}$, associam-se por meio de interações não covalentes formando homodímeros com constante de dissociação de aproximadamente 1 a $2 \mu \mathrm{M}$ (STOWELL et al., 2009). As funções decorrentes da atividade lectínica da Gal-1h devem-se à sua forma dimérica, preferencialmente, apesar de as formas monomérica e oxidada dessa lectina também apresentarem propriedades biológicas (CAMBY et al., 2006; SCOTT et al., 2009). O gene Lgals1, que codifica para a Galectina-1 de camundongo (Gal-1c), localiza-se no cromossomo 15, sendo codificada por uma sequência de 408 pares de base, resultando em uma proteína de 135 aminoácidos (LOHR et al., 2007). 
O alinhamento das sequências das duas proteínas revela uma identidade de $88,15 \%$ (WILSON et al., 1989) havendo manutenção da cisteína C2, presente na região de interação entre os monômeros, e das histidinas $\mathrm{H} 45$ e H53 presentes no $\mathrm{CRD}$, resíduos estes relacionados com o grau de oxirredução da molécula de Gal-1, provocando a perda da capacidade lectínica quando oxidados (STOWELL et al., 2009). Entretanto, existem mutações próximas a resíduos que participam de maneira importante na interação com $\beta$-galactosídeos (FORD et al., 2003), correspondentes a H45, N47, R49, D55, N62, W69, E72 e R74 (VARKI et al. 2009), o que pode interferir na interação da Gal-1 com os mesmos (Figura 1) .

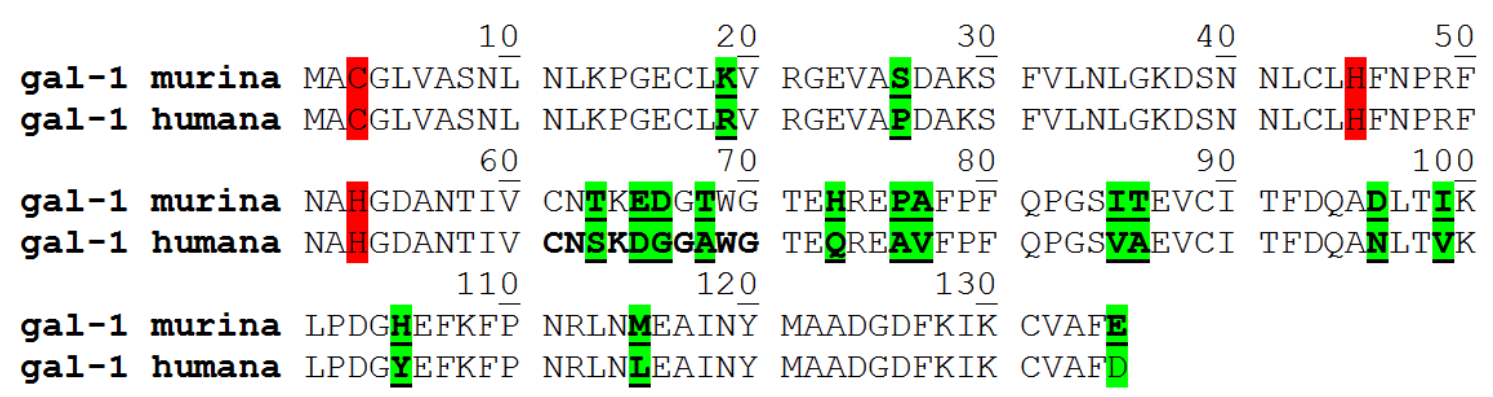

Figura 1. Comparação entre a sequência de aminoácidos da Gal-1c e da Gal-1h. Verde e sublinhado: aminoácidos que diferem nas duas lectinas. Vermelho: aminoácidos relacionados com o grau de oxirredução da Gal-1 (C2, H45 e H53) e importantes para a propriedade lectínica. Os aminoácidos compreendidos entre resíduos de número 43 e 79 compõem o domínio de reconhecimento de carboidratos (CRD) (WILSON et al., 1989, VARKI et al., 2009).

\subsection{Funções Biológicas da Gal-1}

A Gal-1 apresenta tipicamente atividade hemaglutinante, associada à sua atividade lectínica (do latim, legere, que significa capacidade de discriminação), já que essa proteína é capaz de reconhecer carboidratos presentes na superfície de eritrócitos, o que torna o teste de hemaglutinação um método útil para avaliação da atividade das galectinas (BOYD, 1970; VARKI et al., 2009).

A Gal-1 tem sido descrita como uma proteína multifuncional, atuando nos mais diversos processos, desde os mais simples até em vias de sinalização elaboradas e complexas (CAMBY et al., 2006).

Estudos demonstraram, logo após a sua descoberta, que a Gal-1h atua como um efetivo mitógeno para alguns tipos celulares, como os do baço, linfócitos e células 
endoteliais (LIPSICK et al., 1980; SANFORD et al., 1993; ANGINOT et al., 2013). Em contrapartida, evidências indicam que a Gal-1h inibe o crescimento celular, promovendo a apoptose de células ativadas, mas não das células em repouso no sistema imune (PERILLO et al., 1995; BLASER et al., 1998; RABINOVICH et al., 1998; TOSCANO et al., 2007). Estes relatos da literatura demonstram que a Gal-1h pode participar da regulação do ciclo celular, atuando, em circunstâncias distintas, como mitógeno ou como inibidor da proliferação celular e promotor de apoptose. Muitas dessas atividades, principalmente a de mitógeno, seguem-se à interação da Gal-1h com $\beta$-galactosídeos na superfície celular, apesar de haver fortes evidências de ocorrência de interação proteína-proteína envolvendo Gal-1h e de um mecanismo citostático independente da interação com açúcares (SCOTT \& WEINBERG, 2004).

A superexpressão de Gal-1 em tumores de diferentes origens (DEMYDENKO et al., 2009; GIORDANO et al., 2013) tem sido associada a um comportamento metastático dessas lesões e ao prognóstico ruim para o paciente. Isto se deve ao envolvimento desta lectina em eventos importantes para a progressão tumoral como a imunossupressão de células $T$, angiogênese anormal e sua expressão em regiões de hipóxia tissular (THIJSSEN et al., 2010; ITO et al., 2012; OUYANG et al., 2013). Sob essa perspectiva, seria de grande interesse o desenvolvimento racional de inibidores específicos para essa proteína, com finalidade terapêutica (SCOTT et al., 2007; ITO et al., 2012).

No contexto intracelular, a atividade da Gal-1 não se limita apenas ao citoplasma, havendo indícios de sua atuação também no núcleo, principalmente nos processos de edição (splicing) do pré-RNA mensageiro (VYAKARNAM et al., 1997; PATTERSON et al., 2004). Nessa linha, foi descrito que mutações sítio dirigidas comprometedoras da atividade lectínica da Gal-1 não interferem em sua atividade de splicing de pré-RNA (VOSS et al. 2008). Segundo estes autores, a capacidade de Gal-1 reconhecer carboidratos pode não estar associada a sua atividade de edição de RNA. Curiosamente, assim como as galectinas, os membros da família de proteínas SR parecem atuar como fatores de splicing de RNA de modo independente de suas capacidades de reconhecer carboidratos nas superfícies de células (HAUDEK et al., 2010). 
Existem, ainda, evidências de que a forma oxidada de Gal-1, sem atividade lectínica, promove regeneração axonal em baixas concentrações (INAGAKI et al., 2000; WATANABE, 2010), corroborando com a possibilidade de existência de interações outras que não as relacionadas ao domínio de reconhecimento de carboidratos. Por outro lado, em processos inflamatórios do sistema nervoso central, a Gal-1 secretada por astrócitos pode se ligar a carboidratos da molécula CD45 expressa na superfície de micróglias e promover nestas células um fenótipo neuroprotetor de padrão M2 (NONAKA \& FUKUDA, 2012). KURIHARA e colaboradores (2010) demonstraram também que a Gal-1h pode participar da patogênese nas lesões de medula, já que identificaram sua expressão em neurônios e células da glia após injúria no tecido nervoso. Além disso, verificou-se que a Gal1h é responsável pela regulação do número de células progenitoras neurais em camundongos adultos (KAJITANI et al., 2009; SAKAGUCHI et al., 2010). Esse papel da Gal-1 é essencial para a geração de novos neurônios que migram para regiões lesionadas do cérebro após injúria, e para a recuperação de deficiências comportamentais resultantes de lesão cerebral (ISHIBASHI et al. 2007; KAJITANI et al. 2009). Assim, a elucidação das funções da Gal-1 em células progenitoras neurais de adultos é importante para entender os mecanismos moleculares da neurogênese adulta e desenvolvimento de novos recursos de reparação tecidual do sistema nervoso (SAKAGUCHI et al., 2010).

\subsection{Atuação da Gal-1 na Resposta Imune}

Uma das atividades biológicas mais estudadas da Gal-1 é a sua capacidade de modular a resposta imunológica inata e adaptativa (RABINOVICH e TOSCANO, 2009; CERLIANI et al., 2010). Diversos estudos demonstram a atuação das galectinas sobre as células do sistema imune, sendo essa interação dependente do contexto em que a célula se encontra e do seu estado de ativação, além do tipo de galectina envolvida (RUBINSTEIN et al., 2004).

Tem-se destacado também a atuação das galectinas como PRRs (Pattern Recognition Receptors) no reconhecimento de padrões moleculares associados a patógenos (Patogen Associated Molecular Patterns - PAMPs). Dessa forma, essas lectinas estão envolvidas tanto no processo de eliminação de organismos invasores 
pela imunidade inata, por se ligarem a carboidratos presentes na superfície de patógenos, quanto nos mecanismos de evasão dos processos imunes por meio dos quais os microrganismos atuam para invadir o hospedeiro (VASTA, 2012). Assim, a interação das galectinas com carboidratos de microrganismos pode auxiliar no combate, como a interação de Gal-4 e -8 com bactérias que expressam antígenos do grupo sanguíneo B (STOWELL et al., 2010) e a interação de Gal-1 com glicanas específicas do vírus nipah (GARNER et al. 2010) ou favorecer a ocorrência de processos infecciosos, como descrito para o vírus HIV (SATO et al., 2012).

Sendo as galectinas sintetizadas e armazenadas no citoplasma, sem sinal para exportação, e considerando que elas são liberadas para o meio externo, tanto por extravasamento do conteúdo celular, quanto por vias de exportação não usuais, em situações de lesão tecidual por infecção e/ou inflamação, tem-se considerado essas lectinas também como "alarminas" ou padrões moleculares associados a dano celular (damage associated molecular patterns - DAMPs), atuando ali como sinalizadores de injúria tecidual, no recrutamento de fagócitos para o local de infecção para o auxílio da eliminação do agente agressor, e reparo tecidual subsequente (SATO et al., 2009; MISHRA et al., 2013). MISHRA e colaboradores (2013) descreveram que as galectinas podem participar da fisiopatologia da sepse experimental provocada pela infecção de camundongo por bactérias virulentas por atuarem como importantes alarminas e promotoras de um aumento da resposta inflamatória.

Sabe-se que, durante o processo inflamatório e infeccioso, a contração eficiente da população de leucócitos ativados ou hiper-reativos deve ocorrer de maneira controlada para uma efetiva homeostase imunológica. Falhas na eliminação dessas células poderiam gerar danos teciduais, resultando em doenças auto-imunes ou o surgimento de neoplasias (STRASSER et al., 2000; DANIAL \& KORSMEYER, 2004).

Membros da família das galectinas, juntamente com outros mediadores, como os membros da família do TNF (Fas, TRAIL, and TNF- $\alpha$ ) são responsáveis por regular o turnover de leucócitos no sistema imune por meio de apoptose (RABINOVICH et al., 2002; TOSCANO et al., 2007). Diversos estudos demonstraram que a Gal-1 pode atuar sobre células $T$ tanto no timo quanto na periferia, 
controlando assim a população de células nesses locais (BAUM et al. 1995; BLASER et al. 1998; PERILLO et al. 1995; PERILLO et al. 1997).

Toscano e colaboradores (2007) demonstraram que a diferenciação de células $T$ em células $T$ auxiliares modifica sua susceptibilidade a apoptose mediada por Gal-1, pois ocorrem alterações no padrão de glicosilação durante o processo de diferenciação. Células Th-1 e Th-17 expressam em sua superfície um repertório de glicanas importante para apoptose induzida por Gal-1, sendo, portanto, mais suscetíveis a esse efeito da Gal-1 em comparação com células Th-2, que apresentam sialilação de suas glicoproteínas de superfície, o que reduz a afinidade da Gal-1 por essas glicanas, reduzindo, pois, sua ligação a essas células T (MOTRAN et al., 2008). Por outro lado, células B produtoras e secretoras de anticorpos (plasmócitos) provenientes de camundongos deficientes do gene da Gal1 apresentam elevadas taxas de apoptose e menor atividade secretora de anticorpos. Estes autores sugerem que a Gal-1 endógena pode inibir a apoptose e favorecer aspectos funcionais destes linfócitos (ANGINOT et al., 2013).

Sabe-se também que a Gal-1 é capaz de atuar na homeostase do sistema imune por meio da regulação de células $\mathrm{T} \mathrm{CD}^{+} \mathrm{CD} 25^{+}$, as quais representam elementos-chave na supressão da resposta imune e manutenção da tolerância imunológica. Existem evidências de que células $\mathrm{T} C D 4^{+} \mathrm{CD} 25^{+}$, após ativação, apresentam superexpressão de Gal-1, localizada tanto no núcleo quanto no citoplasma (GARIN et al., 2007). Além disso, anticorpos anti-Gal-1 inibem a atividade supressora de células $\mathrm{T} \mathrm{CD} 4^{+} \mathrm{CD} 25^{+}$humanas in vitro e camundongos deficientes do gene da Gal-1 apresentam células T CD4 ${ }^{+} \mathrm{CD} 25^{+}$menos eficientes em suprimir a resposta proliferativa de células $\mathrm{T}_{\mathrm{CD}}{ }^{+}$ativadas (GARIN et al.,2007).

A Gal-1 pode também participar da regulação da resposta imunológica por induzir a liberação de IL-10, uma citocina imunoregulatória, por linfócitos T (STOWELL et al., 2008). Nessa linha, foi demonstrado que a interação da Gal-1 com a superfície de células $T$, via o reconhecimento da glicoproteina CD45, promove a liberação da IL-10 (CEDENO-LAURENT et al., 2012). Alternativamente, a exposição de células dendríticas a Gal-1 promove a liberação de IL-27, via interação desta lectina com a glicoproteína CD43; a IL-27, por sua vez, induz a liberação de IL-10 por células T regulatórias (ILARREGUI et al., 2009). 
TOSCANO e colaboradores (2011) demonstraram que a expressão de Gal-1 é regulada por NF-kB, um fator de transcrição essencial no início do processo inflamatório. A expressão de Gal-1 se eleva quando existe aumento desse fator de transcrição, e a Gal-1 é capaz de reduzir significativamente os níveis de NF-KB. Assim, a Gal-1 está envolvida no processo de resolução da resposta inflamatória e esse efeito deve-se à regulação dos níveis de NF-KB.

Células apoptóticas, além de apresentarem fragmentação de DNA (núcleo picnótico), expressam fosfatidilserina (FS) em suas superfícies, um fosfolipídeo localizado, preferencialmente, na face interna da membrana plasmática de células normais. O reconhecimento da FS na superfície dessas células por macrófagos favorece a fagocitose das mesmas (FADOK et al., 2000; VANCE et al., 2008).

Ao contrário dos mediadores da família do TNF, a Gal-1h pode induzir a exposição reversível de FS em neutrófilos humanos ativados, sem ocorrência de fragmentação de DNA, ou seja, independente de apoptose, favorecendo o reconhecimento fagocítico destas células e a eliminação das mesmas por macrófagos (DIAS-BARUFFI et al., 2003). KARMAKAR e colaboradores (2005) demonstraram que a interação da Gal-1 com as superfícies de neutrófilos ativados promove a ativação de quinases SRC (Lyn e Hck), ativação da fosfolipase $C \gamma 2$, mobilização de $\mathrm{Ca}^{+2}$ e a consequente exposição de FS nas superfícies destes leucócitos. Ainda, nosso grupo demonstrou que a exposição de FS em neutrófilos é reversível e independente da ativação de caspases, alteração de potencial mitocondrial e morte celular (STOWELL et al. 2007; STOWELL et al., 2009). Estes e outros estudos indicam que neutrófilos ativados possuem ligantes particulares, ainda não determinados, importantes para o turnover de neutrófilos (STOWELL et al., 2007, STOWELL et al., 2009).

\subsection{Gal-1 e $\beta$ 2-integrina (Mac-1)}

A interação célula-matriz extracelular através de moléculas de adesão, dentre elas as integrinas, apresenta extrema importância em processos de transdução de sinal. As integrinas são componentes de uma ampla família de receptores transmembrana de adesão que diferem de outros receptores devido a sua baixa 
afinidade por seus ligantes, o que permite uma interação reversível entre célula e matriz (ALBERTS et al., 2008).

A Gal-1 é capaz de interagir com integrinas e, dessa forma, modular diferentes efeitos biológicos. SAKAGUCHI e colaboradores (2010) relatam a regulação do número de células progenitoras neurais na zona subependimal de camundongos adultos por meio de interação carboidrato-dependente da Gal-1 com $\beta 1$ integrinas presentes nessas células. Isso ocorre provavelmente por modulação da capacidade de adesão dos progenitores neurais adultos. Estudos de ROMANIUK e colaboradores (2012) sugerem que a interação entre Gal-1 e $\alpha_{\| \mathrm{Ib}} \beta_{3}$-integrina está envolvida em um mecanismo não clássico de ativação plaquetária, pois demonstram que camundongos deficientes de Gal-1 apresentam tempo de sangramento prolongado não associado com deficiência na função plaquetária.

As $\beta 2$-integrinas são moléculas indispensáveis para a adesão e transmigração de neutrófilos através do endotélio ativado, assim como outras funções neutrofílicas dependentes de adesão, como o clearance fagocítico de patógenos (MAYADAS e CULLERE, 2005; FILEP e KEBIR, 2009).

A família das $\beta 2$ integrinas é restrita a leucócitos e é composta de quatro membros: CD11a/CD18 [lymphocyte function-associated antigen-1 (LFA-1)], CD11b/CD18 (Mac-1), CD11c/CD18 e CD11d/CD18, os quais são heterodímeros compostos de uma única subunidade a (CD11) complexada com uma subunidade $\beta 2$ (CD18) comum. Essas moléculas estão presentes em um estado inativo em leucócitos circulantes, sofrendo uma alteração conformacional durante o processo de ativação dessas células, o que resulta numa configuração molecular ótima denominada ativa (MAYADAS e CULLERE, 2005; LEFORT et al., 2009).

As integrinas, em sua configuração molecular ativa, são responsáveis por mediar a adesão de leucócitos e sua transmigração através do endotélio por meio de interações com ICAM-1 no endotélio ativado. As integrinas Mac-1 e CD11c/CD18 também promovem a fagocitose de microorganismos, reconhecendo diretamente diversos patógenos (ROSS, 2000). Outras funções de neutrófilos dependentes de adesão, como ligação a fibrinogênio, imunocomplexos e plaquetas, são também dependentes de Mac-1, considerando a ampla variedade de ligantes de Mac-1 e sua 
habilidade de cooperar funcionalmente com uma gama de outros receptores de superfície (EHLERS, 2000).

Mutações no gene ITGB2, localizado no braço longo do cromossomo 21q22, e codificante para a subunidade $\beta 2$ comum da integrina (CD18), desencadeiam uma desordem de grande importância clínica denominada leukocyte adhesion deficiency I ( $L A D$ ), caracterizada pela deficiência de moléculas de adesão em leucócitos, o que impede a migração para locais de infecção. Indivíduos acometidos por essa desordem exibem maior suscetibilidade a infecções e neutrofilia periférica (HANNA e ETZIONI, 2012).

COXON e colaboradores (1996) demonstraram que neutrófilos provenientes de camundongos deficientes de CD11b/CD18 apresentam capacidade reduzida de adesão ao endotélio, acumulando-se nos locais de inflamação nesses animais. Esse dado, associado ao fato de neutrófilos apresentarem maior expressão de $\beta 2$ integrina em sua superfície após ativação (PLUSKOTA et al., 2008), e de que esta molécula está envolvida no processo de sinalização para apoptose (MAYADAS e CULLERE, 2005) e fagocitose (BERTON e LOWELL, 1999) de neutrófilos, são indícios da importância de $\beta 2$-integrina para o turn-over dessas células da imunidade inata.

A Gal-1, assim como o Mac-1, participa de eventos relacionados à biologia dos neutrófilos, como adesão celular, degranulação, produção de espécies reativas de oxigênio, regulação positiva/negativa da migração para o sítio inflamatório e controle da meia vida desses leucócitos por apoptose e/ou remoção fagocítica (DIAS-BARUFFI et al., 2003, ZHANG et al., 2003; LA et al., 2003; ELOLA et al., 2005; COOPER et al., 2008; AUVYNET et al., 2013).

O domínio carboxiterminal da galectina-8 (Gal-8C) é capaz de ligar-se a $\beta 2$ integrina de neutrófilos de modo carboidrato dependente (NISHI et al., 2003). STOWELL e colaboradores (2009) destacam a capacidade deste domínio da Gal-8 de induzir a exposição de FS na superfície de neutrófilos. Sabe-se também que Gal1 derivada de extrato de macrófagos murinos pode se ligar a Mac-1 dessas células e esta interação molecular pode ser importante em eventos de sinalização (AVNI et al., 1998). 
Curiosamente a Gal-1 pode apresentar um comportamento anti-inflamatório ou pró-inflamatório quanto a capacidade de modular funções de neutrófilos em função do cenário biológico. Esta lectina pode promover a geração de espécies reativas de oxigênio apenas em neutrófilos ativados (ELOLA et al., 2005). Ainda, pode promover a migração de neutrófilos não ativados e inibir a migração destes fagócitos quando da prévia instalação de um processo inflamatório agudo (LA et al., 2003; GIL et al., 2010; AUVYNET et al., 2013). GIL e colaboradores (2010) demonstraram que a Gal-1 inibe a migração de neutrófilos para o local de inflamação, e esse processo pode estar relacionado à ligação dessa lectina a Mac-1 e a L-selectina, o que sugere a existência de vias de sinalização celular dependentes da interação Gal-1-Mac-1, podendo haver associação entre a ligação de Gal-1 a Mac-1, exposição de FS e o clearance de neutrófilos ativados.

\section{Justificativa}

$\mathrm{Na}$ literatura existem vários relatos sobre o uso da Gal-1h como um agente imunoregulador em modelos murinos (SANTUCCI et al. 2000; CAMBY et al., 2006; ILARREGUI et al., 2009; TOSCANO et al., 2010; CEDENO-LAURENT et al., 2012). Isto poderia representar uma variação experimental importante nestes estudos, considerando-se que a Gal-1h é imunogênica em camundongos, como demonstrado por DIAS-BARUFFI e colaboradores (2010). Assim, pode-se suspeitar que as diferenças sequenciais entre Gal-1c e Gal-1h possam resultar em modificações estruturais com implicações biofísicas e biológicas importantes para as proteínas estudadas, repercutindo diretamente na fidedignidade dos resultados obtidos em ensaios in vivo. Isso motivou a clonagem da Gal-1c pelo nosso grupo de pesquisa, a qual foi bem sucedida, sendo assim possível, no presente trabalho, elucidar diferenças estruturais e biológicas existentes entre a proteína murina e a humana por meio da análise comparativa entre as mesmas. Considerando a possível interação entre Gal-1 e Mac-1 na biologia dos neutrófilos, o presente trabalho tem também como objetivo investigar a participação do complexo Gal-1-Mac-1 na indução da exposição de FS na superfície de neutrófilos ativados utilizando modelo murino com produção deficiente de Mac-1. 


\section{Objetivos}

\subsection{Geral}

- Avaliar as diferenças existentes entre Gal-1c e Gal-1h sob os aspectos molecular e biológico.

\subsection{Específicos}

- Caracterização da Gal-1c recombinante obtida;

- Obtenção de soro imune contendo anticorpos anti-Gal-1c;

- Resolução da estrutura da Gal-1c;

- Análise da capacidade hemaglutinante de Gal-1c e Gal-1h quando na presença de hemácias de diferentes espécies;

- Avaliação comparativa da capacidade de Gal-1c e de Gal-1h em reconhecer diferentes glicanas presentes no sistema de glycan array;

- Comparação da capacidade de Gal-1c e de Gal-1h de induzir reversivelmente a exposição de fosfatidilserina na superfície de neutrófilos de camundongos, obtidos de animais que apresentam expressão normal ou diminuída de $\beta 2$ integrina (Mac-1).

\section{Materiais e Métodos}

\subsection{Obtenção e purificação da galectina-1 recombinante de camundongo}

A Gal-1c foi obtida de cultura de bactérias (E. coli cepa BL21-DE3) transformadas com plasmídio pGal-1c construído com o uso do vetor comercial pET29a (Novagen) com fragmento gênico referente a fase aberta de leitura do gene da Gal-1c (Lgals1) obtido de músculo esquelético de camundongo C57BL/6. Estes procedimentos foram realizados de forma semelhante a descrita por $\mathrm{CHO}$ \& CUMMINGS (1995). As bactérias foram cultivadas em $50 \mathrm{~mL}$ de meio LB Broth Base (Invitrogen, Gibco, Carlsbad, CA, EUA) com kanamicina $(25 \mu \mathrm{g} / \mathrm{mL}$ ) (USB Corporation, EUA) sob agitação $(200 \mathrm{rpm})$ a $37^{\circ} \mathrm{C}$, por $16-18$ horas. Após este período, e constatado o crescimento bacteriano, foram transferidos $20 \mathrm{~mL}$ desta cultura para cada litro de meio LB, previamente autoclavado contendo kanamicina 
(25 $\mu \mathrm{g} / \mathrm{mL}$ ). Em seguida, esta suspensão bacteriana foi incubada, sob agitação (200 rpm), a $37^{\circ} \mathrm{C}$ por aproximadamente 2 horas. Após este período de incubação, foi aferida a densidade óptica $\left(\mathrm{DO}_{600}\right)$ para verificar a taxa de crescimento bacteriano, considerada ótima quando atingiu a faixa de $\mathrm{DO}_{600}$ entre $0.45-0.5$. Em seguida, foi adicionado $1 \mathrm{~mL}$ de uma solução 0,5M de IPTG (Promega, WI, EUA) para cada litro de cultura, resultando numa concentração de $0,5 \mathrm{mM}$, para a indução da expressão da Gal-1c. O cultivo prosseguiu em agitador $\left(37^{\circ} \mathrm{C}-250 \mathrm{rpm}\right)$ por 4 horas. Após este período de incubação, a suspensão bacteriana foi centrifugada a $4500 \mathrm{~g}$ por 20 minutos a $4^{\circ} \mathrm{C}$. O pellet bacteriano obtido após centrifugação foi reservado para posterior purificação da proteína obtida.

A forma dimérica da Gal-1c foi purificada a partir da lise mecânica do pellet bacteriano. Inicialmente, o pellet foi ressuspendido em tampão de lise contendo um comprimido de inibidor de proteases (Complete Mini, EDTA Free - Roche Diagnostics, Indianápolis, IN, USA), RNAse $(10 \mu \mathrm{L}-10 \mathrm{ng} / \mathrm{mL})$; DNAse (10 $\mu \mathrm{L}-$ $10 \mathrm{ng} / \mathrm{mL})$, lisozima $(1 \mathrm{~mL}-1 \mathrm{mg} / \mathrm{mL})$ e $\beta$-mercaptoetanol (2-ME - $14 \mathrm{mM})$. Em seguida, em banho de gelo, a suspensão bacteriana foi submetida a 5 pulsos de 40 W com intervalos de 30 segundos entre os pulsos, com o uso de um sonicador (Sonics Vibracell-VCX130- Sonics \& Material Inc. New Down, CT - USA). O lisado bacteriano foi centrifugado $\left(10000 \mathrm{~g}\right.$ a $\left.4^{\circ} \mathrm{C}\right)$ e o sobrenadante foi submetido à cromatografia de afinidade em coluna de agarose-lactose. Esse processo cromatográfico foi monitorado por aferição da $\mathrm{DO}_{280}$ e eletroforese em gel de poliacrilamida (12,5\% - SDS-PAGE). As preparações de Gal-1c foram estocadas em tampão de conservação contendo lactose (100 mM) e 2-ME (14 mM) em PBS a $80^{\circ} \mathrm{C}$. Para o uso, as preparações de Gal-1c em tampão de conservação foram submetidas à cromatografia de exclusão molecular em colunas PD10 (Sephadex G25-SF, GE Healthcare, USA) para remoção de lactose e 2-ME. As concentrações protéicas das soluções de Gal-1c foram determinadas pela aferição da $\mathrm{DO}_{280}$ e estes valores foram convertidos para concentração $(\mathrm{mg} / \mathrm{mL})$ considerando seu coeficiente de extinção molar $6990 \mathrm{M}^{-1} \mathrm{~cm}^{-1}$, calculado utilizando a ferramenta ExPASy ProtParam (GASTEIGER et al., 2005). 


\subsection{Obtenção e purificação de galectina-1 recombinante humana}

A Gal-1h foi obtida de culturas de bactérias (E. coli cepa M-15) transformadas com plasmídeo PQU-50 contendo o gene completo da lectina, como descrito anteriormente, utilizando ampicilina $(25 \mathrm{mg} / \mathrm{mL})$ como antibiótico de seleção, e induzidas com $1 \mathrm{mM}$ de IPTG. As bactérias citadas foram cedidas, gentilmente, pelo Prof. Dr. Richard D. Cummings, chefe do Biochemistry Department do Medicine College da Emory University, Atlanta, Georgia - EUA. As concentrações protéicas das soluções de Gal-1h foram determinadas pela aferição da $\mathrm{DO}_{280}$ e estes valores foram convertidos para concentração $(\mathrm{mg} / \mathrm{mL})$ considerando o coeficiente de extinção molar da proteína $8480 \mathrm{M}^{-1} \mathrm{~cm}^{-1}$, calculado utilizando a ferramenta ExPASy ProtParam (GASTEIGER et al., 2005).

\subsection{Caracterização molecular da Gal-1c}

\subsubsection{Espectrometria de Massas}

A análise da Gal-1c por espectrometria de massas foi realizada em colaboração com o prof. Dr. Norberto Peporine Lopes, do Núcleo de Pesquisa em Produtos Naturais e Sintéticos da Faculdade de Ciências Farmacêuticas de Ribeirão Preto da Universidade de São Paulo, por meio da técnica de MALDI-TOF (Matrix-assisted laser desorption ionization - time of flight) em espectrômetro de massas UltrafleXtreme com frequência de laser de $1000 \mathrm{~Hz}$. A matriz de ácido 2,5dihidroxibenzóico (DHB) $(20 \mathrm{mg} / \mathrm{mL})$ e a preparação de Gal-1c foram misturados em proporção de 1:1 para a realização das análises.

\subsubsection{Dicroísmo Circular (DC)}

A obtenção dos dados de DC foi realizada em colaboração com o prof. Dr. Antônio José da Costa Filho, do Grupo de Biofísica Molecular Sérgio Mascarenhas, Instituto de Física de São Carlos da Universidade de São Paulo.

Os espectros de DC foram adquiridos no espectropolarímetro Jasco J815 (Jasco Corporation, Japan) acoplado a um módulo Peltier para o controle de variação de temperatura. As medidas foram coletas entre os comprimentos de onda de $200 \mathrm{e}$ $197 \mathrm{~nm}$ a uma velocidade de varredura de $50 \mathrm{~nm} / \mathrm{min}$, sob um fluxo constante de $\mathrm{N}_{2}$ purgando de acordo com as instruções do fabricante. No estudo de desnaturação térmica, variou-se a temperatura entre 10 e $80^{\circ} \mathrm{C}$ a uma taxa de $2{ }^{\circ} \mathrm{C}$, tendo sido 
testadas condições contendo somente a Gal-1c, Gal-1c na presença de lactose e Gal-1c na presença de sucrose. Utilizaram-se cubetas de quartzo com caminho óptico de $1 \mathrm{~mm}$. Os espectros medidos são resultado da média de oito scans acumulativos, para diminuir a relação sinal/ruído. As concentrações das amostras utilizadas foram $15 \mu \mathrm{M}$ de Gal-1c em tampão PBS e $1 \mathrm{mM}$ de $\beta$-mercaptoetanol. $\mathrm{Na}$ presença de carboidratos lactose e sucrose, a concentração utilizada dos mesmos foi de dez vezes a de proteína $(150 \mu \mathrm{M})$. Foi utilizado o programa Spectral Analysis da Jasco para subtrair o espectro do tampão do espectro da amostra e para eliminar a interferência causada pelo ruído gerado durante a aquisição dos dados. Os espectros foram coletados em graus de elipticidade $(\theta)$ e, então, são transformados para elipticidade molar residual, [ $\theta$ ], ou seja, foram normalizadas pela concentração e pelo número de resíduos.

\subsection{Obtenção de soro imune de coelho contendo anticorpos anti-Gal-1c}

Coelhos albinos machos e adultos (New Zeland) foram imunizados com $600 \mu \mathrm{g}$ (4 etapas de $150 \mu \mathrm{g}$ cada) de Gal-1c emulsificados com adjuvante completo ou incompleto de Freund (Difco Laboratories Inc., Detroit, MI, USA) conforme protocolo descrito por HARLOW E LANE (1988) previamente aprovado pelo Comitê de Ética no Uso de Animais (CEUA), protocolo $n^{\circ}$ : 11.1.269.53.3. Previamente à primeira imunização, foram colhidos $5 \mathrm{~mL}$ de sangue total do coelho para obtenção de soro pré-imune. Para cada etapa posterior, de imunização, foram colhidos $5 \mathrm{~mL}$ de sangue total, a fim de determinar, por ELISA, o título de anticorpos anti-Gal-1c no soro, para análise da eficiência do procedimento de hiperimunização. Resumidamente, placas de polipropileno de 96 poços foram sensibilizadas com Gal1c $\left(1 \mu \mathrm{g} / 50 \mu \mathrm{L} /\right.$ poço) overnight, a $4^{\circ} \mathrm{C}$. Sequencialmente, os poços foram submetidos a etapa de bloqueio com PBS-gelatina $3 \%$ por $2 \mathrm{~h}$ a $37^{\circ} \mathrm{C}$. Em seguida, os soros imunes anti-Gal-1c (anticorpos primários), diluídos em PBS Tween 20 0,05\% gelatina $1 \%$, foram distribuídos nos poços $(50 \mu \mathrm{L})$ e a placa de ELISA foi incubada por 1 hora a $37^{\circ} \mathrm{C}$. Os soros pré-imunes e poços sem anticorpos primários foram utilizados como controles negativos. Após etapas de lavagens com PBS Tween 20 $0,05 \%$, foram adicionados aos poços $50 \mu \mathrm{L}$ do anticorpo secundário, anticorpo de camundongo anti Ig-G de coelho conjugado com peroxidase (1:20000, em PBS Tween 20 0,05\% gelatina 1\%), e foi feita incubação por 1 hora. Após lavagens, as 
imunoreações foram reveladas com o uso de solução reveladora para peroxidase contendo o TMB (tetrametilbenzidina, Organon Teknika, Boxtel, NL). Finalmente, as leituras de absorvância $(450 \mathrm{~nm})$ foram realizadas com o uso de espectrofotômetro (Spectramax Plus - Molecular Devices).

\subsection{Determinação da estrutura cristalográfica da galectina-1 de camundongo}

\subsubsection{Cristalização}

A cristalização da Gal-1c é uma etapa essencial para a realização de experimentos de difração de raios $X$ para a obtenção e estudo da estrutura tridimensional cristalográfica da lectina em estudo.

O crescimento de um cristal se dá através do processo que leva a solução de proteína a um estado de supersaturação; nesse estado, parâmetros físico-químicos, bioquímicos, biofísicos e biológicos podem ser combinados de modo a levar a formação do cristal. Dentre esses parâmetros estão: temperatura, pH, força iônica, efeitos de densidade e viscosidade, tempo, sensibilidade conformacional, contaminantes macromoleculares, homogeneidade da amostra, entre outros (DRENTH, 2006).

Os ensaios de cristalização foram realizados em colaboração com a $\operatorname{Prof}^{a}$. $\operatorname{Dr}^{\mathrm{a}}$. Maria Cristina Nonato, do Laboratório de Cristalografia de Proteínas, da Faculdade de Ciências Farmacêuticas de Ribeirão Preto da Universidade de São Paulo. Os primeiros experimentos de cristalização da galectina-1 de camundongo foram realizados utilizando os kits de cristalização comercialmente disponíveis: Crystal Screen I e II (Hampton Research) e PEG/ION Screen (Hampton Research) que utiliza uma ampla variação de combinações com diferentes tipos de agentes precipitantes, tampões e aditivos, baseados no conceito de matriz esparsa (JANCARIK e KIM, 1991).

Os ensaios foram feitos inicialmente às temperaturas de $4{ }^{\circ} \mathrm{C}$ e $21^{\circ} \mathrm{C}$, utilizando o método de difusão de vapor por gota sentada (sitting drop), em placas de 24 poços. As gotas foram feitas empregando-se $2 \mu \mathrm{l}$ de solução de proteína homogeneizada, previamente dialisada contra $14 \mathrm{mM} \beta$-mercaptoethanol, $50 \mathrm{mM}$ 
HEPES pH 7.2, $50 \mathrm{mM} \mathrm{NaCl}$ e concentrada a $30 \mathrm{mg} / \mathrm{ml}$ (Millipore Ultrafree membrane; 10 kDa molecular-mass cutoff), com $2 \mu$ de solução do reservatório, no qual foi adicionado $500 \mu \mathrm{l}$ da solução de cristalização contida no kit.

\subsubsection{Coleta e processamento de dados}

Os dados foram coletados na linha de luz W01B-MX2 no Laboratório Nacional de Luz Síncrotron (CNPEM/MCT - LNLS) utilizando o detector MarMosaic225 CCD (Mar Research) a um comprimento de onda de $1.459 \AA$ com 60 s de exposição por imagem e $1^{\circ}$ por ângulo de oscilação (POLIKARPOV et al., 1998; GUIMARÃES et al., 2009) em temperatura criogênica (100 K). O conjunto de 190 imagens coletado foi processado usando o programa MOSFLM (LESLIE et al., 2007) e escalonado com o programa SCALA (CCP4) (EVANS et al., 1997), separando-se $5 \%$ das reflexões totais para o conjunto teste $\left(R_{\text {free }}\right)$ a ser utilizado no teste de validação cruzada.

\subsubsection{Faseamento e refinamento}

Os conjuntos de fases iniciais, e consequente determinação da estrutura cristalográfica da Gal-1c foram obtidos por técnicas de substituição molecular com o programa Phaser implementado dentro do pacote de programas Phenix (ADAMS et al., 2010) utilizando as coordenadas do monômero da Gal-1 de rato (Gal-1r; PDB 3M2M) como modelo, com a qual a Gal-1c compartilha 95,6\% de identidade sequencial.

As posições atômicas do modelo gerado inicialmente através da substituição molecular, que continha 4 moléculas na unidade assimétrica, foram modificadas de forma a satisfazer o mapa de densidade eletrônica, calculado a $2.4 \AA$. O modelo refinado satisfez tanto aos parâmetros estereoquímicos, como também aos dados de difração de raios-X. O refinamento da estrutura foi realizado utilizando 0 programa Phenix.refine (AFONINE et al., 2012) onde está implementado o princípio de máxima entropia. Inicialmente foram utilizados vínculos de simetria não cristalográfica do tipo torsional. O programa gráfico Coot (EMSLEY e COWTAN, 2004; EMSLEY et al., 2010) foi utilizado para visualização, manipulação e refinamento manual da estrutura. $O$ ajuste manual das posições atômicas foi 
realizado levando-se em consideração as restrições estereoquímicas, assim como a concordância com os mapas pesados de densidade eletrônica $2 F_{o}-F_{c}\left(2 m F_{o}-D F_{c}\right)$, com $\sigma$ igual a 1 , e o mapa diferença $F_{0}-F_{c}\left(m F_{0}-D F_{c}\right)$, com $\sigma$ igual a 3 , onde $F_{o}(h k l)$ corresponde ao fator de estrutura observado para a relfexão hkl e $F_{c}$ corresponde ao fator de estrutura para a reflexão hkl calculado baseado no modelo. $\mathrm{m}$ e D são estimativas de erro para cada reflexão hkl, calculadas a partir do conjunto teste de reflexões. Após o ajuste de todos os aminoácidos na densidade eletrônica $\left(2 \mathrm{~F}_{\mathrm{o}}-\mathrm{F}_{\mathrm{c}}\right)$, moléculas de água foram automaticamente adicionadas pelo programa Coot através das posições dos picos no mapa diferença $F_{o}-F_{c}$, com $\sigma$ igual a 3 , e validadas através da checagem visual levando-se em consideração o ambiente químico de cada molécula de solvente. Algumas águas, que não foram encontradas automaticamente, foram adicionas manualmente. O sucesso de cada ciclo de refinamento foi monitorado através da diminuição dos valores de $R_{\text {factor }}$ e $R_{\text {free, até a }}$ obtenção de valores aceitáveis para a resolução na qual o modelo estava sendo refinado. A validação da qualidade estereoquímica do modelo obtido foi realizada no programa Molprobity (CHEN et al., 2010), onde são verificados parâmetros como comprimentos e ângulos de ligação, quiralidade, planaridade das ligações

peptídicas, entre outros. Os programas gráficos Pymol (http://www.pymol.org) e Chimera (http://www.cgl.ucsf.edu/chimera/) foram utilizados para visualização, análise da estrutura e construção de imagens.

\subsection{Ensaio de hemaglutinação}

O ensaio de hemaglutinação foi realizado utilizando-se suspensão de hemácias humanas, de coelho e de carneiro a 3\%, em PBS. O presente trabalho possui aprovação do Comitê de Ética no Uso de Animais (CEUA) (Protocolo $n^{\circ}$ 11.1.269.53.3) e do Comitê de Ética em Pesquisa (Protocolo CEP/FCFRP $n^{\circ} 231$ ).

A reação foi realizada em placas de poliestireno de fundo em $U$, sendo que cada poço receberá $50 \mu \mathrm{L}$ da suspensão de hemácias e $50 \mu \mathrm{L}$ de cada amostra-teste. A leitura da hemaglutinação foi feita por análise visual, após 2 horas do inicio da reação, a temperatura ambiente. As preparações de Gal-1c e Gal-1h foram testadas em diferentes concentrações $(150,75,37,5,18,75,9,375,4,687 \mu \mathrm{g} / \mathrm{mL})$ na presença e ausência de açúcar-hapteno específico (lactose - 10mM) ou não-específico 
(hapteno controle - sucrose - 10mM). Os ensaios foram realizados para determinação da preservação da atividade lectínica das preparações de Gal-1 além de possíveis comparações entre Gal-1c e Gal-1h quanto à atividade hemaglutinante de diferentes tipos de hemácias. Os resultados foram expressos em concentração de Gal-1 mínima capaz de promover a aglutinação. Com o objetivo de impedir a oxidação das galectinas testadas e uma possível perda de suas atividades lectínicas (VARKI et al., 2009) foram realizados experimentos aglutinação na presença de $4 \mathrm{mM}$ de 2-ME às preparações de Gal-1 e suspensão de hemácias a $2 \%$, com base em procedimento descrito por MIURA e colaboradores (2004). Ainda, foram realizados ensaios de microhemaglutinação (ODOM e VASTA, 2006) com a finalidade de otimizar a análise de atividade aglutinante das galectinas testadas. Basicamente, aos poços de microplacas de Terasaki (60 poços) foram adicionados 4 $\mu \mathrm{L}$ de solução de Gal-1c ou Gal-1h (10 $\mu \mathrm{M})$ em diferentes concentrações. A seguir foi adicionada suspensão de hemácias 0,5\% em 1\% BSA/PBS (4 $\mu \mathrm{L})$, com incubação da placa por $2 \mathrm{~h}$. Após este período foi realizada a leitura das microplacas em microscópio óptico invertido (Axiovert $40 \mathrm{CFL}$ ) para verificação de ausência ou presença de microhemaglutinação.

\subsection{Análise da capacidade de reconhecimento de glicoconjugados}

Para avaliação do perfil de reconhecimento de glicoconjugados tanto pela Gal-1c quanto pela Gal-1h utilizou-se um sistema de glycan array, contendo 611 glicanas provenientes de células de mamíferos (mammalian array 5.0) imobilizadas em uma matriz sólida (BLIXT et al.. 2004) de acordo com a representação esquemática da Figura 2. 


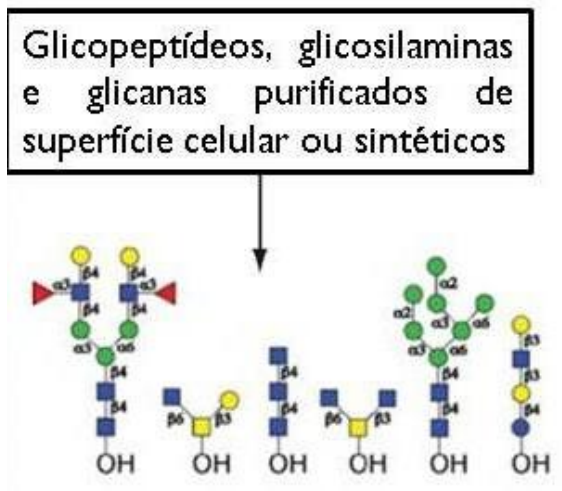

Glicanas com extremidade redutora

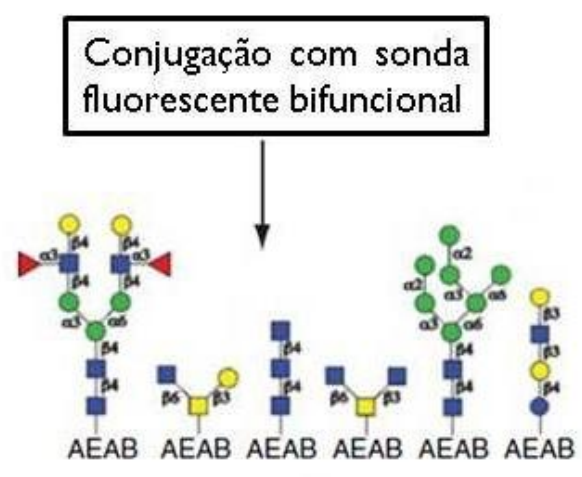

Purificação e quantificação dos conjugados
Lâmina de vidro pré-ativada com NHS

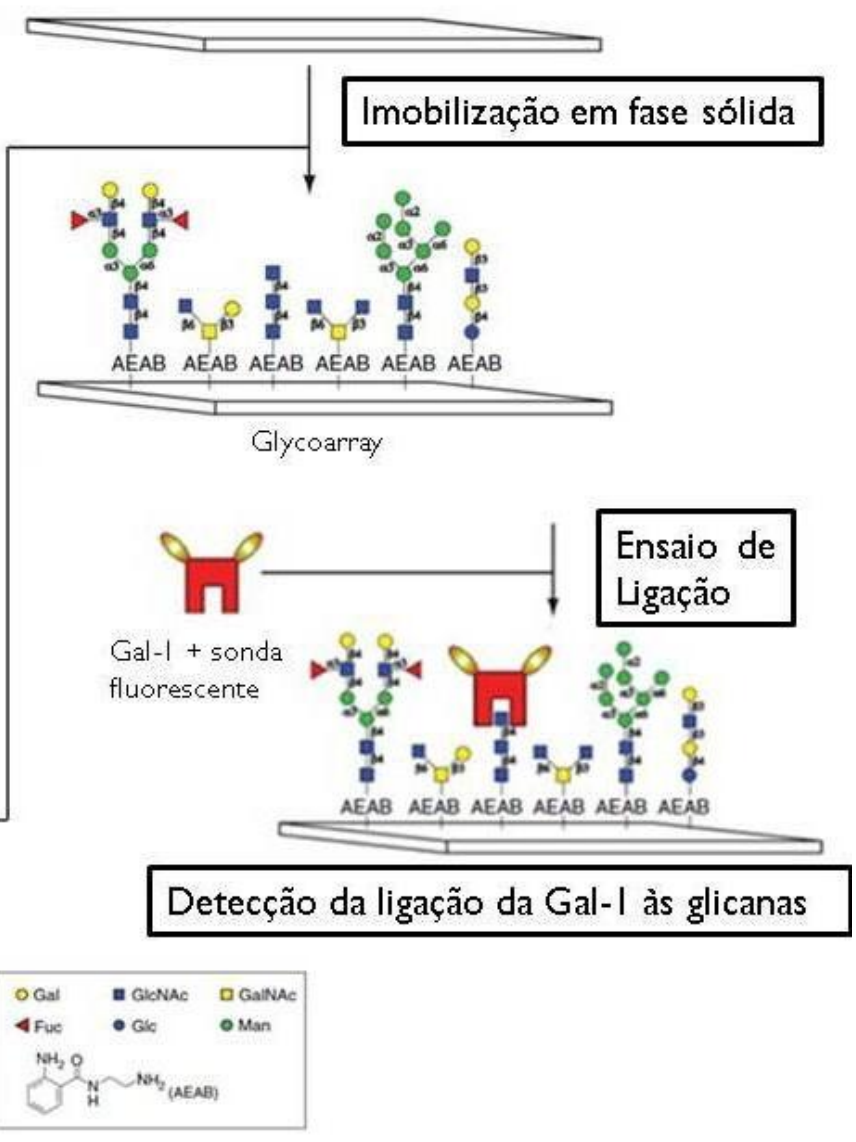

Heimburg-Molinaro J, Song $\times$, Smith DF, Cummings RD.Curr Protoc Protein Sci.Chapter I 2:Unit I 2.10.201 I.

Figura 2. Representação esquemática da preparação de um arranjo de glicanas ( glycan array) para a análise da capacidade de reconhecimento de carboidratos das galectinas e outras proteínas ligantes de glicanas (modificado de HEINBURG-MOLINARO, 2011).

O ensaio foi realizado em colaboração com o Consortium for Functional Glycomics (http://www.functionalglycomics.org/) glycan microarrays. Para geração do array, uma biblioteca de glicanas naturais e sintéticas de mamíferos, contendo ligantes amino-terminais, é impressa sobre lâminas de vidro pré ativadas com Nhidroxisuccinilimida (NHS) (SCHOTT Nexterion), sendo, assim, covalentemente ligadas às lâminas por meio de ligações amida.

Foram testadas concentrações de $0,1 \mu \mathrm{M}, 0,5 \mu \mathrm{M}, 1 \mu \mathrm{M}, 5 \mu \mathrm{M}$ e $10 \mu \mathrm{M}$ tanto de Gal-1h quanto de Gal-1c conjugadas a biotina. A ligação às glicanas foi detectada por meio da utilização de estreptavidina-Cy5. As intensidades de fluorescência foram adquiridas e analisadas no software EXCEL (Pacote Office 2007). 


\subsection{Avaliação da exposição de fosfatidilserina (FS) nas superfícies de neutrófilos}

\subsubsection{Separação de neutrófilos de camundongos C57BL/6 que expressam níveis normais e reduzidos de Mac-1}

Os camundongos utilizados nesses experimentos foram obtidos do biotério tipo Speficif Pathogens Free (SPF) da Faculdade de Ciências Farmacêuticas de Ribeirão Preto - USP. Um esquema representativo do protocolo de isolamento de neutrófilos medulares pode ser observado na figura 3.

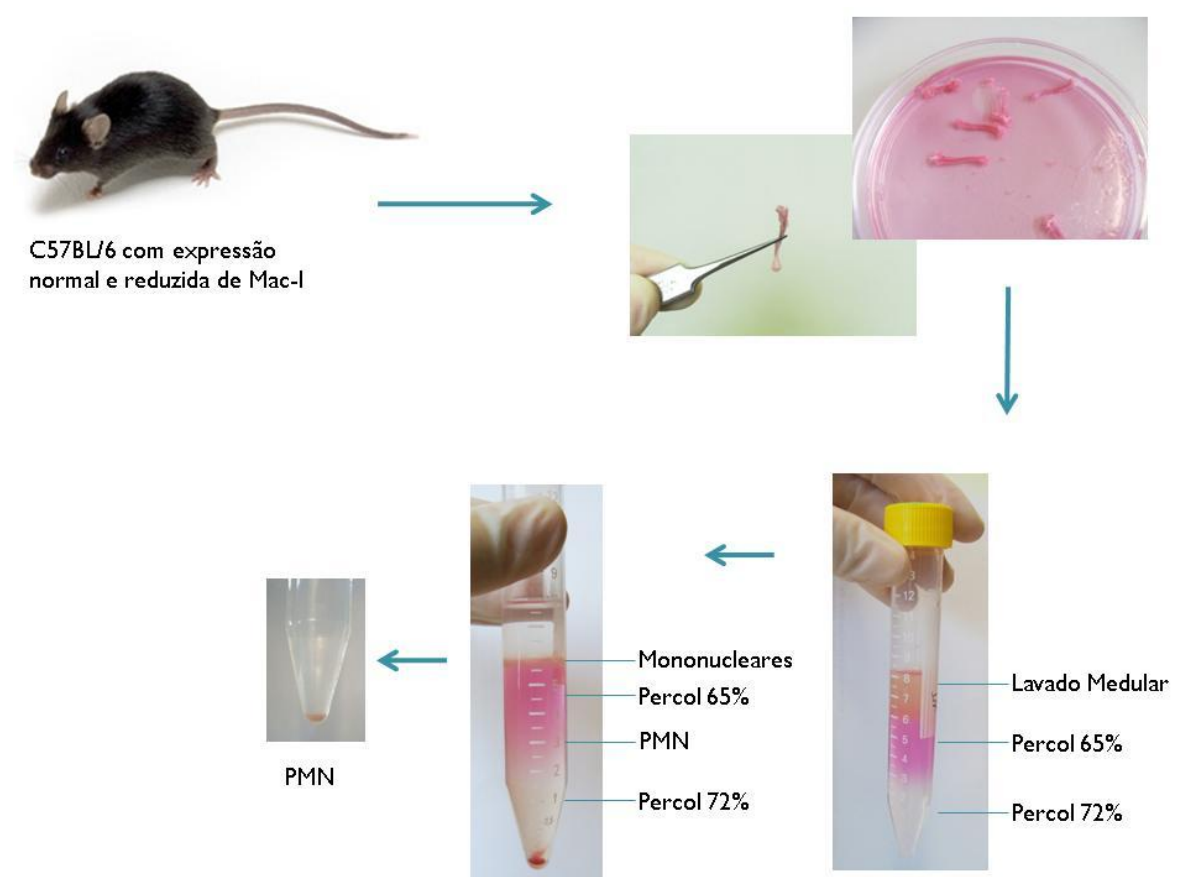

Figura 3. Esquema representativo do processo de isolamento de neutrófilos medulares de camundongos.

Basicamente, os neutrófilos foram obtidos a partir da medula óssea do fêmur e da tíbia desses animais, procedimento aprovado pelo Comitê de Ética no Uso de Animais (CEUA), protocolo $\mathrm{n}^{\circ}$ : 11.1.269.53.3. O lavado medular previamente homogeneizado foi então centrifugado em gradiente de Percoll (Sigma) 72\% e 64\% em HBSS livre de $\mathrm{Ca}^{2+}$ e $\mathrm{Mg}^{2+}$, a $1200 \mathrm{~g}$ por 30 minutos, a $20^{\circ} \mathrm{C}$, sendo então recuperado o anel de células correspondente à faixa de polimorfonucleares, com auxílio de uma pipeta de Pasteur. As hemácias foram, então lisadas com $\mathrm{NH}_{4} \mathrm{Cl}$ 
0,83\% pH 7,4 e as células posteriormente lavadas com HBSS. O número de células foi determinado por contagem em câmara de Neubauer e o valor ajustado em $1 \times 10^{6}$ células/mL em meio HBSS para serem utilizados nos respectivos ensaios.

\subsubsection{Avaliação da exposição de fosfatidilserina (FS) nas superfícies de neutrófilos através da metodologia de citometria de fluxo}

Como descrito na literatura, a Gal-h, preferencialmente, induz a exposição de FS na superfície de neutrófilos ativados (DIAS-BARUFFI et al.., 2003; STOWELL et al., 2009). Assim, após o isolamento, as células foram ativadas, ou não, com fMLP $\left(10^{-6} \mathrm{M}\right)$ durante 10 minutos a $37^{\circ} \mathrm{C}$ em câmara úmida a $5 \%$ de $\mathrm{CO}_{2}$. Posteriormente, essas células foram submetidas, ou não (controle negativo), ao tratamento com Gal1c e Gal-1h $(10 \mu \mathrm{M})$ durante 3 a 4 horas. Após estímulo, as células foram lavadas com RPMI+lactose $(20 \mathrm{mM})$, para "desmontar" possíveis agregados de neutrófilos provocados pela interação dessas lectinas com esses fagócitos, e com tampão de ligação para anexina $\mathrm{V}(10 \mathrm{mM}$ HEPES - $\mathrm{pH} 7.4,150 \mathrm{mM} \mathrm{NaCl}, 5 \mathrm{mM} \mathrm{KCl}, 1 \mathrm{mM}$ $\mathrm{MgCl}_{2}, 1,8 \mathrm{mM} \mathrm{CaCl}_{2}$ ). Após as lavagens, as células foram centrifugadas a $300 \mathrm{~g}$ por 5 minutos e posteriormente incubadas com $100 \mu \mathrm{L}$ de anexina $\mathrm{V}$ conjugada a FITC (Apoptest-FITC, DakoCytomation, Golstrup, Denmark) na diluição 1:1000 em tampão de ligação por 20 minutos, protegidas da luz a temperatura ambiente. Posteriormente, foram adicionados às células $400 \mu \mathrm{L}$ de tampão de ligação de anexina $\mathrm{V}$ e as amostras foram analisadas em citômetro de fluxo (FACSCanto, Becton Dickinson, San Jose, CA-USA), com o auxílio do software FACSDiva. No momento das aquisições de dados de citometria, foram adicionados $2 \mu \mathrm{L}$ de iodeto de propídeo $(\mathrm{PI})(1 \mathrm{mg} / \mathrm{mL})$ para determinação da taxa de necrose. Os neutrófilos foram classificados por parâmetros morfométricos (tamanho e granularidade) e imunofenotipagem com auxílio de anticorpos anti-LY6C, anti-LY6G e anti-CD11b. Ainda, as suspensões de neutrófilos foram coradas com auxílio do corante pancrômico de Rosenfeld e analisadas e por meio de microscopia óptica convencional. Como controle positivo para apoptose utilizou-se tratamento com etoposídeo $25 \mu \mathrm{M}$ durante 4 horas. 


\section{Análise dos resultados}

A análise dos resultados obtidos foi feita de modo comparativo considerando a Gal-1c e a Gal-h. O tratamento estatístico utilizado para comparação entre os diferentes grupos experimentais foi a análise de variância (ANOVA) "two-way", seguido do pós-teste de Bonferroni, ou, para comparação de dois grupos em um único ponto, Teste t de Student não-pareado, através do programa GraphPad Prism (versão 4 Prism, GraphPad, USA).

\section{Resultados e Discussão}

\subsection{Obtenção e purificação de Gal-1c e Gal-1h}

Com o objetivo de obter uma preparação adequada de Gal-1c para ser usada em experimentos posteriores, a Gal-1c foi clonada a partir de amostras de músculos esqueléticos de camundongo macho da linhagem C57BL/6. O protocolo de clonagem foi desenvolvido anteriormente em nosso grupo de pesquisa, tendo-se obtido com sucesso o vetor de expressão de Gal-1c (pGal-1c) em pET-29a (Novagen).

Utilizando-se da metodologia descrita nos itens 4.1 e 4.2, realizou-se produção e purificação de Gal-1c e Gal-1h.

O acompanhamento da purificação foi realizado por espectrofotometria com leitura de absorbância no comprimento de $280 \mathrm{~nm}$ e por SDS-PAGE $12,5 \%$ e os resultados obtidos encontram-se a seguir nas Figuras 4 e 5 . 
a)

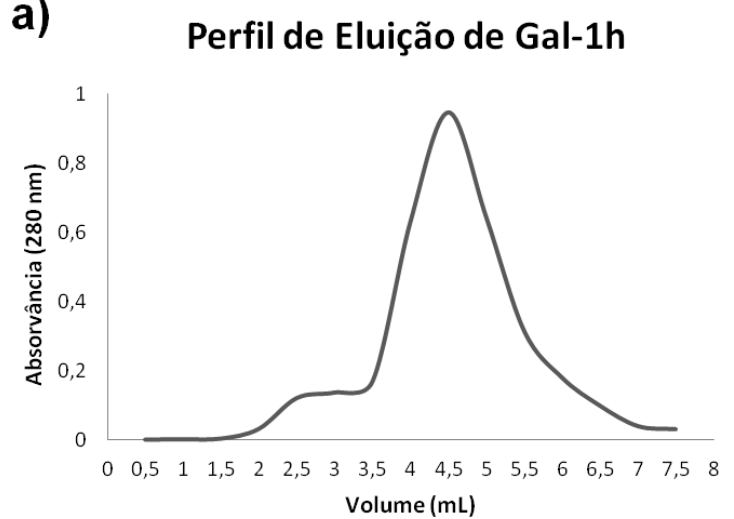

b)

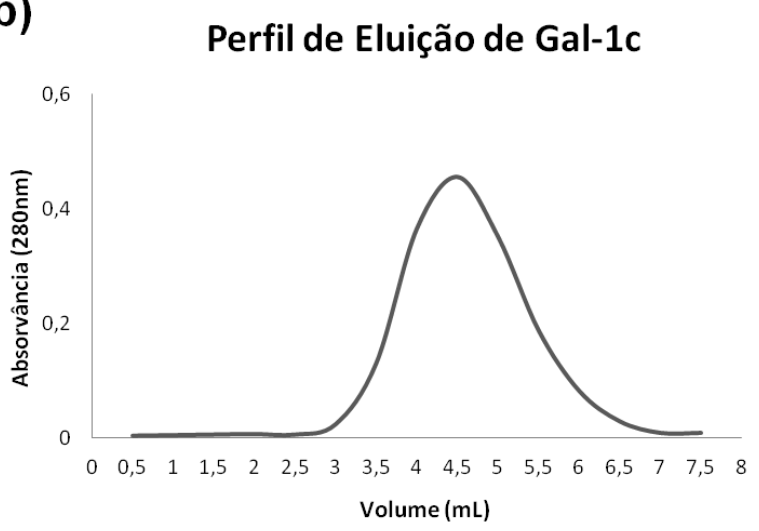

Figura 4. Perfil de eluição de Gal-1h (a) e Gal-1c (b) em coluna de agarose-lactose com o tampão de eluição contendo lactose $100 \mathrm{mM}$ e 2-ME $14 \mathrm{mM}$, em PBS. Observa-se que para ambas as proteínas o início do pico de eluição se dá após a passagem de aproximadamente 3,5-4 $\mathrm{mL}$ de tampão de eluição pela coluna, sendo finalizado após a passagem de $7 \mathrm{~mL}$.

Pode-se observar a presença de um ombro na purificação da Gal-1h (Figura 4a), que pode corresponder a frações proteicas de baixa afinidade. Esse ombro pode ter se formado também devido à dificuldade de controle de vazão da coluna, já que a purificação é realizada por gravidade, ou seja, sem auxílio de sistema de pressão. Assim, apenas as frações correspondentes ao pico de eluição foram utilizadas para as análises.

As frações correspondentes ao pico de eluição foram reunidas e submetidas à análise por SDS-PAGE 12,5\%, para verificação do grau de homogeneidade das frações proteicas (Figura 5).

a)

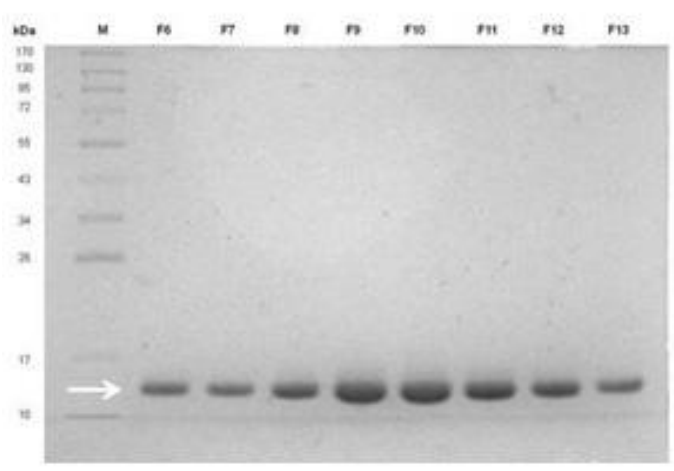

b)

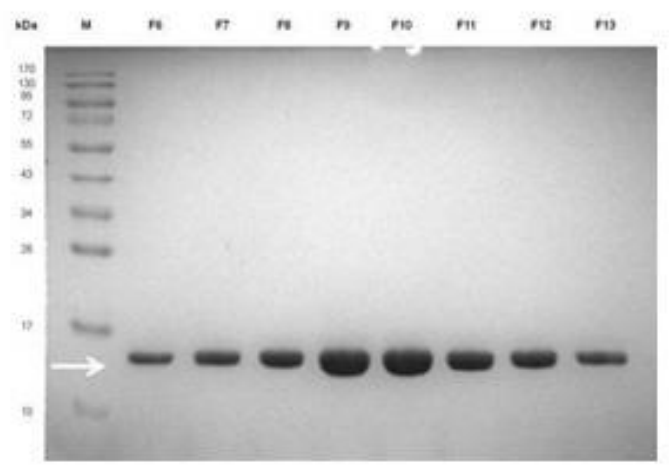

Figura 5.SDS-PAGE 12,5\%, mostrando as frações correspondentes ao pico de eluição de Gal-1h (a) e Gal-1c (b) em coluna de agarose-lactose. Obtiveram-se bandas de peso molecular aproximado de $15 \mathrm{kDa}$ (setas) correspondente ao peso molecular esperado tanto para Gal-1c quanto para Gal-1h. M: Marcador de peso molecular; F6, F7, F8, F9, F10, F11, F12 e F13: Frações cromatográficas. 
Como ilustrado na figura 5, foi possível obter preparações homogêneas, solúveis e ativas (ligantes de lactose imobilizada em agarose) de Gal-1c e Gal-1h para os experimentos posteriores.

\subsection{Caracterização molecular da Gal-1c}

\subsubsection{Espectrometria de Massas}

A análise em MALDI-TOF foi realizada a fim de determinar a massa molecular da Gal-1c recombinante obtida.

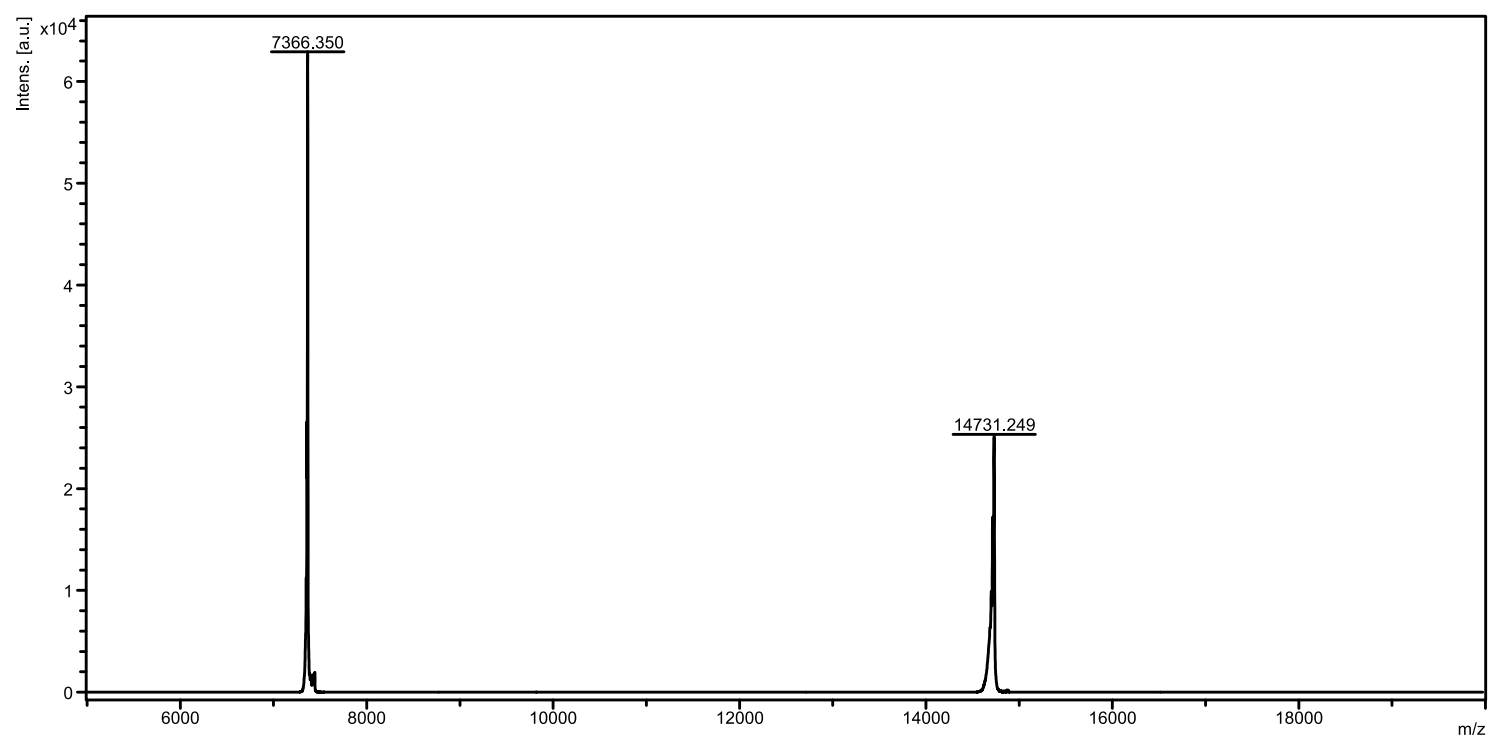

Figura 6. Espectro de massas (MALDI-TOF) obtido para Gal-1c.

Pode-se observar que o espectro da figura 6 apresenta um pico de massa molecular de 14731.249 Da, correspondente ao monômero de Gal-1c sem a metionina inicial. Os resultados obtidos corroboram com os previamente obtidos por MIURA e colaboradores (2004) para monômeros de rmGal-1a, ali descrita como correspondente à Gal-1c dimérica.

\subsubsection{Obtenção dos Espectros de Dicroísmo Circular (DC)}

A análise por DC pode ser utilizada para predizer a estrutura secundária de uma proteína, baseando-se na quiralidade dos aminoácidos, na assimetria das 
ligações peptídicas e, consequentemente, nas diferenças na absorção da luz circularmente polarizada nos lados direito e esquerdo da amostra (CORRÊA e RAMOS, 2008). Esse método foi utilizado para obtenção do perfil da estrutura secundária de preparações de Gal-1c. Os resultados obtidos por meio dessa análise encontram-se na figura 7.
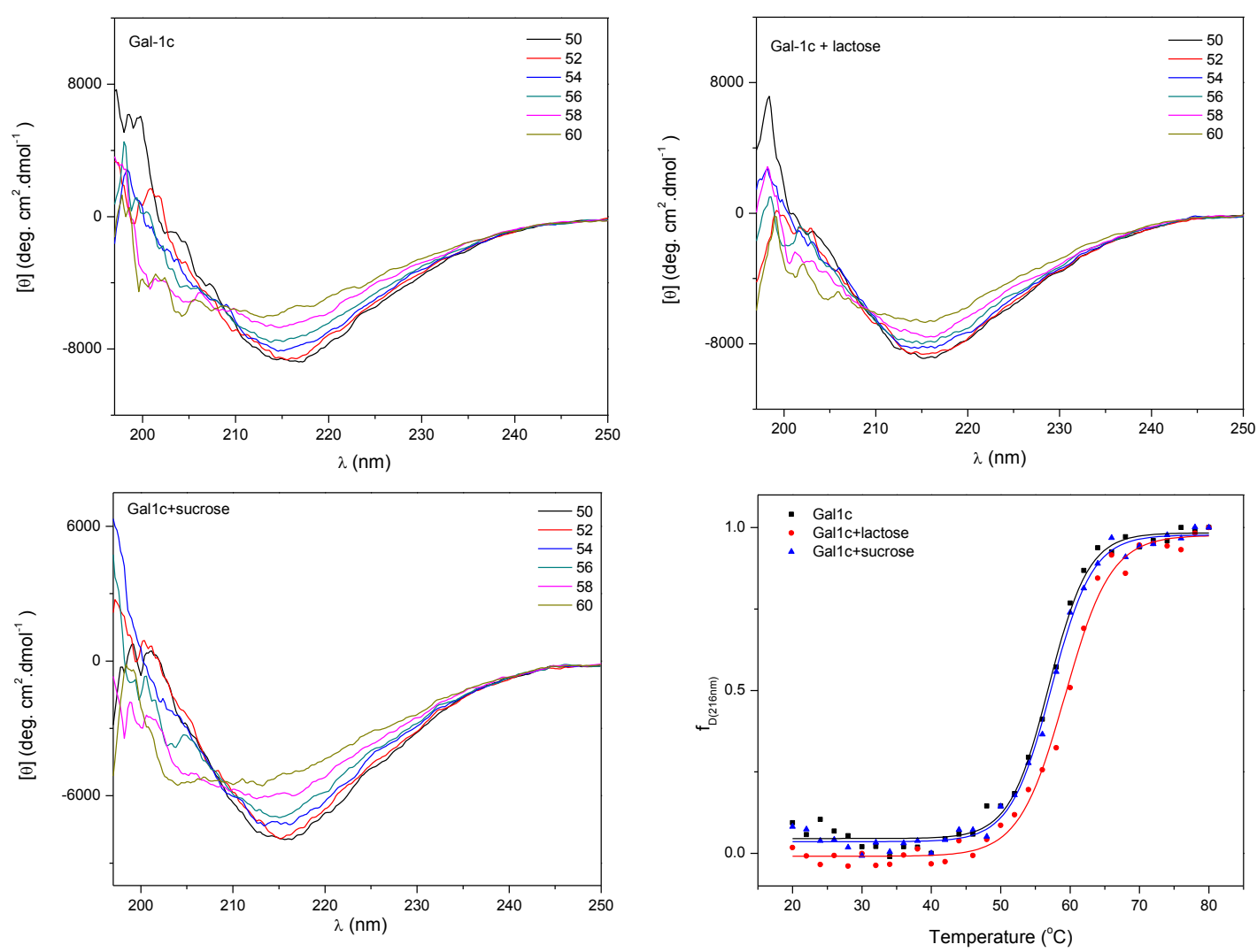

Figura 7. Espectros de Dicroísmo Circular (DC) para Gal-1c na ausência de ligante (a), na presença de lactose (b), e na presença de sucrose (c). Curva de melting $(216 \mathrm{~nm})$ para Gal-1c na presença e na ausência de ligantes (lactose e sucrose) (d).

O perfil do espectro de DC obtido para Gal-1c demonstrou uma banda negativa em 216 nm e uma banda positiva próxima a 200 nm (Figura 7a). Esses resultados indicam um espectro de folha beta pregueada, que apresenta tipicamente uma banda negativa próxima a $218 \mathrm{~nm}$ e uma banda positiva próxima a $195 \mathrm{~nm}$ (KELLY e PRICE, 1997; DODERO et al., 2011).

Também a estabilidade de uma preparação proteica pode ser determinada por DC observando mudanças no perfil do espectro conforme são realizadas alterações na temperatura. Isso é realizado por meio da análise da alteração do sinal 
em 216nm de acordo com alterações na temperatura de incubação, sendo denominada temperatura de melting $(\mathrm{Tm})$ ou denaturação a máxima temperatura em que a proteína mantém sua estabilidade (KELLY e PRICE, 1997; CORRÊA e RAMOS, 2008).

A temperatura de melting (denaturação) da Gal-1c ( $\mathrm{Tm}$ ) na presença e na ausência de açúcar hapteno inibidor (lactose) e açúcar controle (sucrose) foi determinada também por essa técnica, analisando a alteração na fração de proteína nativa em $216 \mathrm{~nm}$ de acordo com a alteração na temperatura. A Gal-1c apresentou uma $\mathrm{Tm}$ de aproximadamente $57,2^{\circ} \mathrm{C}$, havendo um deslocamento dessa temperatura para $59,1^{\circ} \mathrm{C}$ quando na presença de lactose. A Tm não foi afetada pela presença de sucrose $\left(\mathrm{Tm}: 57,1^{\circ} \mathrm{C}\right.$ ) (Figura $7 \mathrm{~d}$ ). Assim, a Gal-1c manteve sua estrutura nativa até aproximadamente $57,2^{\circ} \mathrm{C}$, sendo observado um deslocamento na $\mathrm{Tm}$ quando a lactose estava presente em solução, sugerindo que $\mathrm{o}$ ligante específico pode estabilizar a estrutura da Gal-1c ao se ligar no CRD, como previamente descrito por DI LELLA e colaboradores (2010) para Gal-1h.

Sabe-se que a ligação da lactose provoca alterações nos loops e folhas betapregueadas presentes no CRD da Gal-1h, tornando o sítio de ligação mais fechado de modo a alocar a molécula de açúcar e reduzir a mobilidade local, o que é compensado pelo aumento de flexibilidade por toda a extensão restante da proteína, contribuindo, assim, entropicamente para a redução da energia de ligação (NESMELOVA et al., 2010). Desse modo, apesar de a ligação da lactose à Gal-1h não alterar a estrutura da lectina de maneira geral, provoca alterações na flexibilidade e energia interna da proteína, conferindo-lhe maior estabilidade térmica.

Análises previamente realizadas para Gal-1h demonstraram um $T m$ de $65^{\circ} \mathrm{C}$, não havendo alteração na presença de sucrose, e um $\mathrm{Tm}$ de $68^{\circ} \mathrm{C}$ na presença de lactose (DI LELLA et al., 2010). Nesse estudo, DI LELLA (2010) também relata que a Gal-1h monomérica apresenta maior sensibilidade a alterações na temperatura, sendo a oligomerização um processo importante na manutenção da estabilidade da molécula. Esses dados, comparados com os resultados obtidos no presente trabalho, podem sugerir que a Gal-1c apresenta-se mais termosensível que a Gal$1 \mathrm{~h}$, sendo, desse modo, menos estável quando submetida às mesmas condições experimentais. Essa diferença de estabilidade pode ser decorrente tanto de sutis 
diferenças estruturais oriundas da composição de aminoácidos distinta, quanto de diferenças no padrão de oligomerização e do volume de distribuição dessas proteínas.

\subsection{Obtenção do soro imune de coelho contendo anticorpos anti-Gal-1c}

Após os procedimentos de imunização, foi possível obter um título suficientemente alto para os anticorpos anti-Gal-1c em soro de coelho, como se pode observar nos resultados obtidos por ELISA, representados na figura 8.

\section{Titulação de anticorpos policlonais anti-Gal- $1 c$ em soro de coelho}

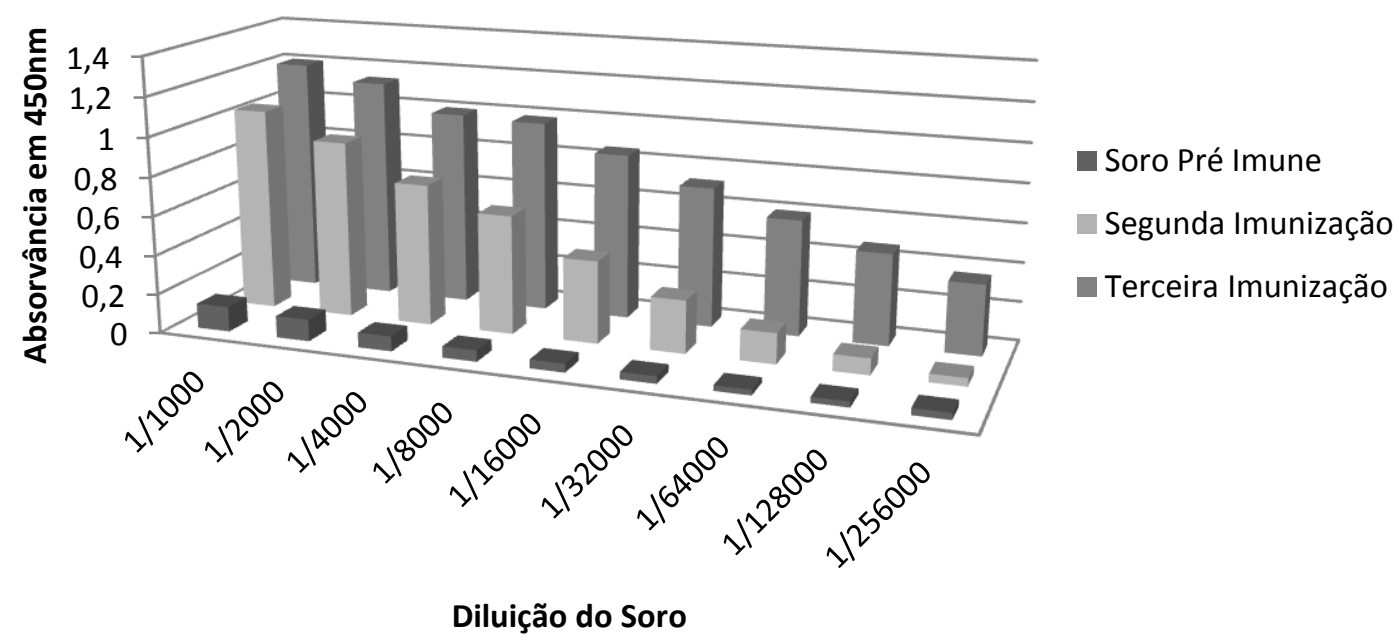

Figura 8. Representação gráfica da elevação do título de anticorpos anti-Gal-1c em coelho após hiperimunização com Gal-1c conforme protocolo descrito por HARLOW \& LANE (1988)

O animal imunizado foi submetido a punção cardíaca para obtenção de soro imune e posterior purificação de anticorpos policlonais anti-Gal-1c.

Durante esse período foi confeccionada resina para purificação dos anticorpos anti-Gal-1c presentes em soro de coelho imunizado. Para isso, utilizou-se resina Affi- Gel 15 (Bio-Rad) para imobilização de proteínas ácidas, conforme recomendação do fabricante. O rendimento obtido na imobilização foi de aproximadamente $67 \%$. 
Posteriormente, para controle de qualidade da coluna confeccionada, coletouse uma alíquota da resina contendo Gal-1c imobilizada e a mesma foi estocada. Então, realizou-se uma "pré-eluição" com glicina $0,1 \mathrm{M}, \mathrm{pH} 2,5$, de modo a simular as condições de purificação de anticorpos e assim, verificar o grau de acoplamento da proteína na resina. Foram coletadas 15 frações do pré-eluído e, posteriormente, uma alíquota da resina pós eluição.

As frações coletadas foram submetidas a SDS-PAGE (12\%). Os resultados encontram-se representados na figura 9.

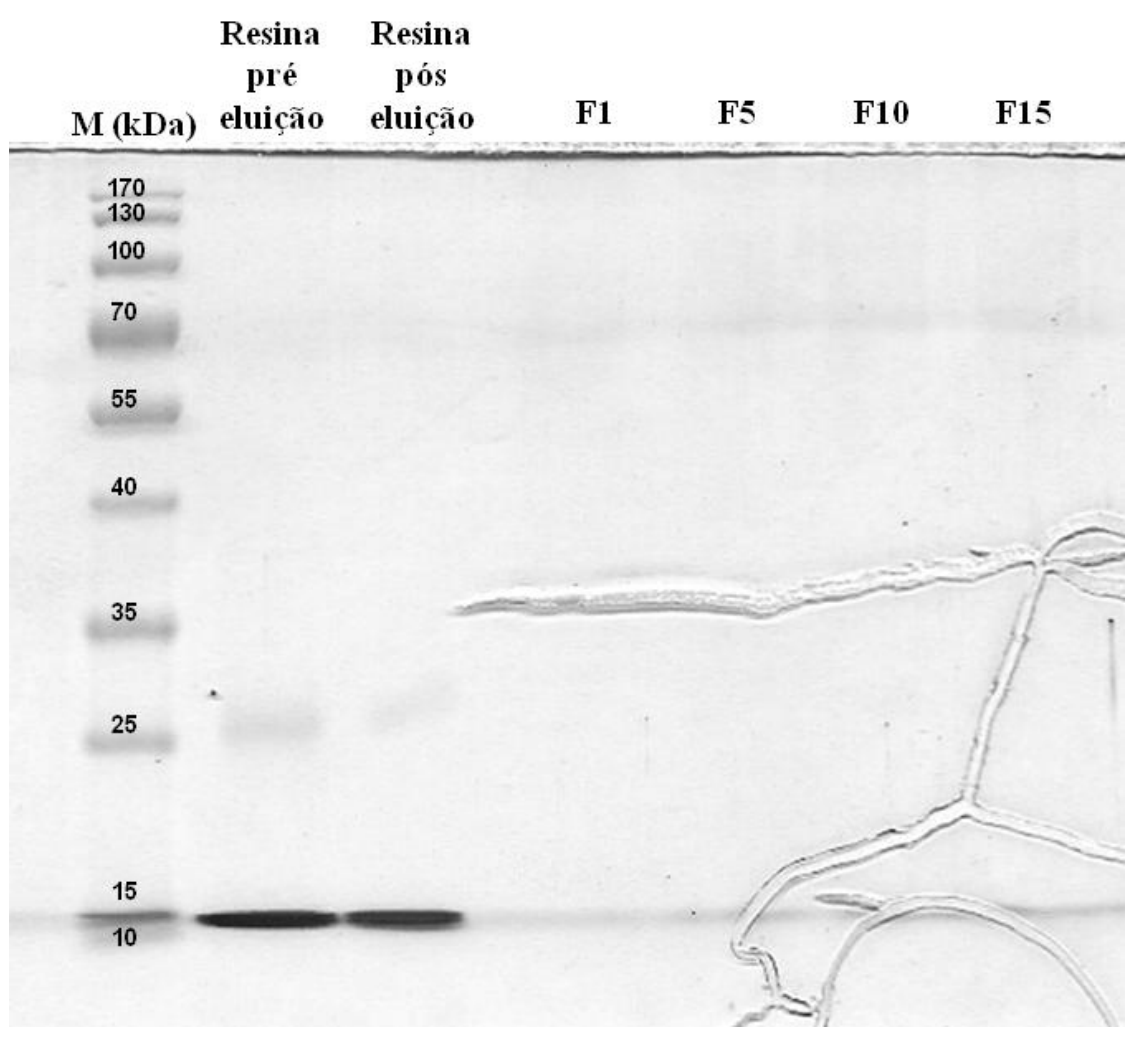

Figura 9. SDS-PAGE $12 \%$ de alíquotas da resina Affi-Gel 15 contendo Gal-1c imobilizada. Resina pré eluição: alíquota da resina não submetida ao tratamento com baixo $\mathrm{pH}$; Resina pós eluição: alíquota de resina submetida a pH 2,5; F1, F5, F10 e F15: Frações da "pré eluição" realizada para verificar o grau de acoplamento da Gal-1c à Affi-Gel 15.

Pode- se observar a presença de uma banda forte de aproximadamente $15 \mathrm{kDa}$, o que indica que a Gal-1 se manteve acoplada à resina mesmo após o tratamento ácido necessário para a purificação dos anticorpos presentes no soro de coelho imunizado. As frações obtidas na "pré-eluição" não apresentaram qualquer indício de carreamento de proteína proveniente da resina, o que valida o procedimento de imobilização para posterior purificação de anticorpos. Com base 
nesses achados, sugere-se que o procedimento de imobilização da Gal-1c foi eficiente.

Para confirmação dos resultados acima, realizou-se também um immunoblotting com as mesmas amostras de modo também a verificar a imunorreatividade dos anticorpos presentes no soro do coelho imunizado com Gal1c antes mesmo dos procedimentos de purificação.

As amostras acima mencionadas foram novamente submetidas a SDS-PAGE $12 \%$, transferidas a membrana de nitrocelulose, e submetidas a tratamento com o soro imune de coelho contendo anticorpos anti-Gal-1c. O immunoblotting foi revelado com anticorpo secundário de galinha anti-lgG de coelho conjugado com peroxidase.

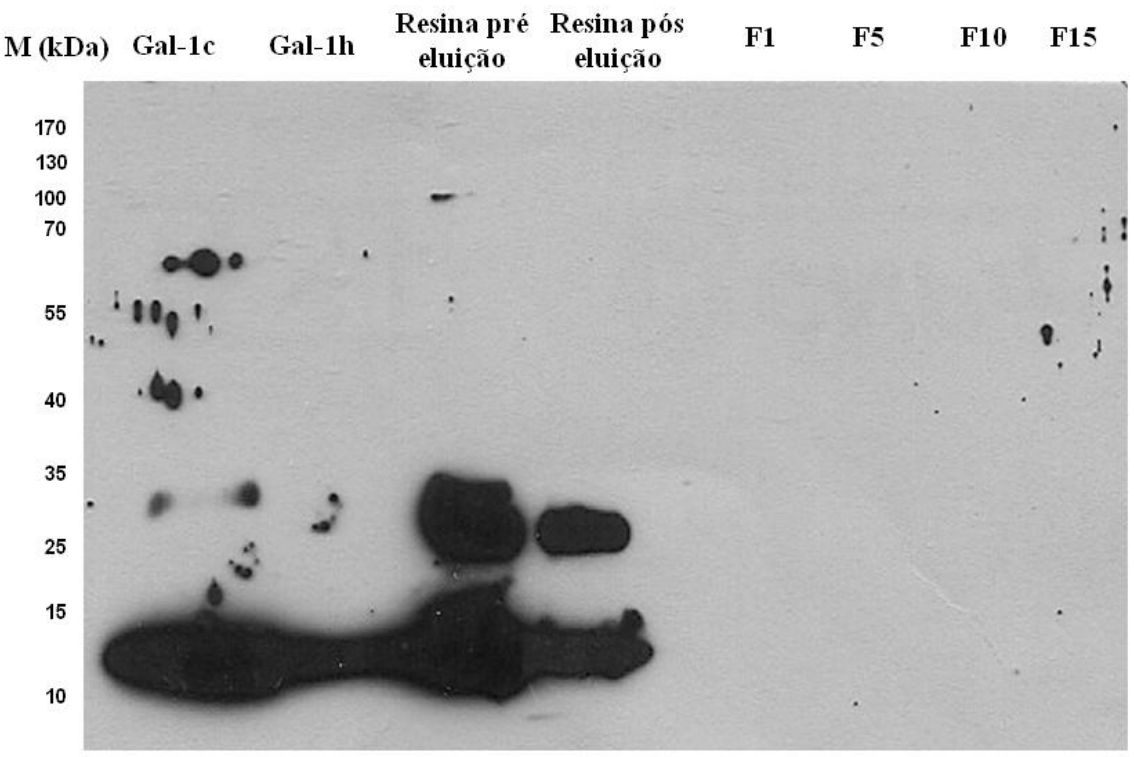

Figura 10. Immunoblotting das frações de Gal-1c, Gal-1h, Affi-Gel 15 acoplada com Gal-1c pré e póstratamento ácido, e frações provenientes da "pré-eluição" da resina (F1, F5, F10 e F15).

Pode-se confirmar o resultado obtido anteriormente por SDS-PAGE com o immunoblotting (Figura 10), já que as frações provenientes da "pré-eluição" (F1, F5, F10 e F15) não apresentaram marcação detectável para galectinas observada tanto nas pistas correspondentes à resina pré e pós tratamento ácido quanto nas pistas correspondentes a Gal-1c e Gal-1h. Pode-se observar que os anticorpos ali presentes apresentam a capacidade de reconhecer tanto a forma monomérica 
quanto a forma dimérica da Gal-1c e da Gal-1h, representadas na figura pelas bandas de peso molecular de aproximadamente 15 e 30kDa.

Os soros-imunes anti-galectinas e as colunas com Gal-1c deverão ser utilizados no futuro na investigação de possíveis diferenças epitópicas entre essas proteínas. Nessa linha, foi descrito um anticorpo monoclonal anti-Gal-1h produzidos em camundongos e que reage com um epitopo na Gal-1h não preservado na Gal-1c (DIAS-BARUFFI et al., 2010). Salienta-se que os dados de estrtutura cristalográficas de Gal-1c ora apresentados validam os achados previamente descritos por DIASBARUFFI e colaboradores (2010).

\subsection{Determinação da estrutura cristalográfica da Gal-1c}

\subsubsection{Caracterização cristalográfica}

A cristalografia é uma metodologia útil para a determinação da estrutura tridimensional de proteínas. A difração de raios-X é a única técnica que permite a visualização direta, a um nível atômico, de uma macromolécula (MCPHERSON, 2009), o que torna possíveis estudos detalhados das mesmas. Os ensaios de cristalização da Gal-1c foram realizados por meio da técnica de difusão de vapor de sitting drop (JANCARIK \& KIM, 1991). Salienta-se que, até o momento, não foi encontrada na literatura nenhuma estrutura cristal de Gal-1c.

Os cristais da Gal-1c recombinante foram obtidos na condição contendo $20 \%$ $(\mathrm{m} / \mathrm{v})$ de polietilenoglicol (PEG) 3350 e 0,2M de fluoreto de amônio (PEG/ION Screen, formulation 3; Hampton Research) (Figura 11). Os cristais surgiram depois de 2 dias da preparação do experimento, na forma de aglomerados cristalinos (clusters). Para a coleta de dados foi necessário, o isolamento de uma parte íntegra e monocristalina a partir desses clusters, a qual foi transferida para uma solução crioprotetora contendo 0,25M de fluoreto de amônio, 22\% de PEG 3350 e 25\% de glicerol, tendo sido diretamente resfriada em fluxo de nitrogênio gasoso a $100 \mathrm{~K}$ na estação de trabalho MX2. 


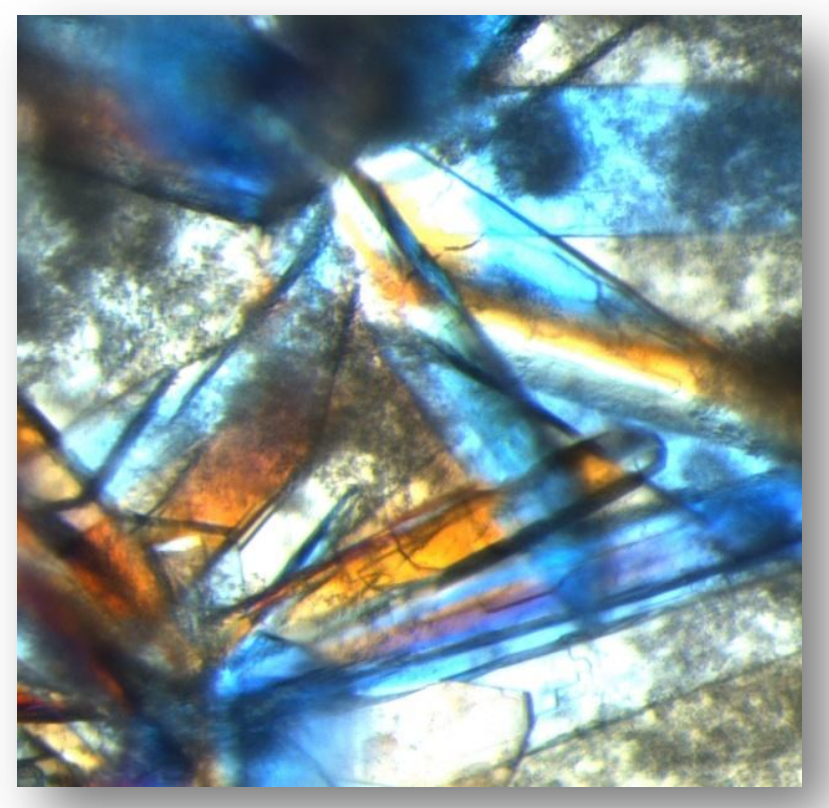

Figura 11. Cristais de Gal-1c em Fluoreto de amônio 0,2M e 20\% de PEG 3350.

Os cristais difrataram a $2.4 \AA$ de resolução (Figura 12). Os parâmetros cristalinos, assim como a análise das reflexões relacionadas por simetria indicam que o cristal de Gal-1c pertence ao grupo espacial monoclínico C2. A estatística dos dados cristalográficos está compilada na Tabela 1.

Considerando que um monômero de Gal-1c possui massa molecular calculada de aproximadamente $15 \mathrm{kDa}$, e assumindo a presença de quatro moléculas na unidade assimétrica, o coeficiente de Mathews é de $2.2 \AA^{3}$. Da ${ }^{-1}$. Baseando-se no volume especifico de $0.74 \mathrm{~cm}^{3} \mathrm{~g}^{-1}$, o conteúdo de solvente calculado é de aproximadamente $42 \%$, valor este dentro da faixa de valores observados para cristais de proteína (MATHEWS, 1968). 


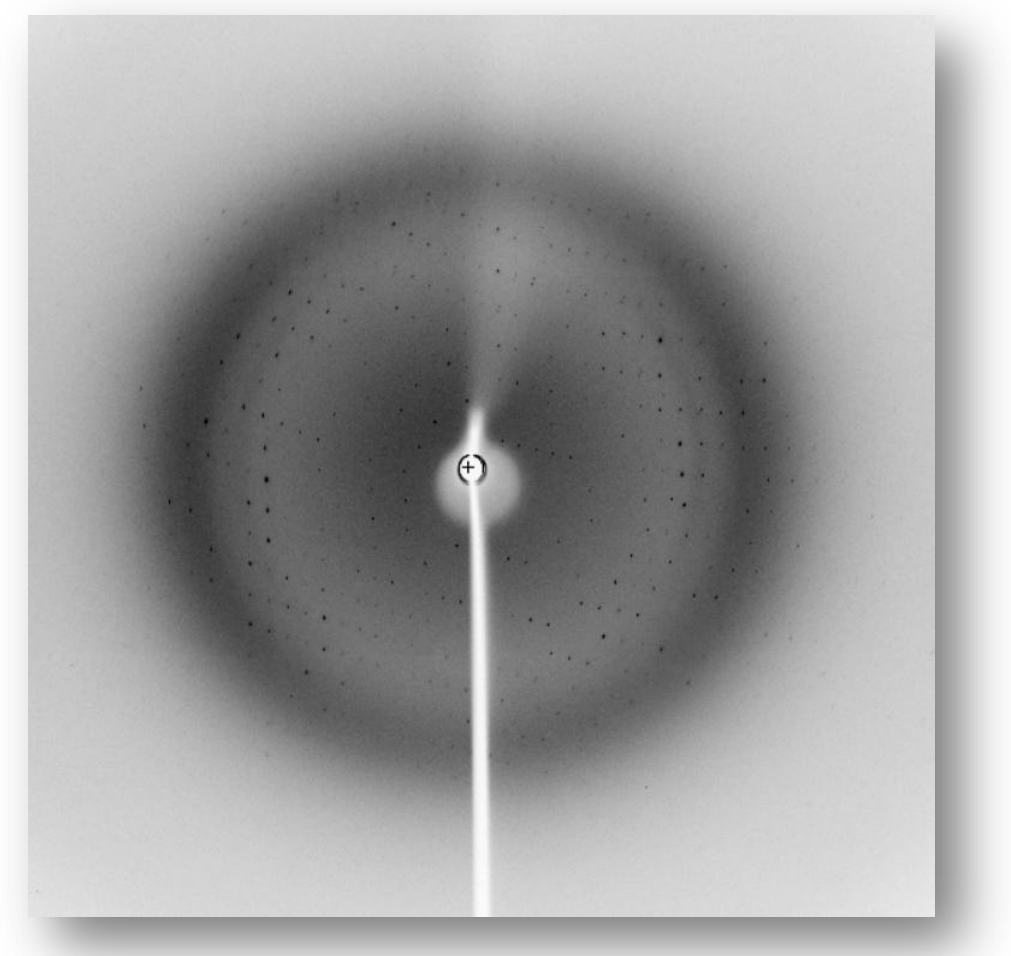

Figura 12. Padrão de difração observado para o cristal de mGal-1. Os dados foram coletados na linha MX-2 do LNLS. 
Tabela 1. Dados Cristalográficos do cristal de Gal-1c.

\begin{tabular}{|c|c|}
\hline Parâmetros Cristalinos & Cristal \\
\hline Grupo espacial & $\mathrm{C} 2$ \\
\hline Parâmetros da cela unitária $(\AA ̊)$ & $a=110.04, b=38.20, c=130.18$ \\
\hline Ângulos & $\alpha=90^{\circ}, \beta=112,71^{\circ}, \gamma=90^{\circ}$ \\
\hline Conteúdo de solvente (\%) & 42.08 \\
\hline $\operatorname{Vm}\left(\AA^{3} \mathrm{Da}^{-1}\right)$ & 2.12 \\
\hline Moléculas por unidade assimétrica (UA) & 4 \\
\hline \multicolumn{2}{|l|}{ Coleta de dados } \\
\hline Temperatura (K) & 100 \\
\hline Comprimento de onda $(\AA)$ & 1.459 \\
\hline Resolução (Å) & $35.75-2.40$ \\
\hline Reflexões únicas & 25903 \\
\hline Completeza dos dados (\%) & $100.0(100.0)$ \\
\hline$I / \sigma(I)$ & $7.6(2.5)$ \\
\hline Redundância & $3.8(3.8)$ \\
\hline Rsym $^{\mathrm{a}}(\%)$ & $11.1(44.4)$ \\
\hline \multicolumn{2}{|c|}{$\begin{array}{l}{ }^{\mathrm{a}} R_{s y m}(I)=\frac{\sum_{h k l} \sum_{i}\left|I_{i}(h k l)-\overline{I(h k l)}\right|}{\sum_{h k l} \sum_{i} I_{i}(h k l)} \text { onde } \overline{I(h k l)} \text { é a intensidade media obtida de múltiplas reflexões } \\
\text { relacionadas por simetria. }\end{array}$} \\
\hline \multicolumn{2}{|c|}{$\begin{array}{l}\text { O faseamento inicial das reflexões foi feito através da aplicação de métodos } \\
\text { bstituição molecular utilizando as coordenadas da Gal-1r como modelo. O } \\
\text { nento foi feito utilizando uma combinação de estratégias que combinaram } \\
\text { os de simetria não cristalográfica, refinamento posicional, torsional e de fatores } \\
\text { nperatura, que resultaram em } \mathrm{R}=23,66 \% \text { e } \mathrm{R}_{\text {free }}=18,19 \% \text {. As estatísticas } \\
\text { do refinamento estão compiladas na tabela } 2 \text {. As coordenadas relativas a } \\
\text { ura cristalográfica foram depositadas no banco de dados (www.pdb.org) sob o } \\
\text { de acesso: } 4 \text { LBQ. }\end{array}$} \\
\hline
\end{tabular}


Tabela 2. Dados de refinamento para o modelo cristalográfico para a estrutura da Gal-1c

Refinamento

Intervalo de resolução $(\AA)$

$35.75-2.4$

Reflexões

Conjunto Trabalho

19996

Conjunto Teste

1947

Número de átomos

4255

Macromoléculas

3983

Ligantes

24

Àgua

Resíduos de proteína

522

RMS(comprimentos de ligação)

0.005

RMS(ângulos de ligação)

0.92

Ramachandran (\%)

99

Ramachandran outliers (\%)

0

Clashscore

4.80

B-factor médio (Fator de temperatura)

44.90

Macromoléculas

45.00

Ligantes

59.30

Solvente

42.00

$R_{\text {factor }}{ }^{a}$

$23,66 \%$

$R_{\text {free }}{ }^{b}$

$18,19 \%$

${ }^{a} R_{\text {factor }}=\Sigma_{\text {hkl }}|| F_{o}|-k| F_{c} / / \Sigma_{h k l}\left|F_{o}\right|$, onde $F_{o}$ e $F_{c}$ são os fatores de estrutura medidos e calculados, respectivamente.

${ }^{b} R_{\text {free }}=\Sigma_{\text {hkl }}|| F_{o}|-k| F_{c}\left|/ \Sigma_{\text {hkl }}\right| F_{o} \mid$, calculados a partir de $5 \%$ das reflexões. 


\subsubsection{Estrutura global}

A estrutura tridimensional da Gal-1c foi determinada a $2.4 \AA$ de resolução. $O$ modelo compreende 4 moléculas na unidade assimétrica (UA) denominadas cadeias A, B C e D (Figura 13). As cadeias A, C e D compreendem os resíduos de 3 a 135 e a cadeia $B$ compreende o intervalo de resíduos de 2 a 135. A ausência de densidade eletrônica para os primeiros resíduos está diretamente relacionada com a intrínseca flexibilidade da região $\mathrm{N}$-terminal.

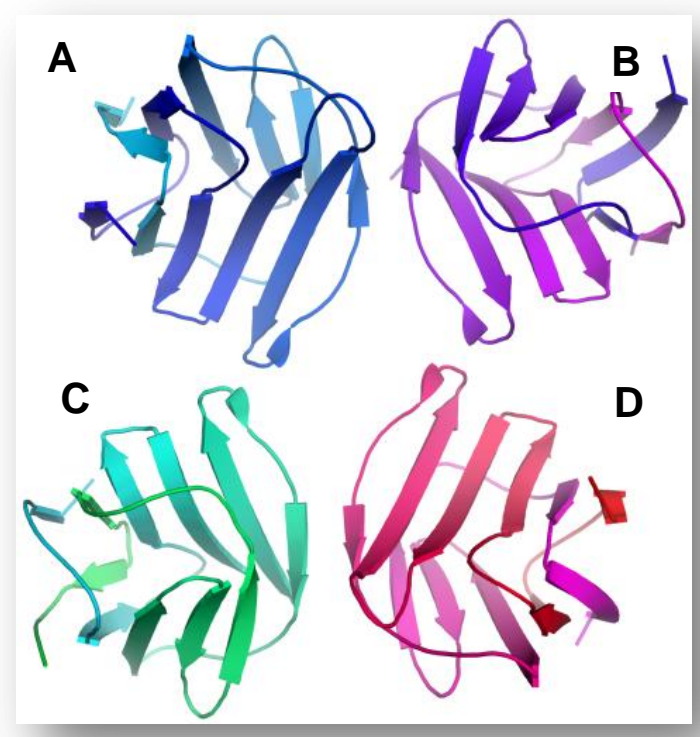

Figura 13. Tetrâmetro encontrado na unidade assimétrica do cristal de Gal-1c.

Cada cadeia apresenta topologia do tipo "jelly-roll", comumente encontrada nas estruturas de galectinas (VARKI et al., 2009) e que envolve um $\beta$-sanduíche constituído de duas folhas $\beta$ antiparalelas de 5 (F1-F5) e 6 fitas (S1-S6a/b), respectivamente (Figura 14). 


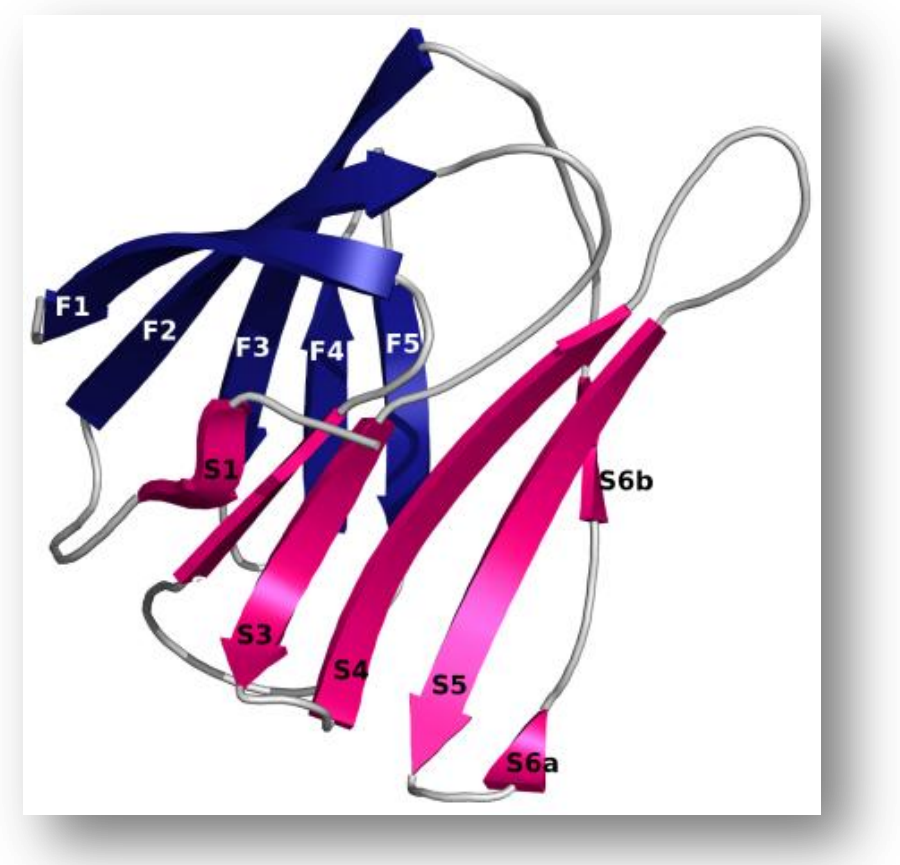

Figura 14. Modelo tridimensional da galectina-1 de camundongo.

\subsubsection{Galectina humana $x$ Galectina de camundongo}

As galectinas-1 humana e de camundongo compartilham aproximadamente $88 \%$ de identidade sequencial (Figura 15).

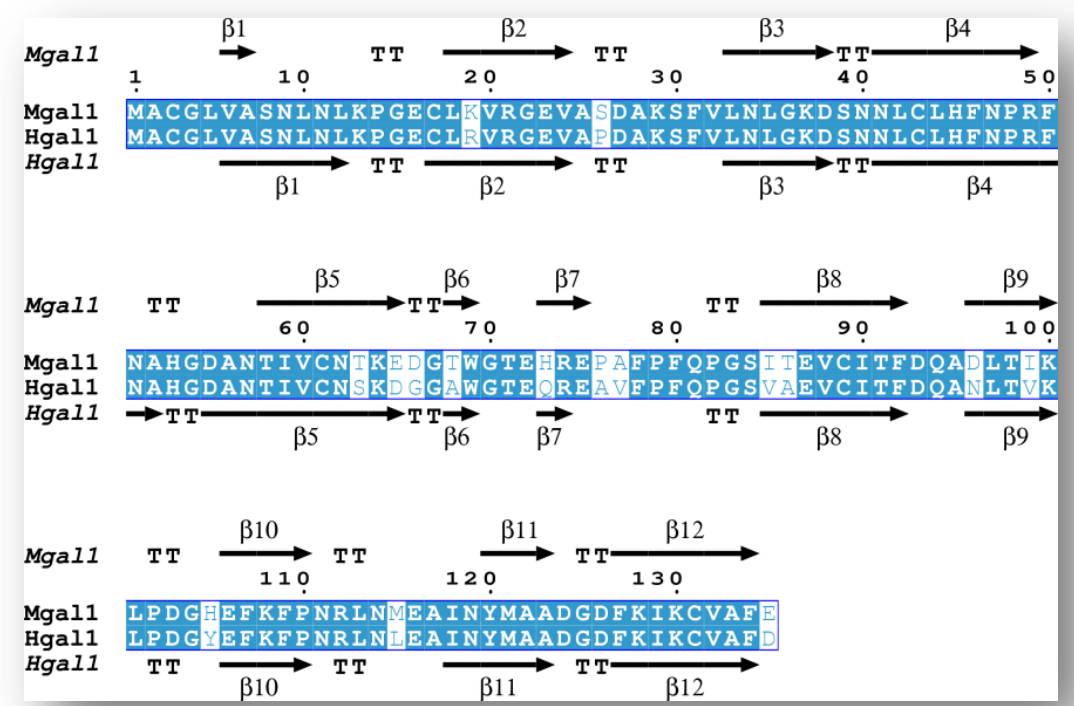

Figura 15. Alinhamento sequencial entre a galectina-1 de camundongo (Mgal-1) e a galectina-1 humana (Hgal-1). 
Uma análise cuidadosa da estrutura tridimensional da Gal-1c indica que as substituições encontradas entre as duas proteínas homólogas estão localizadas expostas ao solvente e se encontram preferencialmente nas regiões onde se localizam os CRDs (idênticos entre as galectinas), mantendo intacta a superfície de dimerização da proteína (Figura 16). 

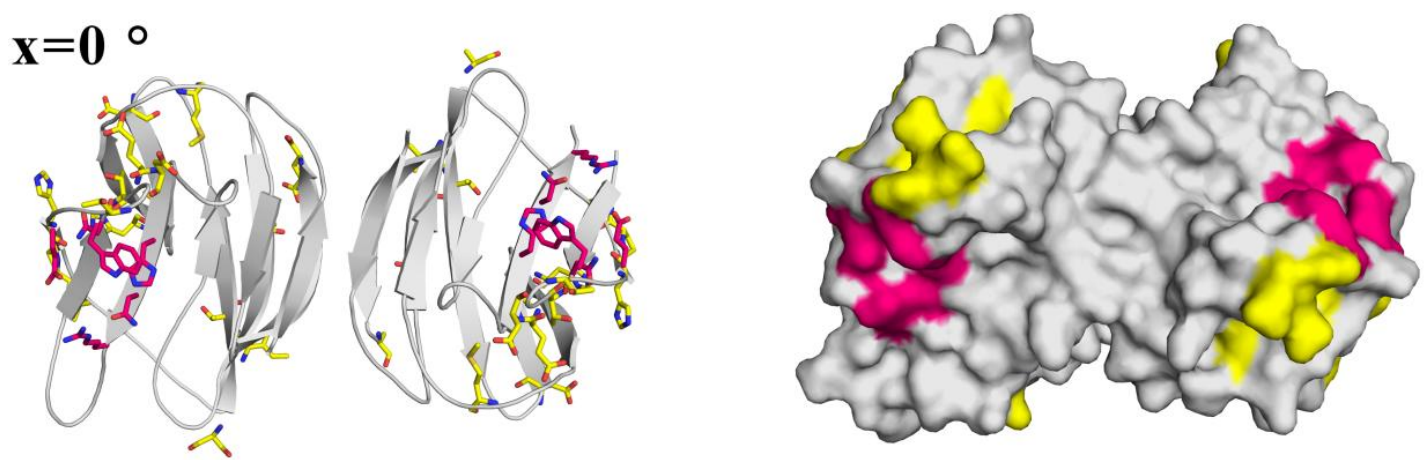

$$
\mathbf{x}=90^{\circ}
$$
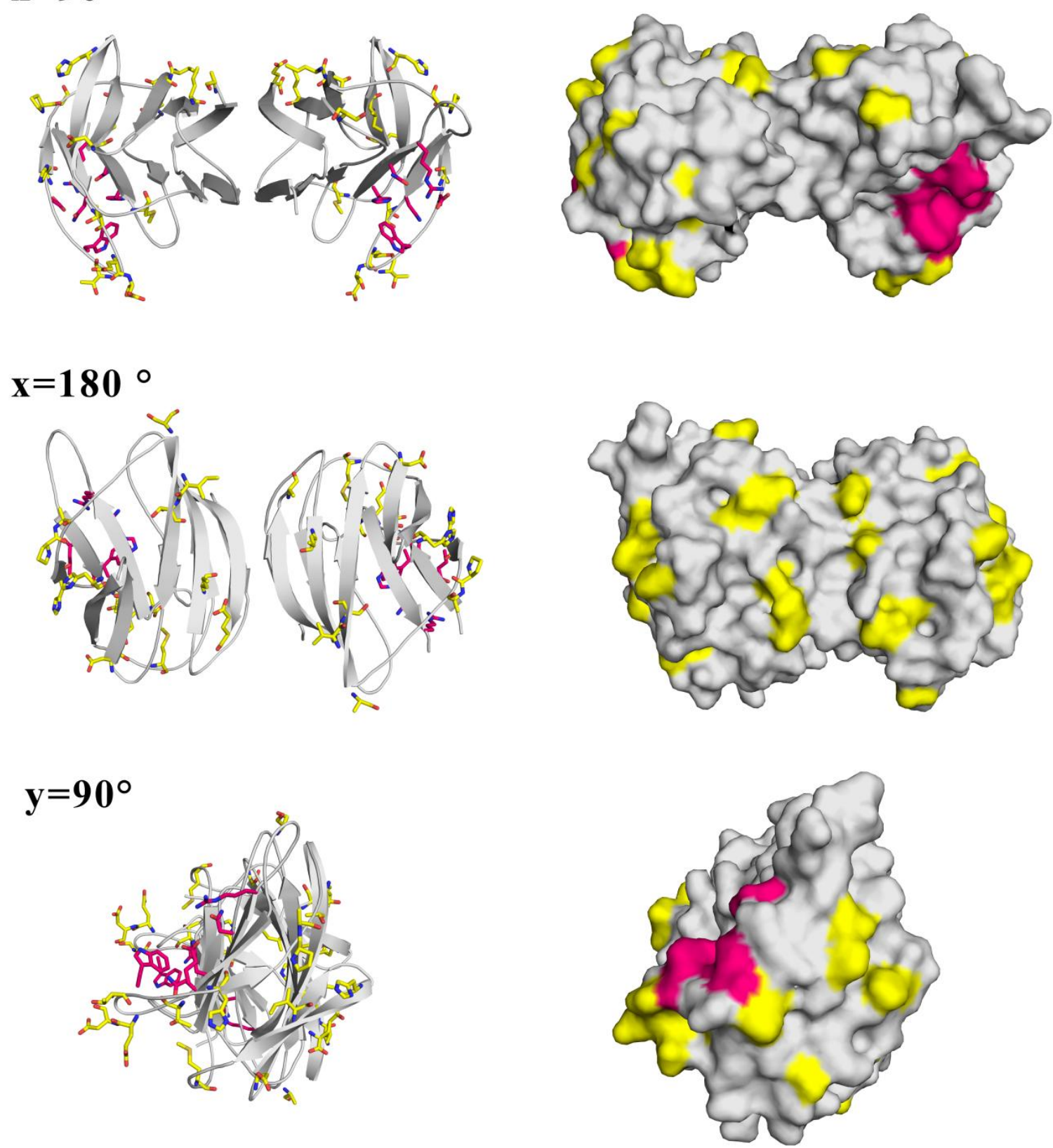

Figura 16. Representação esquemática das substituições (em amarelo) encontradas na Gal-1c em relação a Gal-1h. As substituições estão localizadas próximas à região do CRD (representada em rosa), mas distante da interface de dimerização. 
Em termos de distribuição do potencial eletrostático, as substituições observadas na Gal-1c introduzem uma mudança significativa na distribuição de carga observada na superfície da proteína. De uma forma geral, a proteína de camundongo apresenta uma maior distribuição de resíduos ionizáveis quando comparado com a proteína humana. Por exemplo, são observadas substituições do tipo Pro26Ser, Gly66Asp, Ala86Thr e Asn96Asp, Gln73His e Tyr105His que introduzem, de maneira geral, um caráter mais polar à superfície da proteína de camundongo. Além disso, as mutações associadas à sequência de aminoácidos da proteína também criam regiões "clusterizadas" de caráter mais ácido (Figura 17).
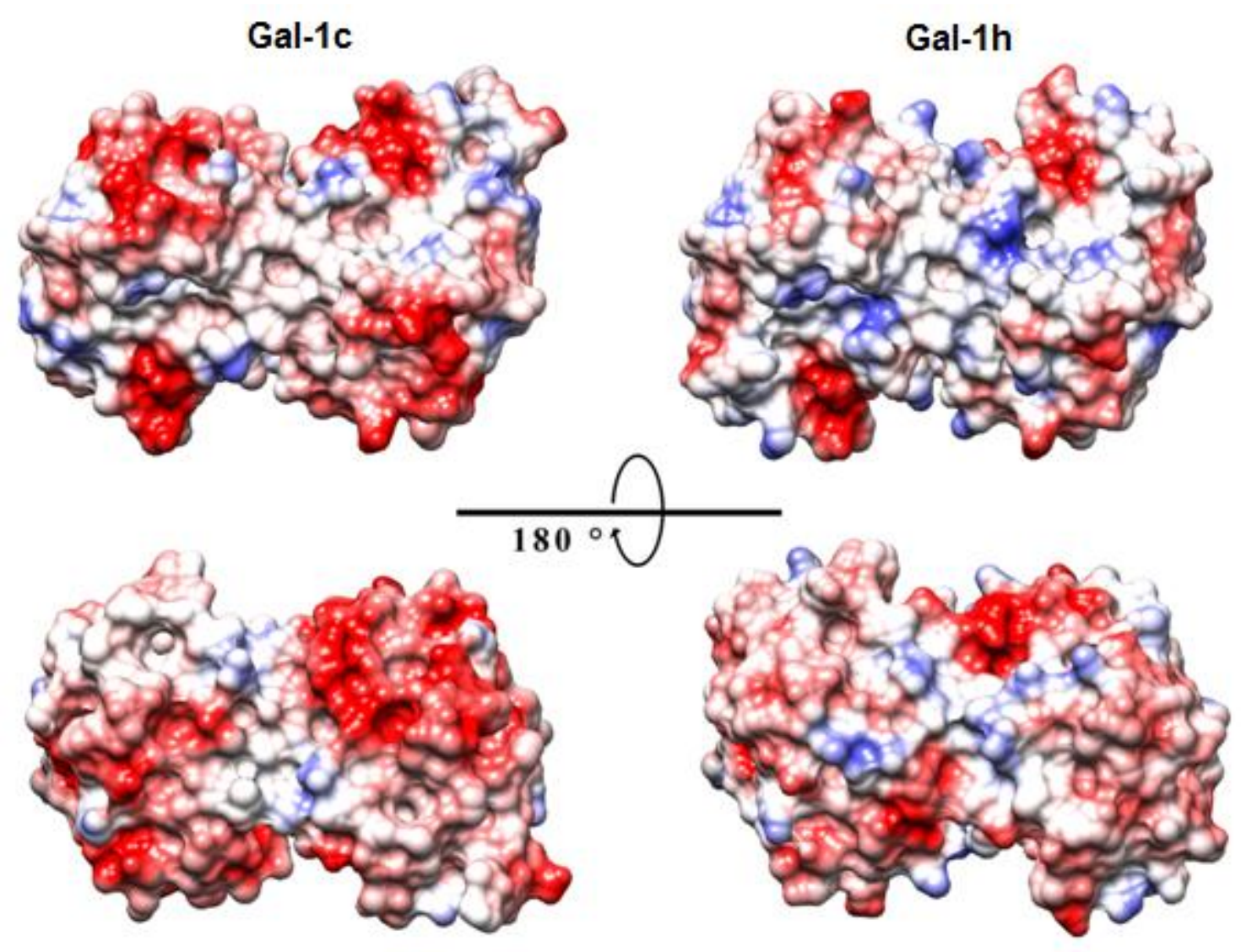

Figura 17. Distribuição do potencial eletrostático para a Gal-1c e Gal-1h (PDB 1GZW). As regiões em vermelho representam regiões negativamente carregadas.

As substituições observadas também contribuem para uma pequena mudança na distribuição de volume entre as proteínas. As diferenças estereoquímicas observadas podem refletir em diferenças biológicas como a 
atividade hemaglutinante e de especificidade entre as proteínas de camundongo e humana. Ainda nessa linha, estas alterações de resíduos de aminoácidos entre essas galectinas podem promover padrões distintos de imunogenicidade.

A superfície de todas as células vivas é decorada por um vasto repertório de glicanas, cuja riqueza estrutural permite que essas moléculas estejam intimamente envolvidas em diversos eventos celulares importantes quando associadas a proteínas denominadas ligantes de glicanas (glycan binding proteins) (SHARON e LIS, 2004; RILLAHAN e PAULSON, 2011), dentre elas, as galectinas.

O padrão de oligomerização das galectinas é crucial para a indução de suas funções celulares (VILLALOBO \& GABIUS, 1998). Além disso, sua configuração espacial do tipo "jellyroll-like" favorece a geração de diferentes formas de oligômeros (LORIS, 2002). Um importante mecanismo pelo qual as galectinas atuam sobre os processos celulares é a ligação a glicanas de superfície celular, formando complexos multivalentes denominados malhas ou lattices, que desencadeiam uma série de sinais intracelulares fundamentais para a homeostase no contexto celular, como geração de sinais de sobrevivência e renovação de receptores (BREWER, 2002; RABINOVICH et al., 2007; GARNER e BAUM, 2008, RABINOVICH et al., 2009).

Baseado em análise por filtração em gel, espalhamento de nêutrons de baixo ângulo e espectrometria de massas, a Gal-1h existe como um homodímero em solução (LOPEZ-LUCENDO et al., 2004). O dímero funcional, descrito para as galectinas-1 baseado nas estruturas das galectinas humana e de rato, pode também ser encontrado para a Gal-1c através da aplicação do eixo de ordem 2 cristalográfico. Os dímeros são formados pelos pares cadeia A-cadeia $D^{\prime}$ (onde D'equivale à cadeia $D$ da unidade assimétrica vizinha) e cadeia B-cadeia $C^{\prime}$ (onde $C^{\prime}$ equivale à cadeia $\mathrm{C}$ da unidade assimétrica vizinha).

Estes resultados sugerem fortemente que o tetrâmero encontrado na unidade assimétrica é apenas consequência do empacotamento cristalino e nenhuma relação com função pode ser associada neste momento a essa forma oligomérica. Entretanto, a partir dos resultados observados para a Gal-1c, pode-se perceber que seu modelo de empacotamento cristalino difere do previamente obtido para Gal-1h (SCOTT et al., 2007), uma vez que o cristal obtido pertence ao grupo cristalino 
monoclínico C2, contendo 4 moléculas na cela unitária, o que mais a aproxima da Gal-1 de rato (Gal-1r) que também apresenta um tetrâmero como unidade assimétrica (SALOMONSSON et al., 2010).

Curiosamente, o contato da Gal-1h com um microambiente hidrofóbico pode causar alteração da estrutura quartenária desta molécula e conduzir a formação de tetrâmeros com uma forma cilíndrica (HE et al., 2003). Assim, maiores investimentos serão necessários para se determinar qual o padrão de oligomerização da Gal-1c e seu impacto biológico.

\subsection{Ensaios de Hemaglutinação}

Eritrócitos apresentam um vasto repertório molecular de superfície (DE OLIVEIRA e SALDANHA, 2010), como glicoproteínas pertencentes aos grupos sanguíneos, as quais representam determinantes antigênicos de grande importância clínica (YAWATA, 2003). As lectinas foram inicialmente denominadas aglutininas devido à sua capacidade de aglutinar eritrócitos (SHARON e LIS, 1972) por reconhecerem os carboidratos presentes na superfície dos mesmos. O próprio termo lectina foi empregado devido a essa capacidade de selecionar (do latim: legere), dentre o repertório molecular na superfície de uma célula, moléculas contendo glicanas em sua composição estrutural (BOYD, 1970).

Os ensaios de hemaglutinação foram inicialmente realizados como descrito no item 4.5 da seção "Materias e Métodos". Para os experimentos, utilizaram-se hemácias provenientes de humanos, carneiro, coelho e camundongo. Cuidou-se para que a Gal-1c e a Gal-1h utilizadas no experimento apresentassem datas de produção próximas e fossem mantidas em tampão contendo lactose e 2-ME até o momento do uso, para descartar possível perda de atividade lectínica devido a oxidação (STOWELL et al., 2009; VARKI et al., 2009). A eletroforese das frações utilizadas nos ensaios mostra que elas apresentaram elevado grau de homogeneidade mesmo após a retirada da lactose e do 2-ME (Figura 18). Utilizouse uma concentração inicial de $10 \mu \mathrm{M}(150 \mu \mathrm{g} / \mathrm{mL})$ de ambas as galectinas tendo sido realizada uma diluição seriada de base 2 até concentração de 0,3125 $\mu \mathrm{M}(4,687$ $\mu \mathrm{g} / \mathrm{mL})$. Foram testadas, nas mesmas condições, a capacidade de inibição da 
reação por solução de lactose $10 \mathrm{mM}$, utilizando solução de sacarose $10 \mathrm{mM}$ como açúcar controle. Os resultados encontram-se ilustrados na figura 19.

kDa

170

100

70

55

40

35

25

15

Gal-1c Gal-1h

10

Figura 18. SDS-PAGE $12 \%$ das preparações de Gal-1c e Gal-1h utilizadas nos ensaios de hemaglutinação. 
a)
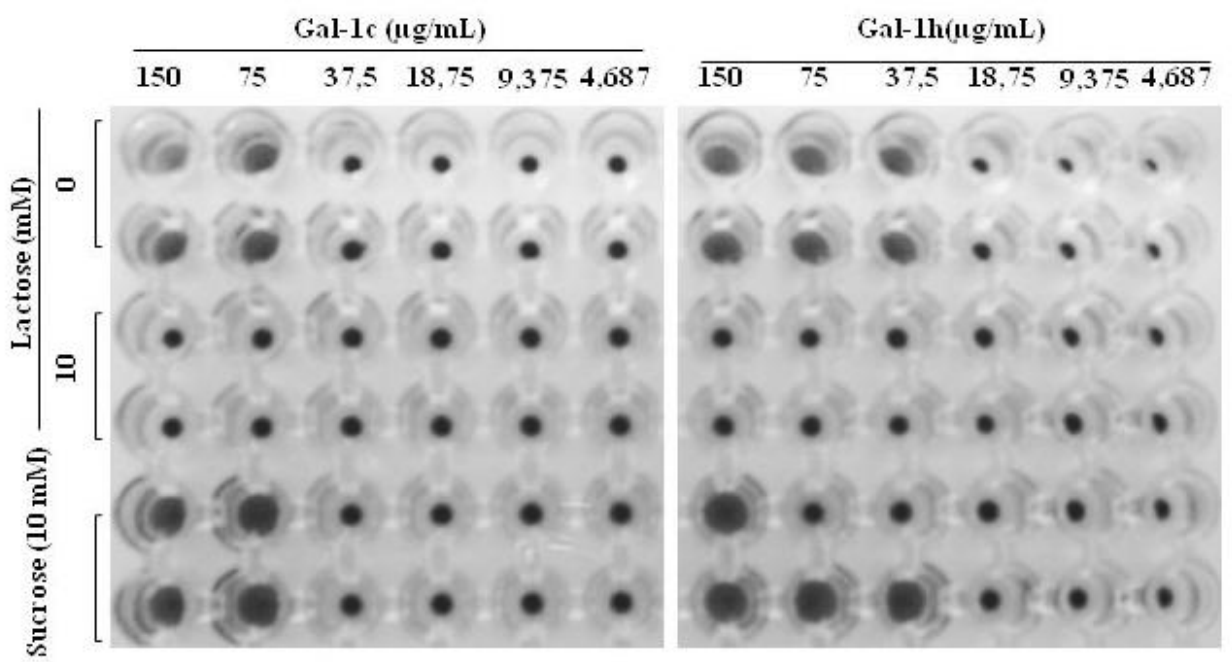

b)
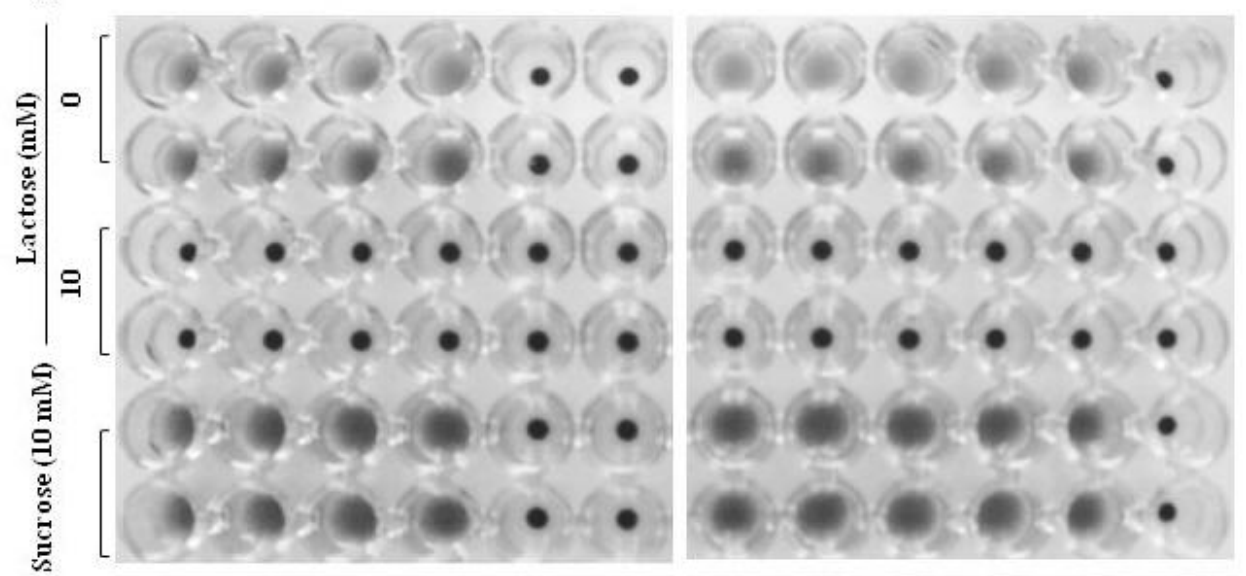

c)
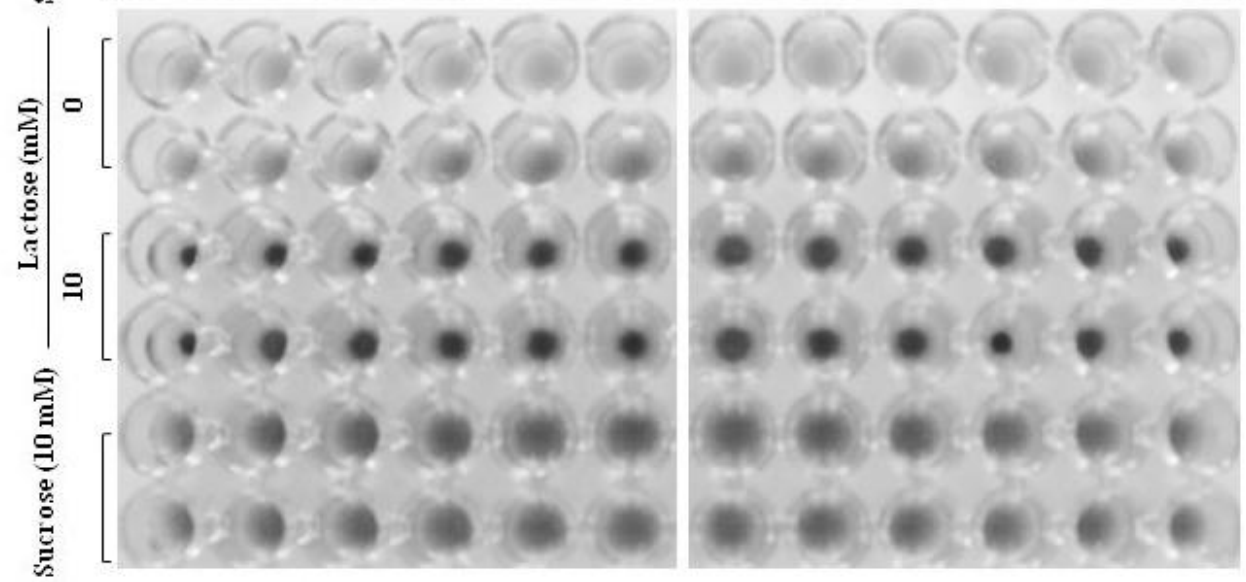

Figura 19. Ensaio de aglutinação com o uso de Gal-1h e Gal-1c e de hemácias: a) humanas; b) de carneiro; c) de coelho.

A atividade hemaglutinante da Gal-1h foi maior que a da Gal-1c para as hemácias humanas, sendo observada até concentração de $37,5 \mu \mathrm{g} / \mathrm{mL}$ de Gal-1h, contra $75 \mu \mathrm{g} / \mathrm{mL}$ de Gal-1c (Figura 19a). A observação de que a Gal-1c e a Gal-1h aglutinam eritrócitos humanos com intensidade distinta motivou-nos a investigar se 
essa atividade se mantinha em eritrócitos de diferentes espécies. Como ilustrado na figura 19b, a concentração aglutinante mínima de Gal-1h para hemácias de carneiro foi de $9,375 \mu \mathrm{g} / \mathrm{mL}$, contra $18,75 \mu \mathrm{g} / \mathrm{mL}$ de Gal-1c. Houve inibição da reação de hemaglutinação por solução de lactose $10 \mathrm{mM}$ e não houve inibição por solução de sacarose $10 \mathrm{mM}$.

Entretanto, todas as concentrações testadas (4,687 a $150 \mu \mathrm{g} / \mathrm{mL})$ de ambas as galectinas foram eficientes em promover a aglutinação de hemácias de coelho. Assim, não se pode obter uma concentração mínima destas lectinas para a aglutinação de dessas hemácias (Figura 19c).

De modo a investigar se a maior atividade hemaglutinante de Gal-1h em relação a Gal-1c se deve à sua maior estabilidade frente a oxidação, e a fim de determinar a concentração aglutinante mínima para hemácias de coelho, utilizou-se a metodologia descrita por MIURA et al. (2004), adicionando $4 \mathrm{mM}$ de 2-ME as preparações de galectinas. Testaram-se novamente as hemácias de coelho, humanas, de camundongo e de carneiro nas concentrações descritas pelo autor. Entretanto, novamente não se obteve um título para as hemácias de coelho. Então, optou-se pela redução da concentração de Gal-1 na reação, utilizando as concentrações de $60,30,15,7,5,3,75,1,87,0,94,0,46,0,23,0,12,0,06 \mu \mathrm{g} / \mathrm{mL}$. Os resultados encontram-se ilustrados nas figuras 20, 21, 22 e 23.

\section{Hemácias de Coelho}
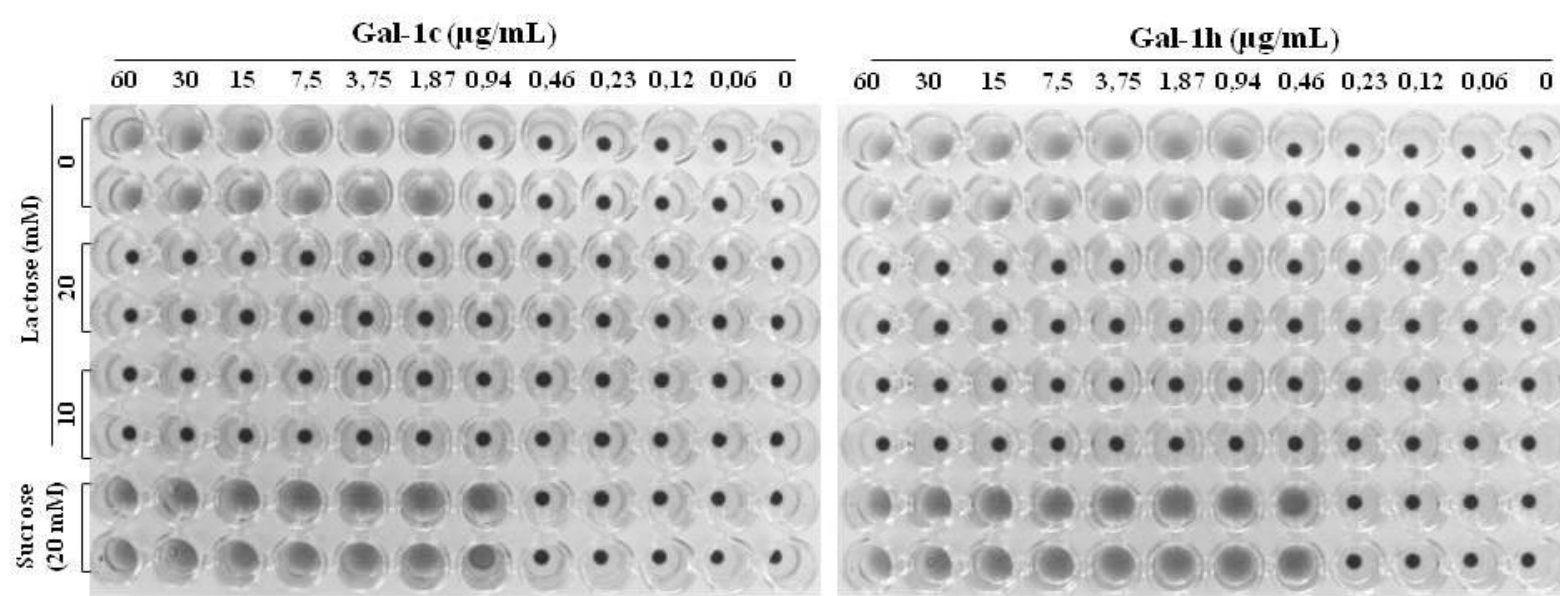

Figura 20. Ensaio de aglutinação de hemácias de coelho. 


\section{Hemácias Humanas}
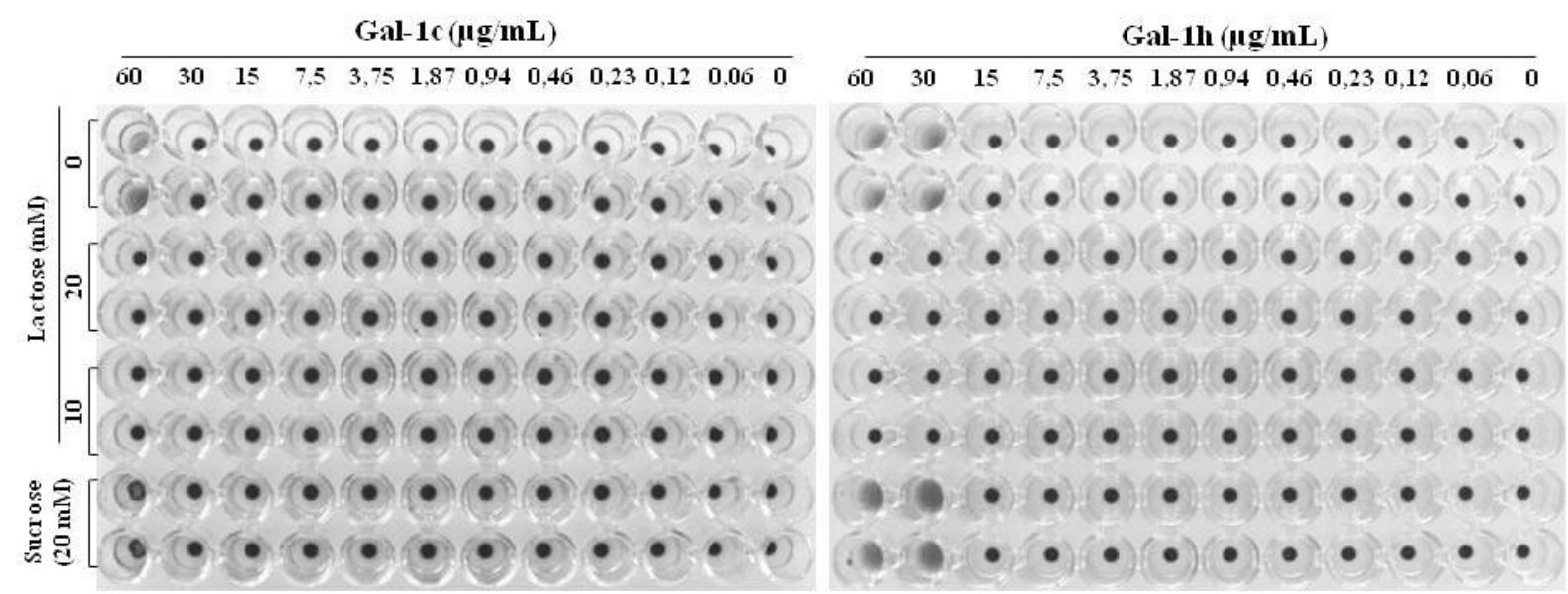

Figura 21. Ensaio de aglutinação de hemácias humanas.

\section{Hemácias de Camundongo}

Gal-1c $(\mu \mathrm{g} / \mathbf{m L})$
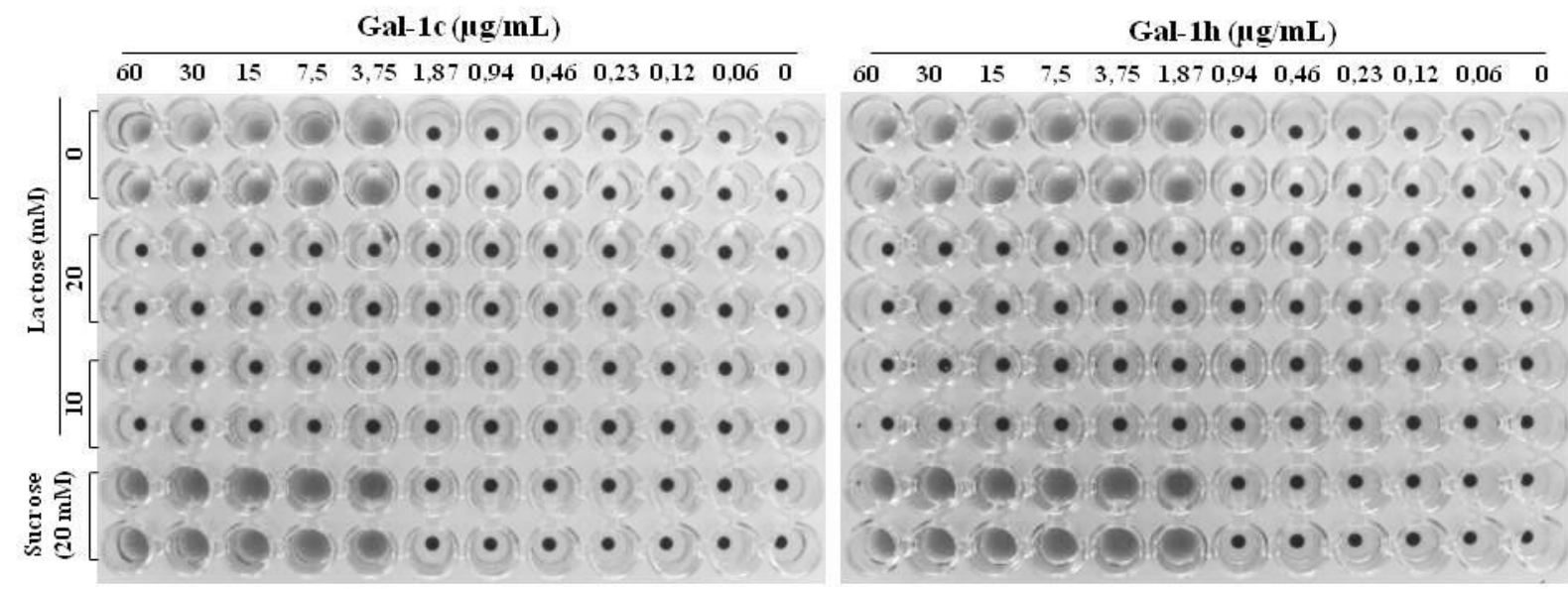

Figura 22. Ensaio de aglutinação de hemácias de camundongo.

\section{Hemácias de Carneiro}
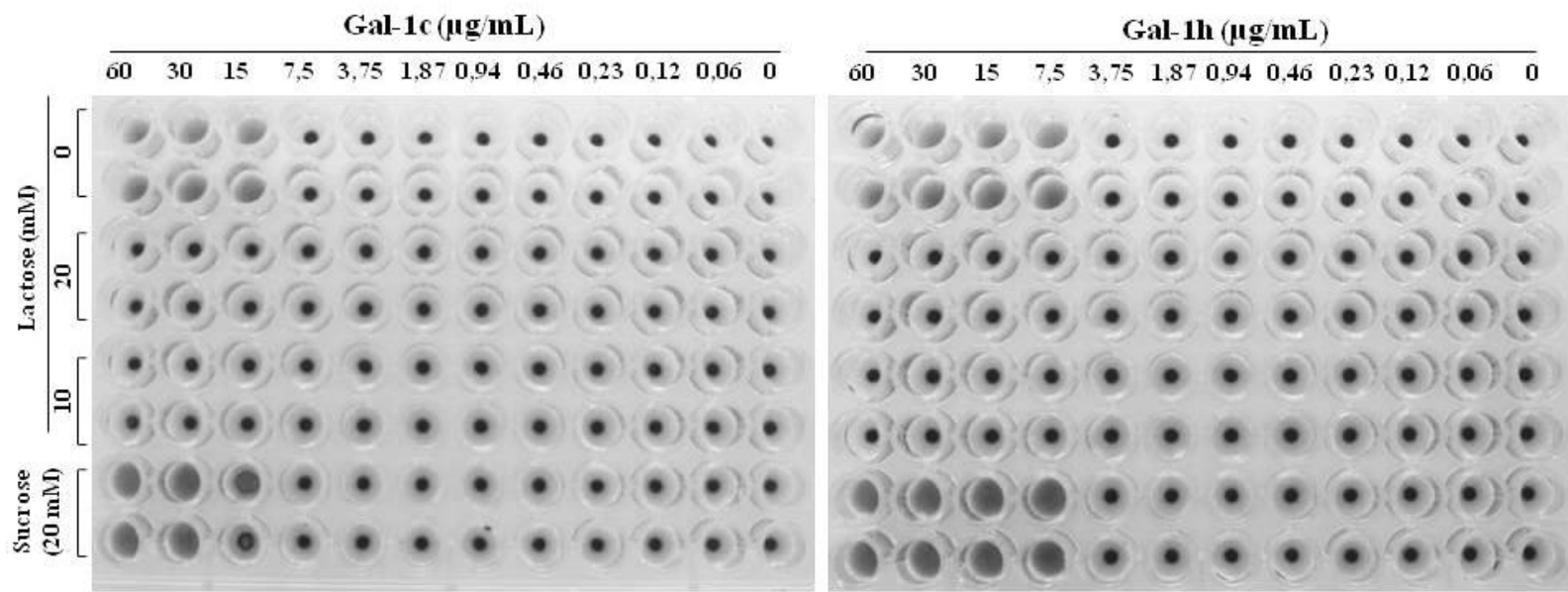

Figura 23. Ensaio de aglutinação de hemácias de carneiro. 
Obteve-se aglutinação de hemácias de coelho até concentração de 0,94 $\mu \mathrm{g} / \mathrm{mL}$ de Gal-1h contra $1,87 \mu \mathrm{g} / \mathrm{mL}$ de Gal-1c (Figura 20); de $30 \mu \mathrm{g} / \mathrm{mL}$ de Gal-1h contra $60 \mu \mathrm{g} / \mathrm{mL}$ de Gal-1c para hemácias humanas (Figura 21); de 1,87 $\mu \mathrm{g} / \mathrm{mL}$ de Gal-1h contra 3,75 $\mu \mathrm{g} / \mathrm{mL}$ de Gal-1c para hemácias de camundongo (Figura 22); e de $7,5 \mu \mathrm{g} / \mathrm{mL}$ de Gal-1h contra $15 \mu \mathrm{g} / \mathrm{mL}$ de Gal-1c para hemácias de carneiro (Figura 23). Houve inibição da reação por solução de lactose 20 e 10 mM, não havendo inibição por solução de sacarose $20 \mathrm{mM}$.

Pode-se observar que as diferenças entre a atividade hemaglutinante de Gal1c e Gal-1h não se devem ao estado de oxidação das mesmas, já que foi obtida a mesma diferença na presença e na ausência de agente redutor (2-ME). Apesar de não ter sido observada a inversão dessa relação quando se comparou a aglutinação de hemácias humanas e de camundongo por Gal-1c e Gal-1h, pode-se inferir que a diferença de glicosilação na superfície das hemácias de espécies distintas, fornece um repertório de glicanas reconhecido de maneira diferenciada pelas duas lectinas, devido provavelmente às peculiaridades de oligomerização, especificidade a carboidratos e perfil eletrostático das mesmas (SHARON \& LIS, 2004; LOKER et al., 2008; VARKI et al., 2009).

A diferença de intensidade de aglutinação pode ser qualitativamente avaliada por microscopia óptica (MO) após ensaio de microaglutinação em placas de Terasaki (Figura 24). Ambas as Gal-1 encontravam-se em uma concentração de $10 \mu \mathrm{M}$, tendo sido realizada diluição de base 2 até concentração de 0,6 $\mu \mathrm{M}$. Utilizou-se suspensão de hemácias humanas, do tipo $\mathrm{O}^{+}$, a $0,5 \%$ em tampão fosfato contendo BSA $1 \%$. Pode-se observar que a atividade hemaglutinante da Gal-1h manteve-se superior à da Gal-1c, e que a intensidade da aglutinação promovida pela Gal-1h também foi superior. 
Gal-1c
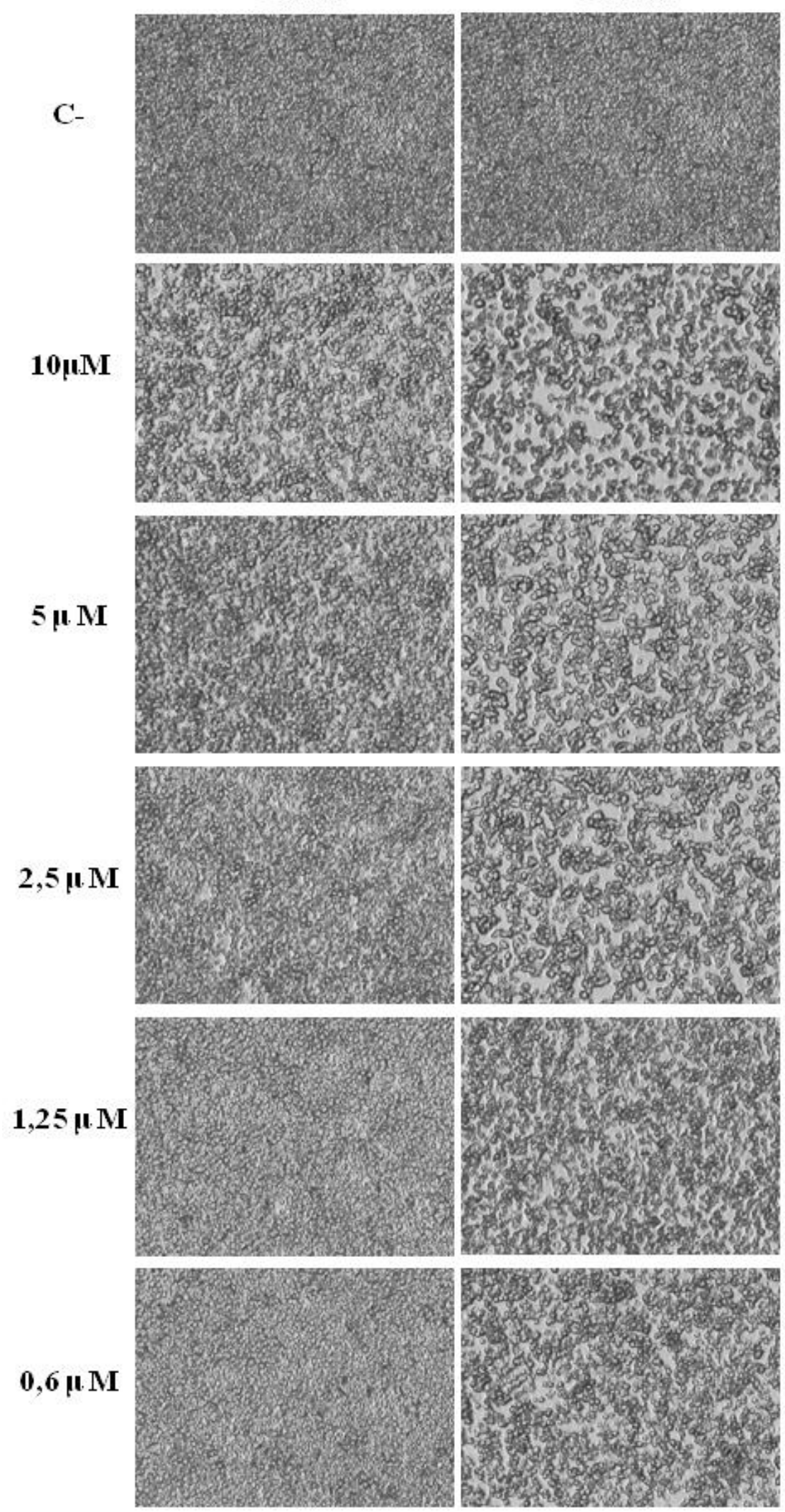

Figura 24. Análise da intensidade da aglutinação de hemácias humanas após incubação com Gal-1c e Gal-1h. C-: Controle negativo. 


\subsection{Análise da capacidade de reconhecimento de glicoconjugados}

$\mathrm{Na}$ literatura, alguns protocolos relacionados ao uso de arranjos de glicanas em fase sólida para a análise de ligantes de lectinas preconizam o uso de elevadas concentrações destas proteínas (CARLSSON et al., 2007). Com o objetivo de otimizar a acurácia deste ensaio, neste trabalho, foram utilizdas as seguintes concentrações de 0,$1 ; 0,5 ; 1,0 ; 5,0$ e $10 \mu \mathrm{M}$ de Gal-1c e Gal-1h em um arranjo de 611 glicanas de mamíferos imobilizadas em suporte sólido (Functinal Glycomics Gateway). Os resultados obtidos para a intensidade de ligação a cada glicana foram expressos como Unidades relativas de fluorescência (URF) e estão representados nas figuras 25 e 26. 

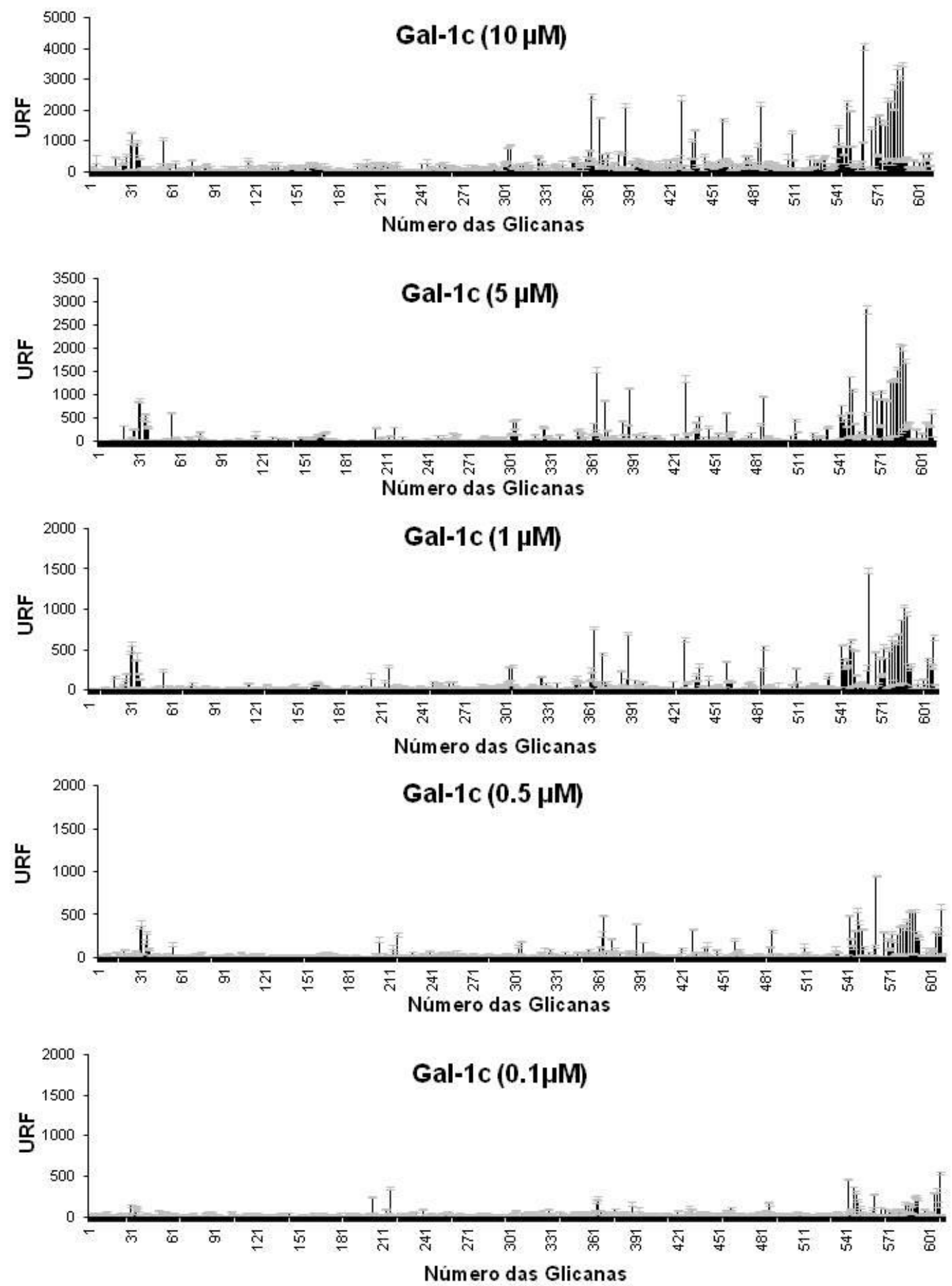

Figura 25. Intensidade de ligação de Gal-1c às glicanas imobilizadas em fase sólida (Mammalian Printed Array version 5.0). 

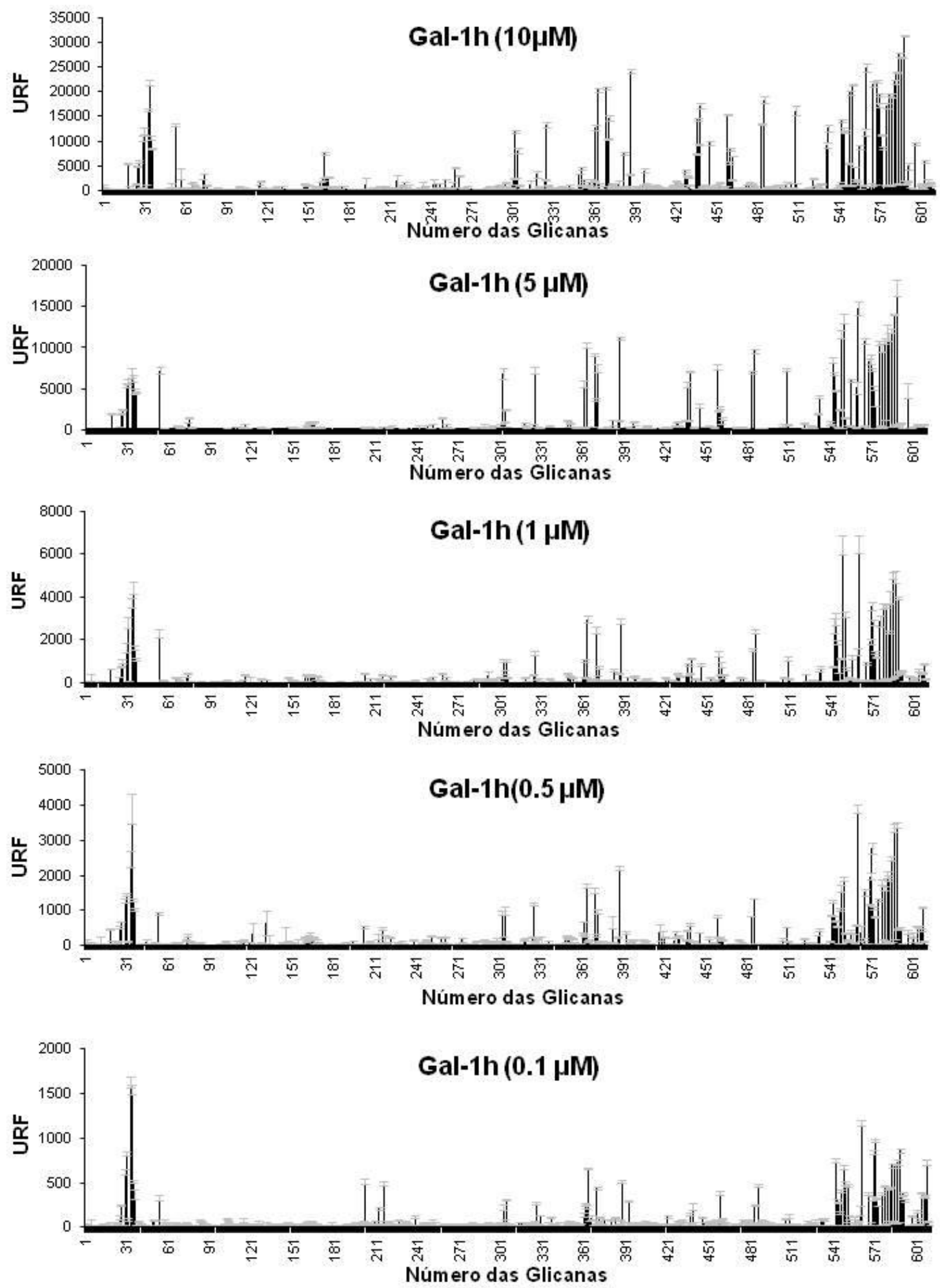

Figura 26. Intensidade de ligação de Gal-1h às glicanas imobilizadas em fase sólida (Mammalian Printed Array version 5.0). 
As glicanas foram ranqueadas de acordo com a intensidade de ligação de cada Gal-1, segundo descrito por HEIMBURG-MOLINARO e colaboradores (2011), tendo sido selecionados para análise os picos de maior intensidade em cada uma das concentrações testadas (Figuras 27 e 28). 
Gal-1c 0,1 $\mu \mathrm{M}$

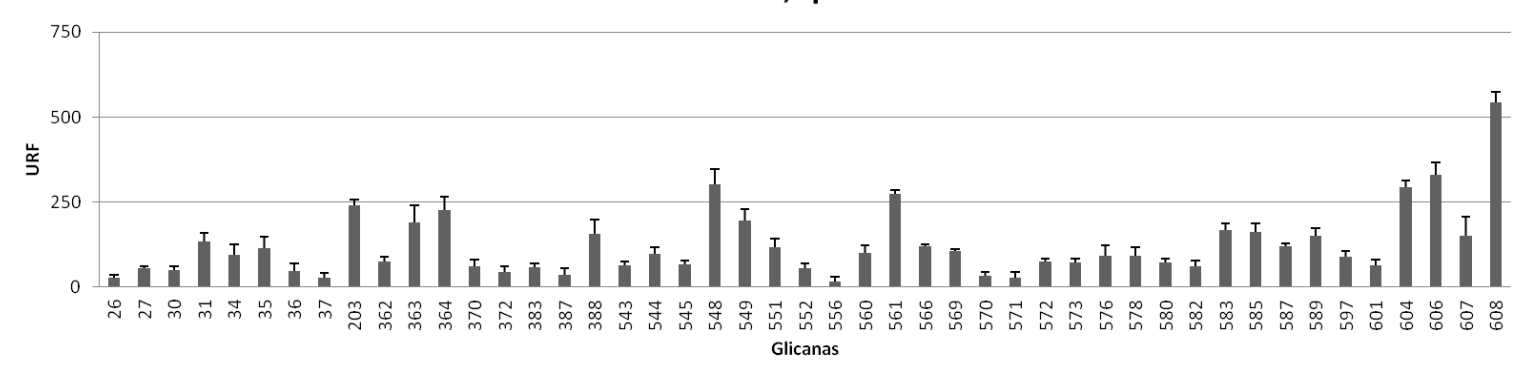

Gal-1c 0,5 $\mu \mathrm{M}$

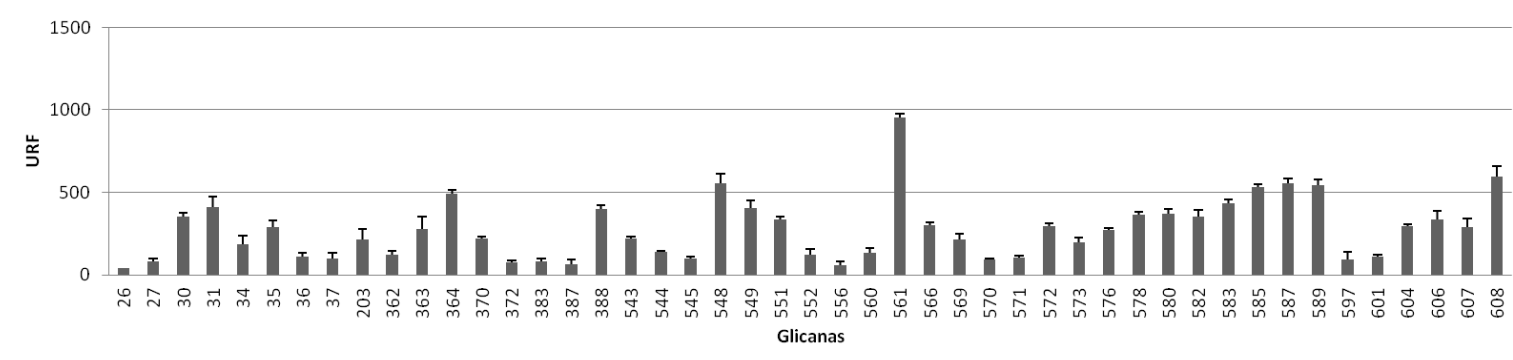

Gal-1c 1 $\mu \mathrm{M}$

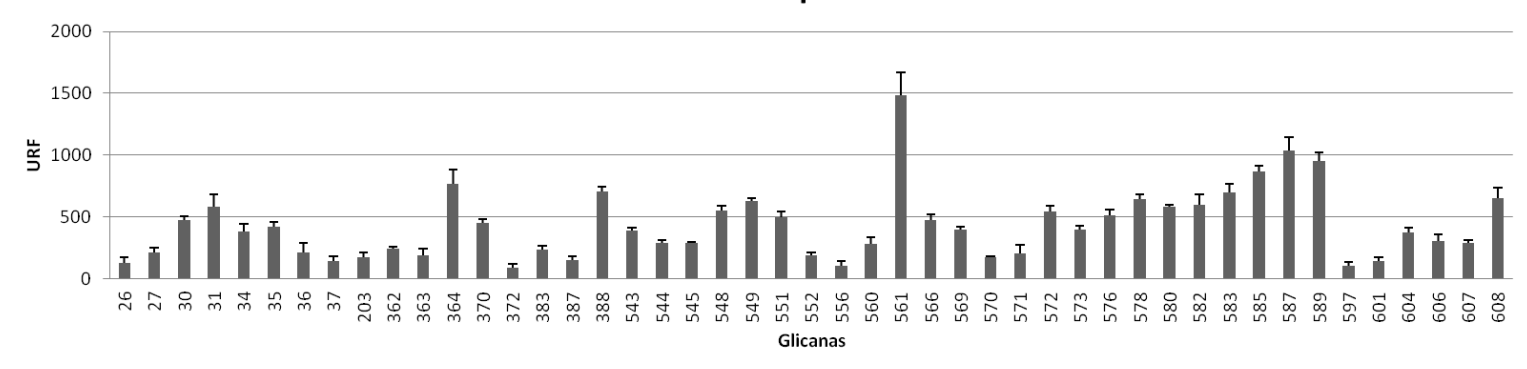

Gal-1c $5 \mu \mathrm{M}$

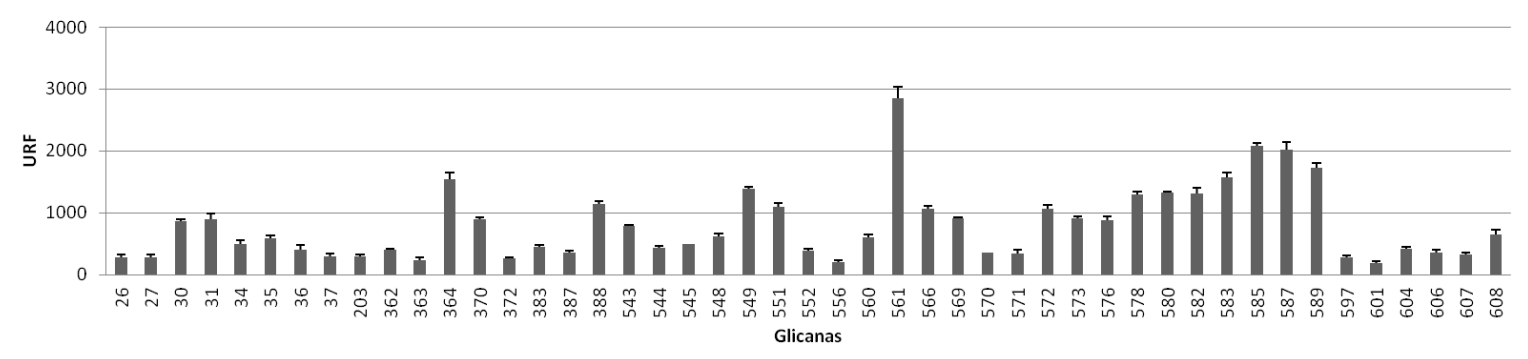

Gal-1c 10 $\mu \mathrm{M}$

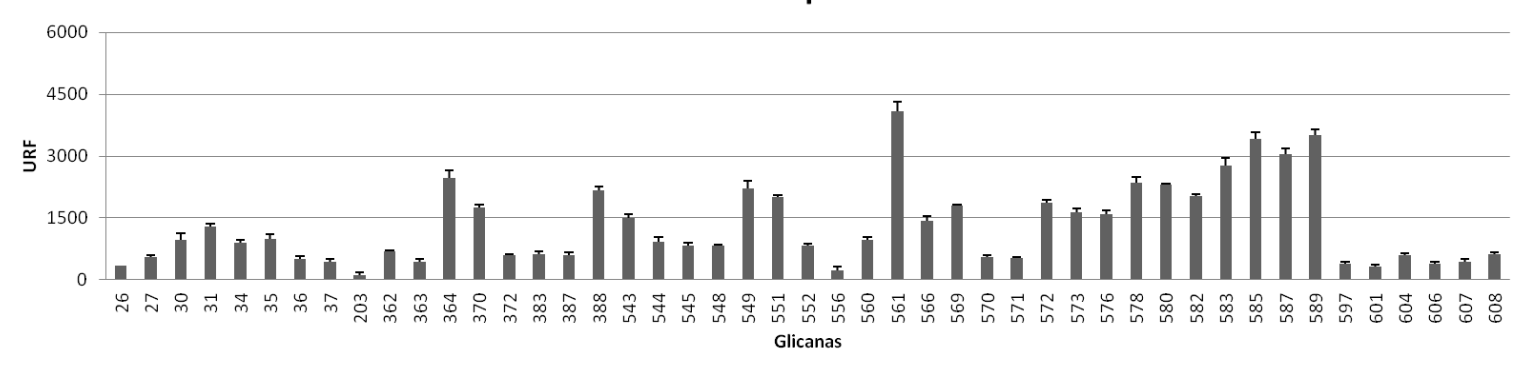

Figura 27. Glicanas correspondentes aos picos de maior intensidade de fluorescência em todas as concentrações testadas de Gal-1c. 
Gal-1h 0,1 $\mu \mathrm{M}$

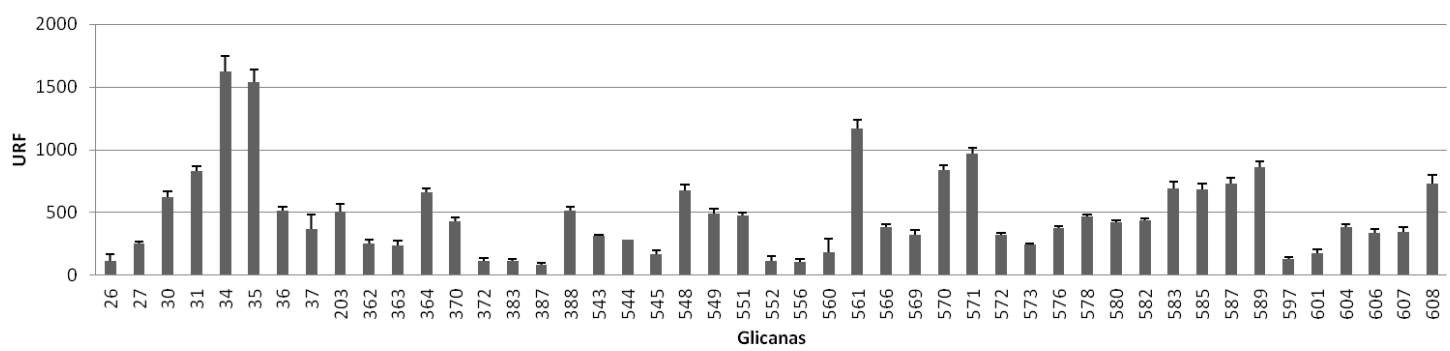

Gal-1h $0,5 \mu \mathrm{M}$

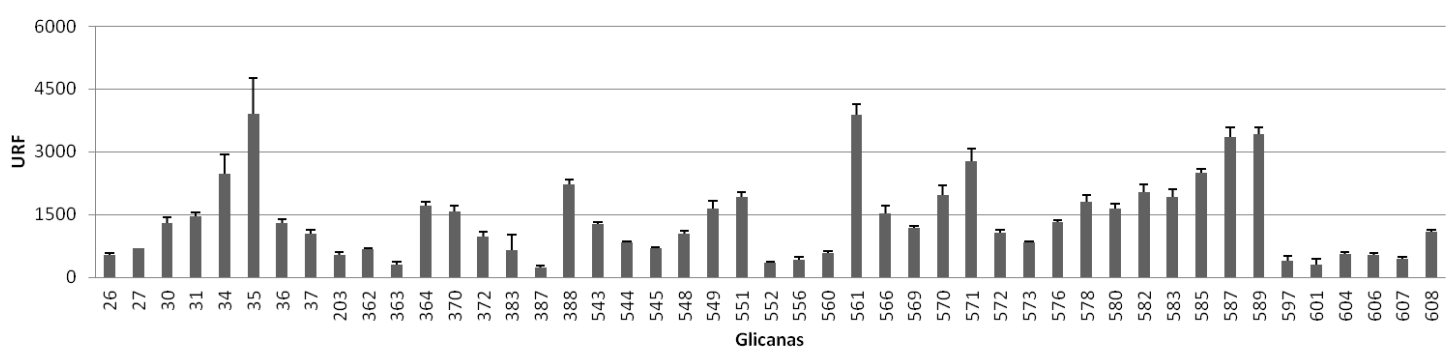

Gal-1h $1 \mu \mathrm{M}$

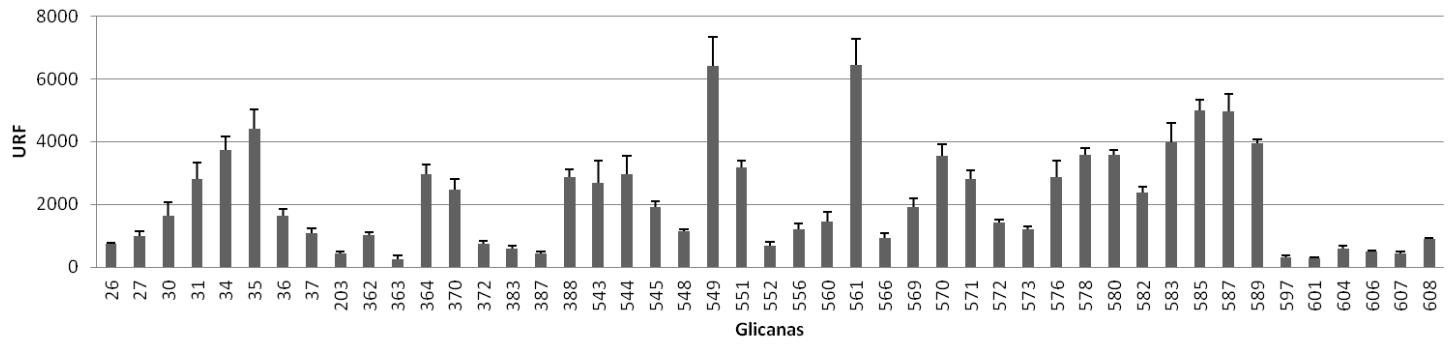

Gal-1h $5 \mu \mathrm{M}$

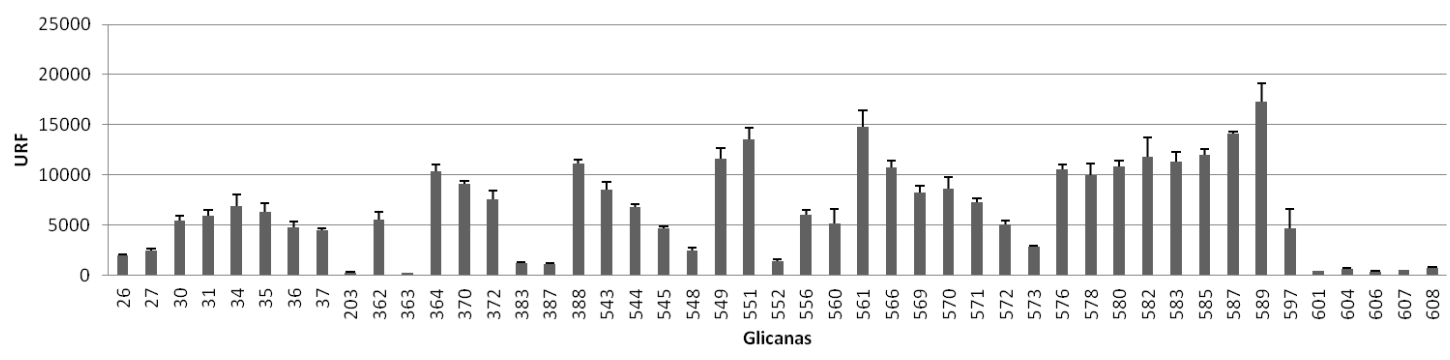

Gal-1h $10 \mu \mathrm{M}$

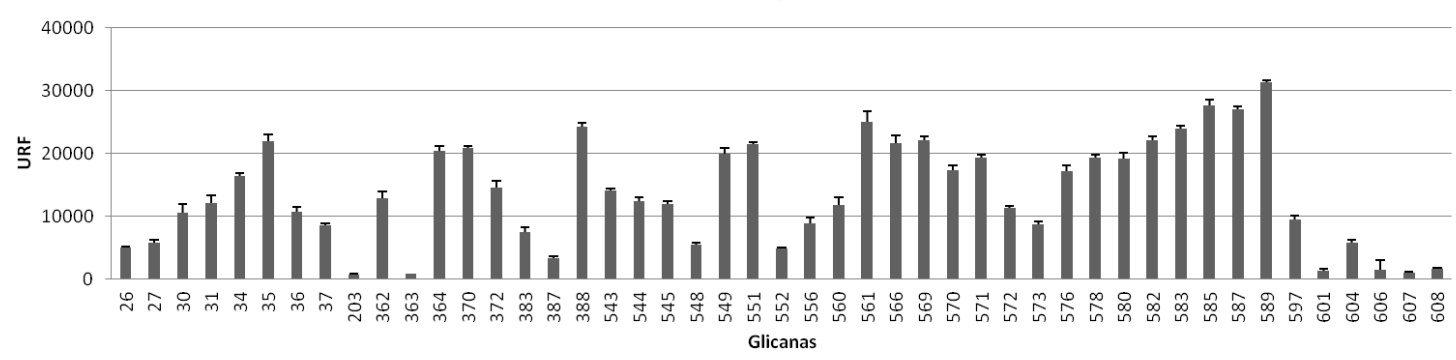

Figura 28. Glicanas correspondentes aos picos de maior intensidade de fluorescência em todas as concentrações testadas de Gal-1h. 
Analisando a intensidade de ligação às glicanas comuns, por meio do teste $\mathrm{t}$ student (versão 4 Prism, GraphPad, USA), pode-se observar que a Gal-1h se liga com intensidade maior a todas as glicanas (valor $p<0,0001$ ), em todas as concentrações testadas, sendo possível observar proximidade nas intensidades de ligação de Gal-1h e Gal-1c apenas na concentração de 0,1 $\mu \mathrm{M}$ (valor $\mathrm{p}=0,0012$ ) (Figura 29). As glicanas analisadas estão representadas na tabela 3.

Tabela 3. Correspondência entre os números arbitrários utilizados para representar cada glicana e a sequência de carboidratos presente em cada glicana.

\begin{tabular}{|c|c|}
\hline $\mathbf{N}^{\circ}$ & Sequência de Carboidratos \\
\hline 26 & (3S)Galb1-4(6S)Glcb-Sp0 \\
\hline 27 & (3S)Galb1-4(6S)Glcb-Sp8 \\
\hline 30 & (3S)Galb1-3GlcNAcb-Sp0 \\
\hline 31 & (3S)Galb1-3GlcNAcb-Sp8 \\
\hline 34 & (3S)Galb1-4(6S)GlcNAcb-Sp0 \\
\hline 35 & (3S)Galb1-4(6S)GlcNAcb-Sp8 \\
\hline 36 & (3S)Galb1-4GlcNAcb-Sp0 \\
\hline 37 & (3S)Galb1-4GlcNAcb-Sp8 \\
\hline 203 & GlcAb-Sp8 \\
\hline 362 & Fuca1-2Galb1-4GlcNAcb1-2Mana1-6(Fuca1-2Galb1-4GlcNAcb1-2Mana1-3)Manb1-4GlcNAcb1-4GlcNAcb-Sp20 \\
\hline 363 & $\begin{array}{l}\text { Fuca1-2Galb1-4(Fuca1-3)GlcNAcb1-2Mana1-6(Fuca1-2Galb1-4(Fuca1-3)GlcNAcb1-2Mana1-3)Manb1- } \\
\text { 4GlcNAcb1-4GIcNAb-Sp20 }\end{array}$ \\
\hline 364 & Gala1-3Galb1-4GlcNAcb1-2Mana1-6(Gala1-3Galb1-4GlcNAcb1-2Mana1-3)Manb1-4GlcNAcb1-4GlcNAcb-Sp20 \\
\hline 370 & $\begin{array}{l}\text { Galb1-4GlcNAcb1-2Mana1-6(Galb1-4GlcNAcb1-4(Galb1-4GlcNAcb1-2)Mana1-3)Manb1-4GlcNAcb1-4GlcNAc- } \\
\text { Sp21 }\end{array}$ \\
\hline 372 & $\begin{array}{l}\text { Gala1-3(Fuca1-2)Galb1-4GlcNAcb1-2Mana1-6(Gala1-3(Fuca1-2)Galb1-4GlcNAcb1-2Mana1-3)Manb1- } \\
\text { 4GlcNAcb1-4GlcNAcb-Sp20 }\end{array}$ \\
\hline 383 & Galb1-3GIcNAcb1-3Galb1-4GIcNAcb1-6(Galb1-3GIcNAcb1-3)Galb1-4Glcb-Sp0 \\
\hline 387 & Galb1-3GlcNAcb1-3Galb1-4(Fuca1-3)GlcNAcb1-6(Galb1-3GlcNAcb1-3)Galb1-4Glc-Sp21 \\
\hline 388 & $\begin{array}{l}\text { Galb1-4GlcNAcb1-6(Galb1-4GlcNAcb1-2)Mana1-6(Galb1-4GlcNAcb1-4(Galb1-4GlcNAcb1-2)Mana1-3)Manb1- } \\
\text { 4GlcNAcb1-4GlcNAcb-Sp21 }\end{array}$ \\
\hline 543 & $\begin{array}{l}\text { Galb1-4GlcNAcb1-3Galb1-4GlcNAcb1-2Mana1-6(Galb1-4GlcNAcb1-3Galb1-4GlcNAcb1-2Mana1-3)Manb1- } \\
\text { 4GlcNAcb1-4GlcNAcb-Sp24 }\end{array}$ \\
\hline 544 & $\begin{array}{l}\text { Neu5Gca2-3Galb1-4GlcNAcb1-3Galb1-4GlcNAcb1-2Mana1-6(Neu5Gca2-3Galb1-4GlcNAcb1-3Galb1- } \\
\text { 4GlcNAcb1-2Mana1-3)Manb1-4GlcNAcb1-4GlcNAcb-Sp24 }\end{array}$ \\
\hline 545 & $\begin{array}{l}\text { Fuca1-2Galb1-4GlcNAcb1-3Galb1-4GlcNAcb1-2Mana1-6(Fuca1-2Galb1-4GlcNAcb1-3Galb1-4GlcNAcb1- } \\
\text { 2Mana1-3)Manb1-4GlcNAcb1-4GlcNAcb-Sp24 }\end{array}$ \\
\hline 548 & $\begin{array}{l}\text { Galb1-4GlcNAcb1-3Galb1-4GlcNAcb1-3Galb1-4GlcNAcb1-2Mana1-6(Galb1-4GlcNAcb1-3Galb1-4GlcNAcb1- } \\
\text { 3Galb1-4GlcNAcb1-2Mana1-3)Manb1-4GlcNAcb1-4GlcNAcb-Sp12 }\end{array}$ \\
\hline 549 & $\begin{array}{l}\text { Galb1-4GlcNAcb1-3Galb1-4GlcNAcb1-3Galb1-4GlcNAcb1-2Mana1-6(Galb1-4GlcNAcb1-3Galb1-4GlcNAcb1- } \\
\text { 3Galb1-4GlcNAcb1-2Mana1-3)Manb1-4GlcNAcb1-4GlcNAcb-Sp24 }\end{array}$ \\
\hline 551 & $\begin{array}{l}\text { Galb1-4GlcNAcb1-3Galb1-4GIcNAcb1-3Galb1-4GIcNAcb1-3Galb1-4GlcNAcb1-2Mana1-6(Galb1-4GIcNAcb1- } \\
\text { 3Galb1-4GlcNAcb1-3Galb1-4GlcNAcb1-3Galb1-4GIcNAcb1-2Mana1-3)Manb1-4GlcNAcb1-4GlcNAcb-Sp25 }\end{array}$ \\
\hline 552 & $\begin{array}{l}\text { Galb1-3GlcNAcb1-3Galb1-4GlcNAcb1-2Mana1-6(Galb1-3GlcNAcb1-3Galb1-4GlcNAcb1-2Mana1-3)Manb1- } \\
\text { 4GlcNAcb1-4GlcNAc-Sp25 }\end{array}$ \\
\hline 556 & Neu5Gca2-8Neu5Gca2-3Galb1-4GIcNAcb1-3Galb1-4GIcNAc-Sp0 \\
\hline 560 & $\begin{array}{l}\text { Galb1-4GlcNAcb1-3Galb1-4GlcNAcb1-6(Galb1-4GlcNAcb1-3Galb1-4GlcNAcb1-2)Mana1-6(Galb1-4GlcNAcb1- } \\
\text { 3Galb1-4GlcNAcb1-2Mana1-3)Mana1-4GlcNAcb1-4GlcNAc-Sp24 }\end{array}$ \\
\hline 561 & Gala1-3Galb1-4GlcNAcb1-2Mana1-6(Gala1-3Galb1-4GlcNAcb1-2Mana1-3)Manb1-4GlcNAcb1-4GlcNAc-Sp24 \\
\hline
\end{tabular}




\begin{tabular}{|c|c|}
\hline 566 & $\begin{array}{c}\text { Galb1-4GlcNAcb1-3Galb1-4GlcNAcb1-3Galb1-4GlcNAcb1-3Galb1-4GlcNAcb1-3Galb1-4GlcNAcb1-2Mana1- } \\
\text { 6(Galb1-4GlcNAcb1-3Galb1-4GlcNAcb1-3Galb1-4GlcNAcb1-3Galb1-4GlcNAcb1-3Galb1-4GlcNAcb1-2Mana1- } \\
\text { 3)Manb1-4GlcNAcb1-4GlcNAcb-Sp25 }\end{array}$ \\
\hline 569 & $\begin{array}{l}\text { Galb1-4GlcNAcb1-3Galb1-4GlcNAcb1-3Galb1-4GlcNAcb1-3Galb1-4GlcNAcb1-3Galb1-4GlcNAcb1-3Galb1- } \\
\text { 4GlcNAcb1-2Mana1-6(Galb1-4GIcNAcb1-3Galb1-4GlcNAcb1-3Galb1-4GlcNAcb1-3Galb1-4GlcNAcb1-3Galb1- } \\
\text { 4GlcNAcb1-3Galb1-4GIcNAcb1-2Mana1-3)Manb1-4GlcNAcb1-4GlcNAcb-Sp25 }\end{array}$ \\
\hline 570 & (3S)GlcAb1-3Galb1-4GlcNAcb1-3Galb1-4Glc-Sp0 \\
\hline 571 & (3S)GlcAb1-3Galb1-4GlcNAcb1-2Mana-Sp0 \\
\hline 572 & $\begin{array}{l}\text { Galb1-3GlcNAcb1-3Galb1-4GlcNAcb1-3Galb1-4GlcNAcb1-6(Galb1-3GlcNAcb1-3Galb1-4GlcNAcb1-3Galb1- } \\
\text { 4GlcNAb1-2)Mana1-6(Galb1-3GlcNAcb1-3Galb1-4GlcNAcb1-3Galb1-4GlcNAcb1-2Mana1-3)Manb1-4GlcNAcb1- } \\
\text { 4(Fuca1-6)GlcNAcb-Sp24 }\end{array}$ \\
\hline 573 & $\begin{array}{l}\text { Galb1-3GlcNAcb1-3Galb1-4GlcNAcb1-6(Galb1-3GlcNAcb1-3Galb1-4GlcNAb1-2)Mana1-6(Galb1-3GlcNAcb1- } \\
\text { 3Galb1-4GlcNAcb1-2Mana1-3)Manb1-4GlcNAcb1-4(Fuca1-6)GlcNAcb-Sp24 }\end{array}$ \\
\hline 576 & $\begin{array}{l}\text { Galb1-4GlcNAcb1-3Galb1-4GlcNAcb1-2Mana1-6(Galb1-4GlcNAcb1-3Galb1-4GlcNAcb1-2Mana1-3)Manb1- } \\
\text { 4GlcNAcb1-4(Fuca1-6)GlcNAcb-Sp24 }\end{array}$ \\
\hline 578 & $\begin{array}{l}\text { Galb1-4GlcNAcb1-3Galb1-4GlcNAcb1-3Galb1-4GlcNAcb1-2Mana1-6(Galb1-4GlcNAcb1-3Galb1-4GlcNAcb1- } \\
\text { 3Galb1-4GlcNAcb1-2Mana1-3)Manb1-4GlcNAcb1-4(Fuca1-6)GlcNAcb-Sp24 }\end{array}$ \\
\hline 580 & $\begin{array}{l}\text { Galb1-4GlcNAcb1-3Galb1-4GlcNAcb1-3Galb1-4GlcNAcb1-3Galb1-4GlcNAcb1-2Mana1-6(Galb1-4GlcNAcb1- } \\
\text { 3Galb1-4GIcNAcb1-3Galb1-4GlcNAcb1-3Galb1-4GlcNAcb1-2Mana1-3)Manb1-4GlcNAcb1-4(Fuca1-6)GlcNAcb- } \\
\text { Sp24 }\end{array}$ \\
\hline 582 & $\begin{array}{l}\text { Galb1-4GlcNAcb1-3Galb1-4GlcNAcb1-3Galb1-4GlcNAcb1-3Galb1-4GlcNAcb1-2Mana1-6(Galb1-4GlcNAcb1- } \\
\text { 3Galb1-4GlcNAcb1-3Galb1-4GIcNAcb1-3Galb1-4GlcNAcb1-2Mana1-3)Manb1-4GlcNAcb1-4(Fuca1-6)GlcNAcb- } \\
\text { Sp24 }\end{array}$ \\
\hline 583 & $\begin{array}{l}\text { Galb1-4GlcNAcb1-3Galb1-4GlcNAcb1-6(Galb1-4GlcNAcb1-3Galb1-4GlcNAb1-2)Mana1-6(Galb1-4GlcNAcb1- } \\
\text { 3Galb1-4GlcNAcb1-2Mana1-3)Manb1-4GlcNAcb1-4(Fuca1-6)GlcNAcb-Sp24 }\end{array}$ \\
\hline 585 & $\begin{array}{l}\text { Galb1-4GlcNAcb1-3Galb1-4GlcNAcb1-3Galb1-4GlcNAcb1-6(Galb1-4GlcNAcb1-3Galb1-4GlcNAcb1-3Galb1- } \\
\text { 4GIcNAb1-2)Mana1-6(Galb1-4GIcNAcb1-3Galb1-4GlcNAcb1-3Galb1-4GlcNAcb1-2Mana1-3)Manb1-4GIcNAcb1- } \\
\text { 4(Fuca1-6)GlcNAcb-Sp24 }\end{array}$ \\
\hline 587 & $\begin{array}{l}\text { Galb1-4GlcNAcb1-3Galb1-4GlcNAcb1-3Galb1-4GlcNAcb1-3Galb1-4GlcNAcb1-6(Galb1-4GlcNAcb1-3Galb1- } \\
\text { 4GlcNAcb1-3Galb1-4GlcNAcb1-3Galb1-4GlcNAb1-2)Mana1-6(Galb1-4GlcNAcb1-3Galb1-4GlcNAcb1-3Galb1- } \\
\text { 4GlcNAcb1-3Galb1-4GlcNAcb1-2Mana1-3)Manb1-4GlcNAcb1-4(Fuca1-6)GlcNAcb-Sp24 }\end{array}$ \\
\hline 589 & $\begin{array}{c}\text { Galb1-4GlcNAcb1-3Galb1-4GlcNAcb1-3Galb1-4GlcNAcb1-3Galb1-4GlcNAcb1-3Galb1-4GlcNAcb1-6(Galb1- } \\
\text { 4GlcNAcb1-3Galb1-4GlcNAcb1-3Galb1-4GlcNAcb1-3Galb1-4GlcNAcb1-3Galb1-4GlcNAb1-2)Mana1-6(Galb1- } \\
\text { 4GlcNAcb1-3Galb1-4GlcNAcb1-3Galb1-4GlcNAcb1-3Galb1-4GlcNAcb1-3Galb1-4GlcNAcb1-2Mana1-3)Manb1- } \\
\text { 4GlcNAcb1-4(Fuca1-6)GlcNAcb-Sp24 }\end{array}$ \\
\hline 597 & $\begin{array}{l}\text { Neu5Aca2-3Galb1-4GlcNAcb1-3Galb1-4GlcNAcb1-6(Neu5Aca2-3Galb1-4GlcNAcb1-3Galb1-4GlcNAcb1- } \\
\text { 3)GalNAca-Sp14 }\end{array}$ \\
\hline 601 & Neu5Aca2-3Galb1-4GlcNAcb1-3Galb1-4GlcNAcb1-6(Galb1-3)GalNAca-Sp14 \\
\hline 604 & $\begin{array}{l}\text { Neu5Aca2-3Galb1-4GlcNAcb1-3Galb1-4GlcNAcb1-2Mana1-6(Neu5Aca2-3Galb1-4GlcNAcb1-3Galb1- } \\
\text { 4GlcNAcb1-2Mana1-3)Manb1-4GlcNAcb1-4GlcNAcb-Sp12 }\end{array}$ \\
\hline 606 & $\begin{array}{l}\text { Neu5Aca2-6Galb1-4GlcNAcb1-3Galb1-4GlcNAcb1-6(Neu5Aca2-6Galb1-4GlcNAcb1-3Galb1-4GlcNAcb1- } \\
\text { 3)GalNAca-Sp14 }\end{array}$ \\
\hline 607 & $\begin{array}{l}\text { Neu5Aca2-6Galb1-4GlcNAcb1-3Galb1-4GlcNAcb1-3Galb1-4GlcNAcb1-2Mana1-6(Neu5Aca2-6Galb1- } \\
\text { 4GlcNAcb1-3Galb1-4GlcNAcb1-3Galb1-4GlcNAcb1-2Mana1-3)Manb1-4GlcNAcb1-4GlcNAcb-Sp12 }\end{array}$ \\
\hline 608 & $\begin{array}{l}\text { Neu5Aca2-3Galb1-4GlcNAcb1-3Galb1-4GIcNAcb1-3Galb1-4GlcNAcb1-2Mana1-6(Neu5Aca2-3Galb1- } \\
\text { 4GIcNAcb1-3Galb1-4GIcNAcb1-3Galb1-4GIcNAcb1-2Mana1-3)Manb1-4GlcNAcb1-4GIcNAcb-Sp12 }\end{array}$ \\
\hline SPO & $\mathrm{CH}_{2} \mathrm{CH}_{2} \mathrm{NH}_{2}$ \\
\hline SP8 & $\mathrm{CH}_{2} \mathrm{CH}_{2} \mathrm{CH}_{2} \mathrm{NH}_{2}$ \\
\hline SP12 & Asparagina \\
\hline SP14 & Treonina \\
\hline SP20 & GENR \\
\hline Sp21 & $\left.\mathrm{H}_{3}\right)-\mathrm{O}-\left(\mathrm{CH}_{2}\right)_{2}$ \\
\hline SP24 & KVANKT \\
\hline SP25 & VANK \\
\hline
\end{tabular}



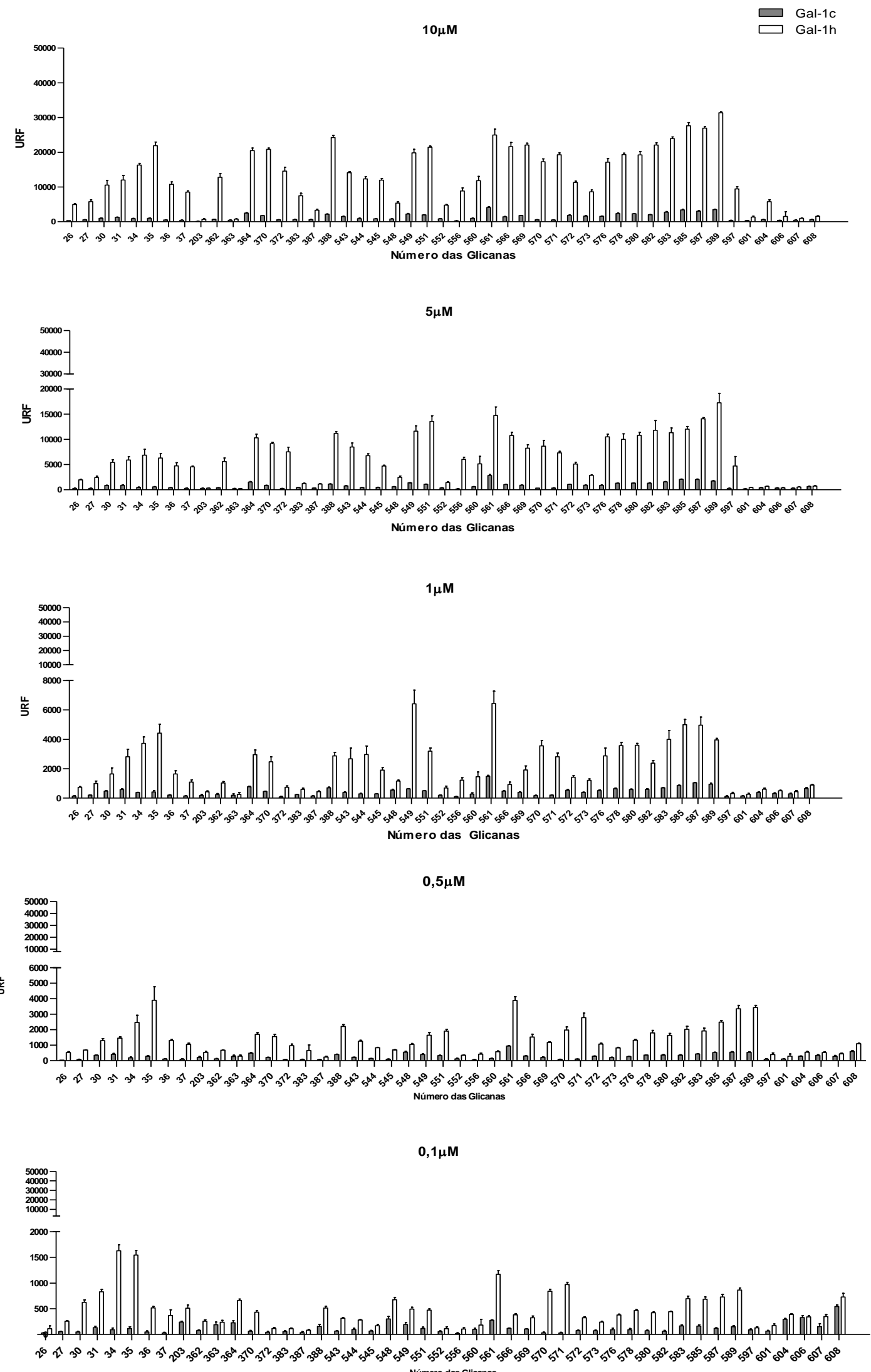

Figura 29. Análise comparativa entre Gal-1c e Gal-1h quanto à capacidade de ligação às glicanas correspondentes aos picos de fluorescência. 
Os resultados obtidos evidenciam que ambas as galectinas apresentam maior intensidade de ligação para glicanas com N-glicosilação bi-antenárias e triantenárias com múltiplas unidades de $\mathrm{N}$-acetil-lactosamina (Galß1-4GlcNac) contendo resíduos de galactose terminal não reduzidas, com especial atenção para as glicanas de número 561, 589, 585 e 587, que estão representadas na figura 30 . Estes achados estão de acordo com dados da literatura que mostram uma forte ligação da Gal-1h com glicanas contendo poli-lactosanimas bi-antenárias e triantenárias (FEIZE et al. 1990; LEE et al. 1990; HIRABAYASHI et al., 2002; STOWELL et al.,2008), motivos esses encontrados em proteínas estruturais da matriz extracelular, como laminina e fibronectina (LEPÄNEN et al., 2004). Análises por microcalorimetria mostram que a Gal-1h pode se ligar a unidades $\mathrm{N}$-acetillactosamina com uma afinidade de ligação 4 vezes maior em relação a lactose (LOPEZ-LUCENDO et al., 2004). Entretanto, as intensidades das interações das galectinas com a $\mathrm{N}$-acetil-lactosamina, determinadas a partir dos ensaios de array de glicanas apresentaram-se muito baixas, não sendo, pois consideradas para análise. 


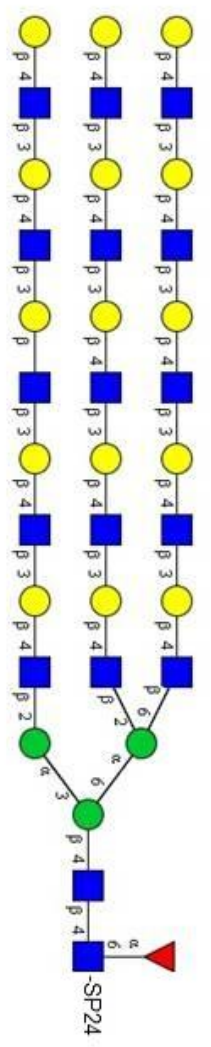

589

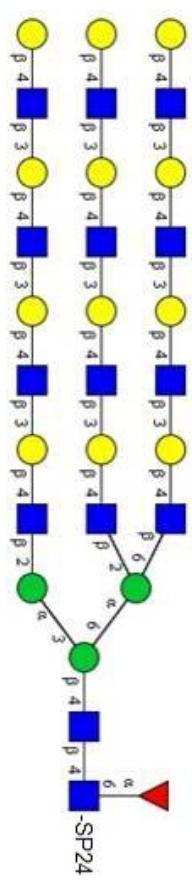

587

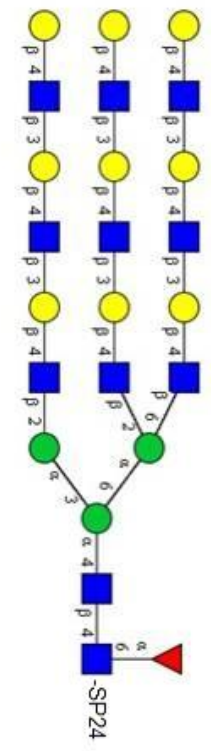

585

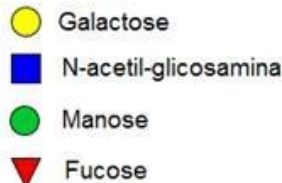

Galactose

N-acetil-glicosamina

$\nabla$ Fucose

Figura 30. Representação esquemática das glicanas a que ambas as Gal-1 se ligam com maior afinidade. As estruturas foram construídas no programa GlycoworkBench 2.1 (CERONI et al., 2008).

Achados da literatura obtidos com o uso de ensaios de ligação a glicanas em fase sólida também reportaram níveis baixos de interação entre unidades de $\mathrm{N}$ acetil-lactosamina isoladas e a Gal-1 (STOWELL et al., 2004; STOWELL et al., 2008; LEPPANEN et al., 2005). Dados conflitantes sobre a análise da interação de Gal-1 com carboidratos tem sido publicados. Esse conflito de informações poderia ser explicado com base nos métodos utilizados. Por exemplo, a baixa densidade de ligantes em ensaios de fase sólida pode dificultar a detecção de interações de baixa afinidade. Por outro lado, ensaios com o uso de ligantes livres e em solução podem causar reações de "cross-linking" dos açúcares com as lectinas imobilizadas e isto podem aumentar a afinidade aparente dessas proteínas por carboidratos (ZHOU \& CUMMINGS, 1993; HIRABAYASHI et al., 2002; APPUKUTTAN et al., 2002; STOWELL et al., 2004; STOWELL et al., 2008).

Existem indícios de que a especificidade de ligação das galectinas a determinadas glicanas é dependente da ramificação dessas glicanas, da repetição 
de unidades de $\mathrm{N}$-acetilglicosamina (Galß1-4GlcNAc), e dos substituintes nas posições 2-OH e 3-OH nos resíduos de galactose terminal. Elas não reconhecem ou reconhecem muito pouco glicanas com substituição nas posições 4-OH e 6-OH, sendo, portanto, necessário um terminal redutor para que exista ligação das galectinas (HIRABAYASHI et al., 2002).

Foi possível observar também que a Gal-1h se liga com afinidade considerável, principalmente em concentrações baixas $(0,5$ e 0,1 $\mu \mathrm{M})$ a glicanas sulfatadas correspondentes aos números 31, 34, 35, 570 e 571, cujas estruturas estão representadas na figura 31 .

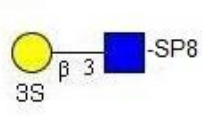

31

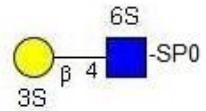

34

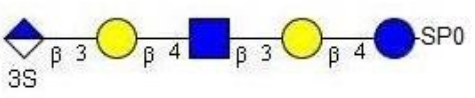

570

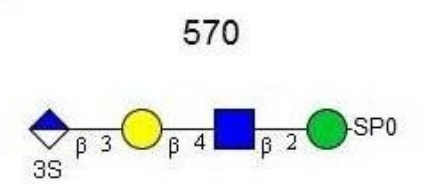

571

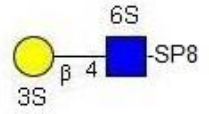

35

Figura 31. Representação esquemática das glicanas sulfatadas às quais a Gal-1h se liga com maior afinidade. As estruturas foram construídas no programa GlycoworkBench 2.1 (CERONI et al., 2008).

Essa observação corrobora com os resultados de STOWELL e colaboradores (2008), que obtiveram um aumento significativo no reconhecimento da Gal-1 por resíduos de Galß1-4GlcNAc após sulfatação na posição 3-O.

A recirculação dos linfócitos é mediada pela interação específica entre Lselectina e glicoproteínas sulfatadas, que são espressas em vênulas endoteliais dos linfonodos. Durante o rolamento e a interação com o endotélio, que é mediada por Lselectina e glicanas sulfatadas, os linfócitos recebem sinais de quimiocinas presentes na superfície endotelial por heparan sulfato, uma glicosaminoglicana sulfatada que conduz a ativação de $\beta 2$-integrinas linfocitárias. Assim, as glicanas sulfatadas estão envolvidas tanto no rolamento quanto nos passos de ativação durante a interação entre linfócitos e as vênulas dos linfonodos (KAWASHIMA, 
2006). A observação de que Gal-1h se liga com grande afinidade a glicanas sulfatadas sugere que ela esteja envolvida na interação entre linfócitos e endotélio, assim como em outros eventos dependentes de integrinas.

Diversos estudos têm apontado que a sialilação e a fucosilação de glicoconjugados pode afetar a afinidade da Gal-1 por seus ligantes. LEPÄNEN e colaboradores (2004) demonstraram que a Gal-1 dimérica reconhece com alta afinidade glicanas mais extensas e a2,3-sialiladas, além de outras glicanas não sialiladas contendo resíduos de polilactosamina terminais, sendo a afinidade proporcional ao número de repetições de polilactosamina. Também afirmam que essa afinidade é muito maior quando as glicanas estão imobilizadas do que quando se encontram em solução.

AUVYNET e colaboradores (2013) demonstraram que a Gal-1 se liga a CD43, uma sialoglicoproteína de superfície, via CRD, em neutrófilos não ativados, favorecendo sua migração através do endotélio. Considerando que a Gal-1 desfavorece a migração de polimorfonucleares durante uma resposta imune, sendo, até então apontada uma lectina antinflamatória, tal estudo apresenta indícios de que, além de se ligar a glicanas sialiladas, gerando sinal intracelular e consequentemente uma resposta, a função da Gal-1 não é pré-estabelecida, sendo uma proteína anti ou pró-inflamatória dependendo do microambiente em que se encontra.

Apesar de a intensidade de ligação da Gal-1h ter sido maior para todas as glicanas, pode-se observar que ambas as galectinas se ligaram às glicanas 383 , 604, 606 e 608 com intensidades próximas, na concentração de $0,1 \mu \mathrm{M}$. Dentre as glicanas citadas, destaca-se a presença de ácido siálico em 3 delas, e a presença de fucose em uma delas (figura 32). Apesar de os estudos de STOWELL e colaboradores (2008) terem demonstrado que a Gal-1 se liga preferencialmente a glicanas contendo ácido siálico terminal ligados na posição a2-3, não se ligando àquelas contendo ácido siálico na posição $\alpha 2-6$, pode-se observar ligação, mesmo que em menor intensidade, tanto da Gal-1c quanto da Gal-1h à glicana de número 606, que apresenta ácido siálico na posição a2-6. É interessante notar que a Gal-1c, nessa concentração, apresenta maior afinidade pela glicana 608 do que pelas demais. Como a constante de dissociação para a formação de dímeros de Gal-1 é aproximadamente de 1 a $2 \mu \mathrm{M}$ (STOWELL et al., 2009), pode-se suspeitar da 
predominância de monômeros na amostra de Gal-1c na concentração de 0,1 $\mu \mathrm{M}$. Assim, pode-se inferir sobre a possibilidade de monômeros de Gal-1c apresentarem maior afinidade por glicanas sialiladas e/ou fucosiladas do que apresentaria na forma dimérica. Isso poderia abrir caminhos para o estudo de outras funções da Gal1 independentes do reconhecimento exclusivo de resíduos de lactosamina.

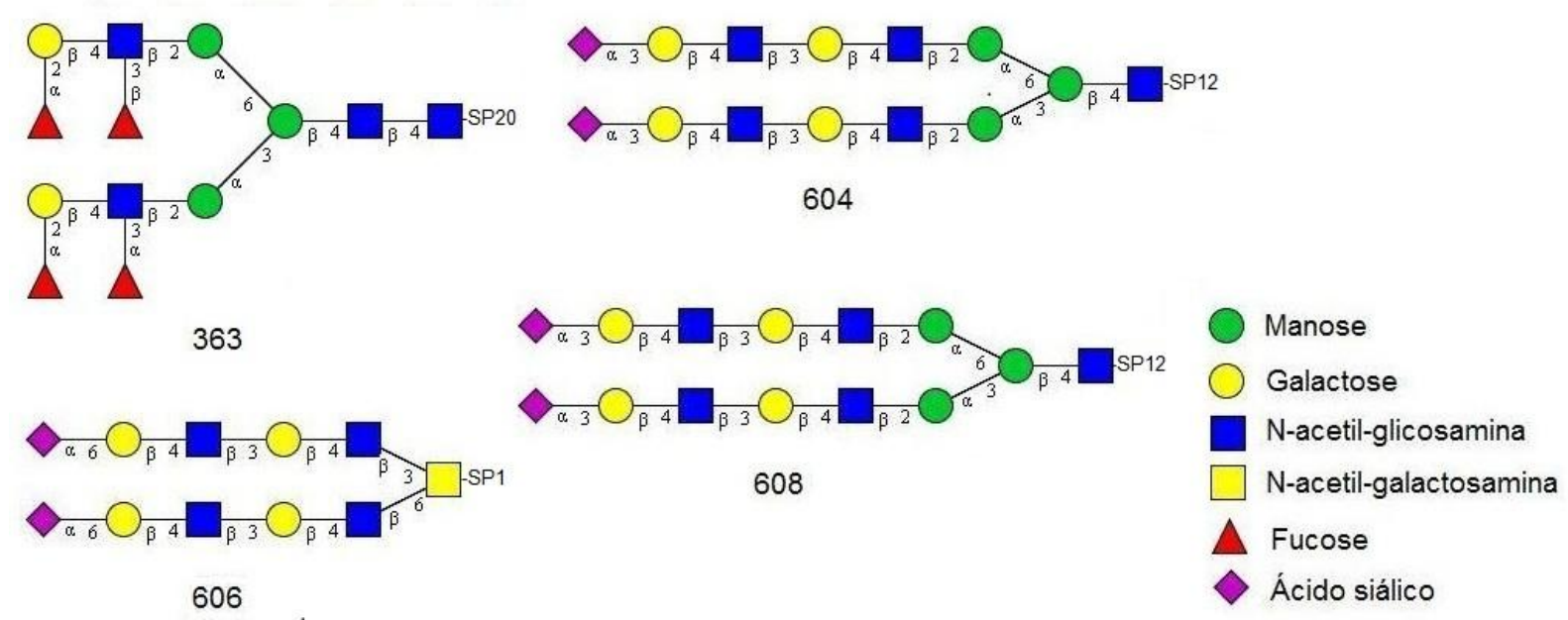

Figura 32. Representação esquemática das glicanas sialiladas a que ambas as Gal-1 se ligam, com intensidades próximas, a baixas concentrações. As estruturas foram construídas no programa GlycoworkBench 2.1 (CERONI et al., 2008).

As diferenças encontradas tanto na capacidade hemaglutinante de Gal-1c e Gal-1h quanto na capacidade de ligação a glicanas imobilizadas em matriz sólida (glycan array), sugerem que as diferenças estruturais indicadas anteriormente entre essas galectinas são capazes de afetar diretamente a sua atividade lectínica, afetando, por conseguinte, diretamente sua função biológica. 


\subsection{Avaliação da exposição de fosfatidilserina (FS) nas superfícies de neutrófilos ativados e ensaio de fagocitose}

\subsubsection{Separação de neutrófilos de camundongos C57BL/6 que expressam níveis normais e reduzidos de Mac-1 e Imunofenotipagem}

Neutrófilos medulares de camundongos com expressão normal e deficiente de Mac-1 foram isolados de acordo com protocolo descrito na seção 4.8.1 do item "4. Materiais e Métodos".

Após isolamento, os neutrófilos foram submetidos a citospin para confeção de lâmina a fim de confirmar, por meio de microscopia óptica, a pureza da preparação. Os resultados obtidos mostraram um rendimento considerável no processo de isolamento, observando-se mais de $90 \%$ de células com núcleo caracteristicamente multilobulado (dados não mostrados).

A imunofenotipagem para confirmação da população analisada por citometria de fluxo foi realizada utilizando-se anticorpos anti- Ly6C/Ly6G/CD11b, buscando-se a população que apresentasse tripla positividade para essas marcações, já que as moléculas alvos (marcadores) consistem em proteínas expressas nas superfícies de neutrófilos e relacionadas à biologia desses leucócitos. Os resultados de imunofenotipagem indicaram que o procedimento de isolamento de neutrófilos de medula foi eficiente, pois a maioria das células contidas nas suspensões obtidas tanto de animais selvagens (Figura 33) quanto dos animais deficientes de Mac-1 (Figura 34) apresentaram positividade elevada para os marcadores em questão. Pode-se observar na figura 33 as seguintes porcentagens de positividade do total de células obtidas da medula de animais selvagens: LY6G $^{+} / \mathrm{CD}_{11 \mathrm{~b}^{+}}(98,5 \%)$; $\mathrm{LY} 6 C^{+} / \mathrm{CD} 11 b^{+}(99,1 \%) ; \mathrm{LY}^{+} C^{+} / \mathrm{LY} 6 G^{+}$(98,6\%). Para as células obtidas da meduda de animais deficientes de Mac-1 as porcentagens de positividade foram:

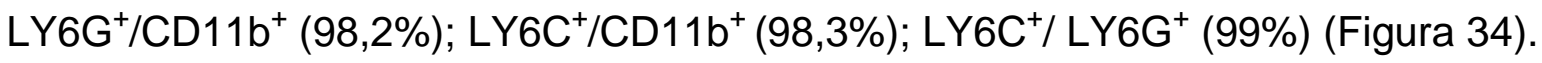


a)

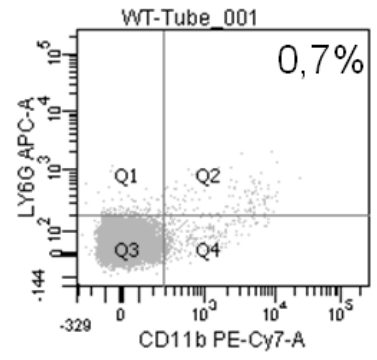

Neutrófilos WT+fmlp

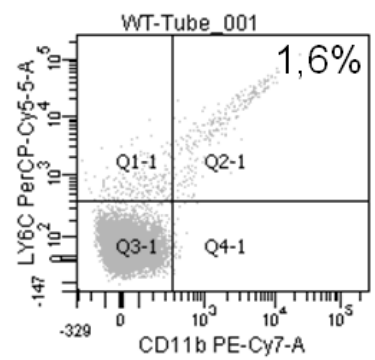

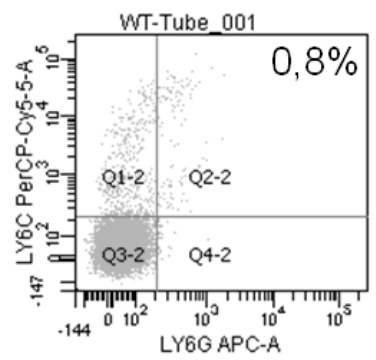

b)

Neutrófilos WT+fmlp + anti LY6C + anti LY6G + anti CD11b
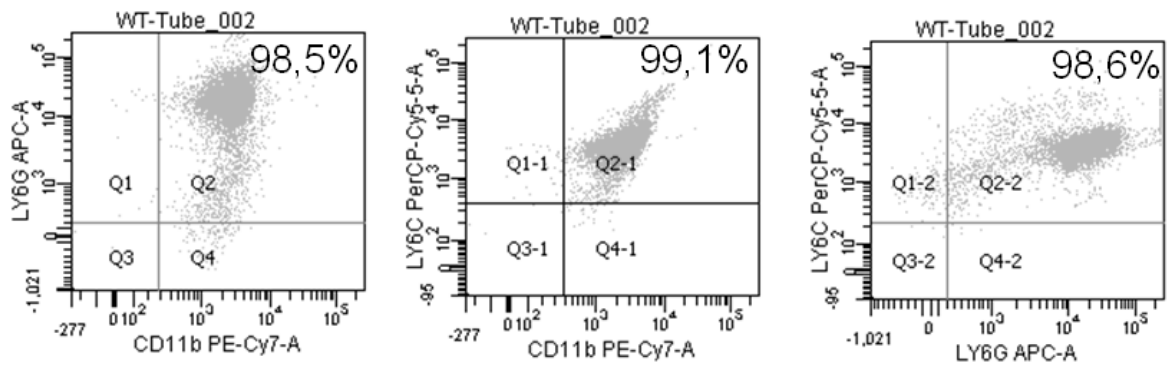

Figura 33. Imunofenotipagem de neutrófilos WT ativados por marcação com anti-LY6C, anti-LY6G e anti-CD11b.

a)

Neutrófilos Mac-1 deficientes $+\mathrm{fmlp}$
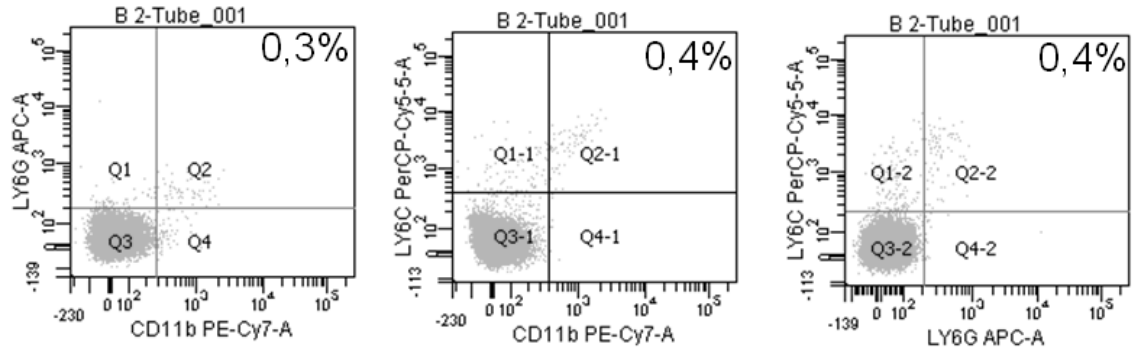

b) Neutrófilos Mac-1 deficientes +fmlp + anti LY6C + anti LY6G + anti CD11b
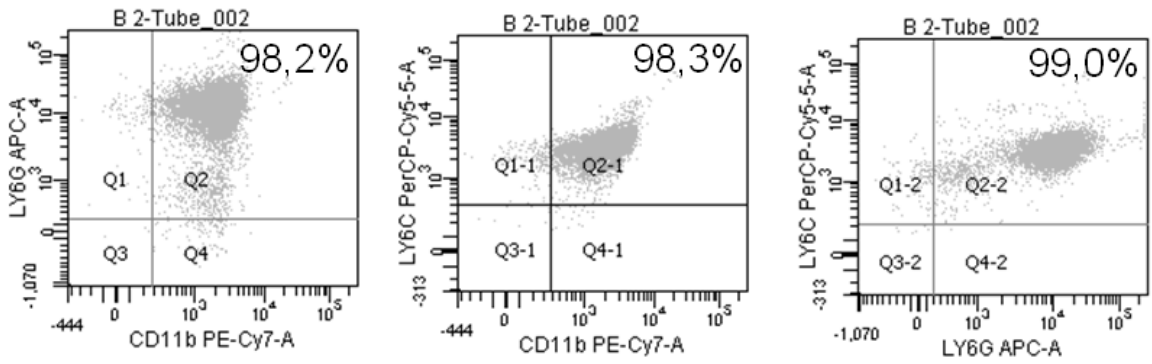

Figura 34. Imunofenotipagem de neutrófilos deficientes de Mac-1 ativados por marcação com antiLY6C, anti-LY6G e anti-CD11b. 


\subsubsection{Avaliação da exposição de fosfatidilserina (FS) nas superfícies de neutrófilos através da metodologia de citometria de fluxo}

Nos ensaios de indução de exposição de FS buscou-se a marcação por anexina $V$ sem ocorrência de marcação por PI (ausência de necrose). Como ilustrado na figura 35, pode-se observar um aumento significativo na expressão de FS em relação ao controle negativo (somente neutrófilos), nos tratamentos por Gal1c, Gal-1h e etoposídeo (valor $p<0,0001$ ) de neutrófilos de animais selvagens. Não houve, entretanto, diferença significativa entre os tratamentos entre Gal-1c e Gal-1h dentro de cada grupo nem diferença significativa entre os grupos de camundongos utilizados (valor $p>0,05$ ).

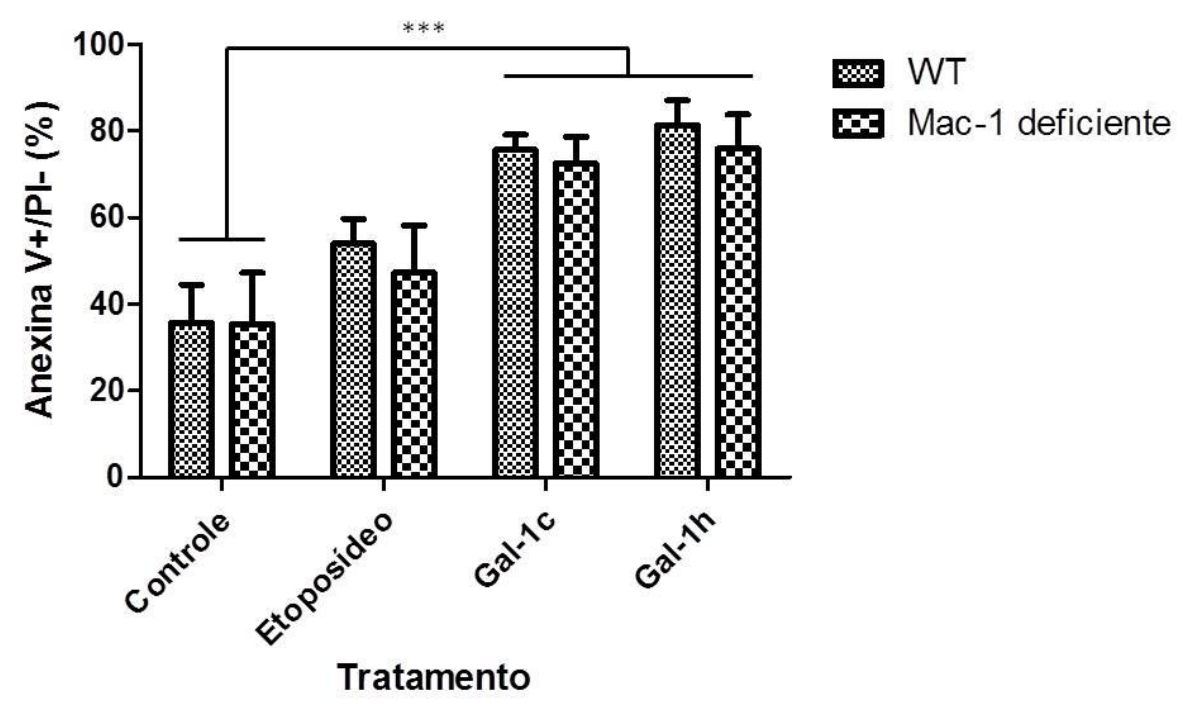

Figura 35. Representação gráfica dos resultados obtidos por citometria de fluxo, utilizando como variáveis o tratamento (Gal-1h, Gal-1c e etoposídeo) e marcação positiva para Anexina (Anexina $V_{+}$) e negativa para $\mathrm{PI}$ (PI-) em dois diferentes grupos (neutrófilos provenientes de camundongos com expressão normal e neutrófilos provenientes de camundongos com expressão reduzida de Mac-1). Os resultados expressos são representativos de 3 experimentos independentes. $O$ tratamento estatístico utilizado para comparação entre os diferentes grupos experimentais foi a análise de variância (ANOVA) "two-way", seguido do pós-teste de Bonferroni com o uso do programa GraphPad Prism (versão 4 Prism, GraphPad, USA).

Desse modo, foi possível observar que ambas as Gal-1 induzem a exposição de FS em neutrófilos ativados de maneira semelhante, diferentemente do observado para os ensaios de glycan array e hemaglutinação, em que foram observadas diferenças significativas de afinidade entre as duas Gal-1. Isso pode ser mais um 
indício de que as características do microambiente em que as galectinas estão inseridas, assim como a oferta dos ligantes e a superfície em que os mesmos se encontram influencia diretamente sua capacidade de ligação e, consequentemente, sua atividade (HIRAMATSU et al, 2013; AUVYNET et al, 2013).

Assim, no glycan array, a grande oferta de ligantes imobilizados em matriz sólida, além de favorecer a ligação dessas lectinas, já que não existe ali a dinâmica do glicocálix presente nas membranas celulares, permite observar mínimas diferenças na capacidade de ligação, fracamente observadas no ensaio de hemaglutinação ou não observadas em outros ensaios, como no de indução da exposição de FS em neutrófilos.

LEE e colaboradores (1990) demonstraram que Gal-1h apresenta grande afinidade por $\mathrm{N}$-glicanas, o que foi confirmado por HIRABAYASHI e colaboradores (2002). KARMAKAR e colaboradores (2008) demonstraram que a inibição do processamento de N-glicanas bloqueia a ligação de Gal-1 a células HL60, Molt-4, Jurkat, além de prevenir a mobilização de $\mathrm{Ca}^{2+}$ e exposição de FS induzida por Gal1. Isso poderia indicar o envolvimento da interação entre Gal-1 e esses glicoconjugados no processo de exposição de FS na superfície de neutrófilos ativados.

Tanto a subunidade $\alpha$ quanto a subunidade $\beta$ das $\beta 2$-integrinas possuem sítios de $\mathrm{N}$-glicosilação e alguns deles mostram-se modificados por cadeias oligossacarídicas ligadas a resíduos de asparagina. $\beta 2$-integrinas derivadas de leucócitos humanos também contém cadeias oligossacarídicas do tipo highmannose e, em menor quantidade, cadeias oligossacarídicas híbridas (ASADA et al., 1991). Nessa linha, foi demonstrado que Mac-1 é ligante de Gal-1, como sugere o estudo de GIL e colaboradores (2010). Entretanto, os dados ilustrados na figura 35 mostram que preparações de Gal-1, de origem murina ou humana, induzem níveis semelhantes de exposição de FS nas superfícies de neutrófilos animais deficientes ou não de Mac-1. Assim, com base nos dados indicados na figura 35, sugere-se que, nas condições experimentais utilizadas, a interação Gal-1/Mac-1 não esteja envolvida no processo de exposição de FS na superfície de neutrófilos ativados. 


\section{Conclusões}

Durante a execução do presente trabalho, foi possível obter preparações solúveis, homogêneas e ativas de Gal-1c e Gal1-h. A estrutura cristalográfica da Gal-1c foi determinada a $2.4 \AA$ de resolução, sendo que a configuração estrutural tridimensional da Gal-1c apresenta o enovelamento do tipo "jelly roll", similar aos modelos já descritos para outras galectinas. A Gal-1c pertence ao grupo espacial monoclínico $\mathrm{C} 2$, com uma unidade assimétrica tetramérica, distinta da previamente descrita para a Gal-1h (PDB 1GZW). Pode-se observar ainda que, apesar da alta identidade sequencial compartilhada entre as proteínas de camundongo e humana (88\%), as poucas substituições entre elas são suficientes para introduzir mudanças estereoquímicas significativas na superfície das proteínas, o que pode ter consequências funcionais importantes. A análise estrutural do CRD da Gal-1c, assim como as possíveis mudanças conformacionais mediadas pela ligação de carboidratos terão papel fundamental no entendimento do mecanismo de reconhecimento dos ligantes e no mapeamento das bases estruturais que definem a especificidade das galectinas por diferentes tipos de carboidratos.

Pode-se observar também, através das técnicas de hemaglutinação e glycan array, que diferenças na estrutura primária entre Gal-1c e Gal-1h podem determinar diferenças terciárias ou quaternárias que alteram a ligação a glicanas tanto em superfície celular quanto imobilizadas em matriz sólida. Além disso, foi possível obter o perfil de ligação a glicanas tanto de Gal-1c quanto de Gal-1h, observando-se, além das diferenças de intensidade de ligação, diferenças referentes ao tipo de glicana a que cada Gal-1 se liga. Uma das hipóteses deste trabalho era que a interação Gal1/Mac-1 pudesse estar associada à propriedade da Gal-1 de promover a exposição de FS na superfícies de neutrófilos ativados. Tanto a Gal-1c quanto Gal-1h induziram níveis semelhantes de exposição de FS na superfície de neutrófilos ativados de camundongos deficientes ou não de Mac-1, nas condições experimentais utilizadas. Assim, apesar de a Gal-1 se ligar a Mac-1, os resultados obtidos sugerem que a participação de Gal-1 no turnover de neutrófilos, via reconhecimento fagocítico seja um processo complexo e independente da interação Gal-1/Mac-1. 


\section{Referências}

ADAMS, P. D. et al. A comprehensive Python-based system for macromolecular structure solution. Acta crystallographica. Section D, Biological crystallography, Copenhagen. v. 66, n. 2, p. 213-221, 2010.

AFONINE, P. V. et al. Towards automated crystallographic structure refinement with phenix.refine. Acta crystallographica. Section D, Biological crystallography, Copenhagen. v. 68, p. 352-367, 2012.

ALBERTS, B.; JOHNSON, A.; LEWIS, J.; RAFF, M.; ROBERTS, K.; WALTER, P. Molecular Biology of The Cell. 5th ed., New York: Garland Science, 2008. 1392 p.

ANGINOT, A. et al. Galectin 1 modulates plasma cell homeostasis and regulates the humoral immune response. Journal of immunology, Baltimore. v. 190, n. 11, p. 5526-33, 2013.

APPUKUTTAN, P. S. Terminal alpha-linked galactose rather than $\mathrm{N}$-acetyl lactosamine is ligand for bovine heart galectin-1 in N-linked oligosaccharides of glycoproteins. Journal of molecular recognition : JMR, London. v. 15, p. 180-187, 2002.

ASADA, M. et al. Structural study of the sugar chains of human leukocyte cell adhesion molecules CD11/CD18. Biochemistry, Washington, v. 30, n. 6, p. 156171, 1991.

AVNI, O. et al. Complement receptor 3 of macrophages is associated with galectin-1like protein. Journal of Immunology, Baltimore. v. 160, n. 12, p. 6151-58, 1998.

AUVYNET, C. et al. Galectin-1 promotes human neutrophil migration. Glycobiology, Oxford. v. 23, n. 1, p. 32-42, 2013.

BARONDES, S. H. et al. Galectins: a family of animal beta-galactoside-binding lectins. Cell, Cambridge. v. 25, n. 4, p. 597-98, 1994.

BAUM, L. G. et al. Human thymic epithelial cells express an endogenous lectin, galectin-1, which binds to core 2 O-glycans on thymocytes and T lymphoblastoid cells. Journal of Experimental Medicine, New York. v. 181, n. 3, p. 877-87, 1995.

BERTON, G.; LOWELL, C. A. Integrin signalling in neutrophils and macrophages. Cell Signal, Oxford. v. 11, n. 9, p. 621-35, 1999. 
BIAN, C. F.; ZHANG, Y.; SUN, H.; LI D. F.; WANG, D. C. Structural basis for distinct binding properties of the human galectins to Thomsen-Friedenreich antigen. PLoS One. San Francisco. v. 6, n. 9, p. e25007 1-10, 2011.

BLASER, C. et al. Beta-galactoside-binding protein secreted by activated T cells inhibits antigen-induced proliferation of T cells. European Journal of Immunology, Weinheim. v. 28, n. 8, p. 2311-9, 1998.

BLIXT, O. et al. Printed covalent glycan array for ligand profiling of diverse glycan binding proteins. Proceedings of the National Academy of Sciences of the United States of America, Washington, D.C. v. 101, p. 17033-8, 2004.

BOYD, W. C. Lectins. Annal Of The New York Academic Sciences, New York, v. 169, n. 1, p. 168-190, 1970.

BREWER, C. F. Binding and cross-linking properties of galectins. Biochim Biophys Acta. Amsterdam. v. 19, n. 1572(2-3), p.255-62, 2002.

CAMBY, I.; LE MERCIER, M.; LEFRANC, F.; KISS, R. Galectin-1: a small protein with major functions. Glycobiology, Oxford. V .16, n. 11, p. 137-157, 2006.

CARLSSON, S. et al. Affinity of galectin-8 and its carbohydrate recognition domains for ligands in solution and at the cell surface. Glycobiology, Oxford. v. 17, p. 663676, 2007.

CEDENO-LAURENT, F. et al. Galectin-1 triggers an immunoregulatory signature in Th cells functionally defined by IL-10 expression. Journal of immunology, Baltimore. v. 188, n. 7, p 3127-37, 2012.

CERLIANI, J. P. et al. Expanding the universe of cytokines and pattern recognition receptors: galectins and glycans in innate immunity. Journal of clinical immunology, Amsterdam. v. 31, n. 1, p. 10-21, 2011.

CERONI, A. et al. GlycoWorkbench: a tool for the computer-assisted annotation of mass spectra of glycans. Journal of proteome research, Washington, D.C. v. 7, n. 4, p.1650-9, 2008.

CHEN, V. B. et al. MolProbity: all-atom structure validation for macromolecular crystallography. Acta Acta crystallographica. Section D, Biological crystallography, Copenhagen. v. 66, p 12-21, 2010.

CHO, M.; CUMMINGS, R. D. Galectin-1, a beta-galactoside-binding lectin in Chinese hamster ovary cells. I. Physical and chemical characterization. The Journal of biological chemistry, Baltimore. v. 270, n.10, p. 5198-206, 1995. 
CONSORTIUM FOR FUNCTIONAL GLYCOMICS (CFG). The Glycomics Center at Emory University School of Medicine, Atlanta. Disponível em: <http://www.functionalglycomics.org/static/consortium/resources/resourcecoreh8.sht ml> Data de acesso: 14/01/2012.

COOPER, D. N.; BARONDES, S. H. God must love galectins; he made so many of them. Glycobiology, Oxford. v. 9, n. 10, p. 979-84, 1999.

COOPER, D.; NORLING, L.V.; PERRETTI, M. Novel insights into the inhibitory effects of Galectin-1 on neutrophil recruitment under flow. Journal of leukocyte biology, New York. v. 83, n. 6, p. 1459-66, 2008.

CORRÊA, D. H. A.; RAMOS, C. H. I. The use of circular dichroism spectroscopy to study protein folding, form and function. African Journal of Biochemistry Research, Lagos. v.3, n.5, p. 164-173, 2009.

COXON, A. et al. A novel role for the beta 2 integrin CD11b/CD18 in neutrophil apoptosis: a homeostatic mechanism in inflammation. Immunity, Cambridge. v. 5, n. 6, p. 653-66, 1996.

DANIAL, N. N.; KORSMEYER, S. J. Cell death: critical control points. Cell, Cambridge. v. 116, n. 2, p. 205-19, 2004.

DAVICINO, R. C.; ELIÇABE, R. J.; DI GENARO, M. S.; RABINOVICH, G. A. Coupling pathogen recognition to innate immunity through glycan-dependent mechanisms. International immunopharmacology, Amsterdam. v. 11, n. 10, p. 1457-63, 2011.

DE OLIVEIRA, S.; SALDANHA, C. An overview about erythrocyte membrane. Clinical hemorheology and microcirculation, Amsterdam. v. 44, n. 1, p. 63-74, 2010.

DEMYDENKO, D.; BEREST, I. Expression of galectin-1 in malignant tumors. Experimental oncology, Kyiv. v. 31, n. 2, p. 74-9, 2009.

DI LELLA, S. et al. Linking the structure and thermal stability of beta-galactosidebinding protein galectin-1 to ligand binding and dimerization equilibria. Biochemistry, Washington. v. 49, n.35, p. 7652-8, 2010.

DIAS-BARUFFI, M. et al. Differential expression of immunomodulatory galectin-1 in peripheral leukocytes and adult tissues and its cytosolic organization in striated muscle. Glycobiology, Oxford. v. 20, n. 5, p. 507-20, 2010.

DIAS-BARUFFI, M. et al. Dimeric galectin-1 induces surface exposure of phosphatidylserine and phagocytic recognition of leukocytes without inducing 
apoptosis. The Journal of biological chemistry, Baltimore, v. 17, n. 42, p. 4128293, 2003.

DODERO, V. I.; QUIROLO, Z. B.; SEQUEIRA, M. A. Biomolecular studies by circular dichroism. Frontiers in bioscience : a journal and virtual library, Tampa. v. 16, p.61-73, 2011.

DRENTH, J. Principles of Protein X-Ray Crystallography. 3rd ed. New York: Springer Science and Business Media, 2006. 348 p.

EHLERS, M.R.W. CR3: a general purpose adhesion-recognition receptor essential for innate immunity. Microbes and infection, Paris. v. 2, p.289-294, 2000.

ELOLA, M. T.; CHIESA, M. E.; FINK, N. E. Activation of oxidative burst and degranulation of porcine neutrophils by a homologous spleen galectin-1 compared to $\mathrm{N}$-formyl-L-methionyl-L-leucyl-L-phenylalanine and phorbol 12-myristate 13-acetate. Comparative biochemistry and physiology. Part B, Biochemistry \& molecular biology, Oxford. v. 141, n. 1, p. 23-31, 2005.

EMSLEY, P.; COWTAN, K. Coot: model-building tools for molecular graphics. Acta Acta crystallographica. Section D, Biological crystallography, Copenhagen. v. 60 , p. 2126-2132, 2004.

EMSLEY, P.; LOHKAMP, B.; SCOTT, W.; COWTAN, K. Features and development of Coot. Acta Crystallographica D, Copenhagen. v. 66, n. 4, p. 486-501, 2010.

EVANS, P. JOINT CCP4/ESF-EAMCB. Newsletter on Protein Crystallography. [S.I]. v. 32, p. 22-24. 1997.

FADOK, V. A. et al. A receptor for phosphatidylserine-specific clearance of apoptotic cells. Nature, London. v. 405, p. 85-90, 2000.

FEIZI, T. et al. The adhesive specificity of the soluble human lectin, IgE-binding protein, toward lipid-linked oligosaccharides. Presence of the blood group A, B, Blike, and $\mathrm{H}$ monosaccharides confers a binding activity to tetrasaccharide (lacto- $\mathrm{N}$ tetraose and lacto-N-neotetraose) backbones. Biochemistry, Washington. V. 33, n. 20, p. 6342-9, 1994.

FILEP, J. G.; EL KEBIR, D. Neutrophil apoptosis: a target for enhancing the resolution of inflammation. Journal of cellular biochemistry. New York. v. 108, n. 5, p. 1039-46, 2009.

FORD, M. G.; WEIMAR, T.; KÖHLI, T.; WOODS, R. J. Molecular dynamics simulations of galectin-1-oligosaccharide complexes reveal the molecular basis for ligand diversity. Proteins, New York. v. 53, n.2, p. 229-40, 2003. 
GARÍN, M. I. et al. Galectin-1: a key effector of regulation mediated by CD4+CD25+ T cells. Blood, New York. v. 109, n. 5, p. 2058-65, 2007.

GARNER, O. B. et al. Endothelial galectin-1 binds to specific glycans on nipah virus fusion protein and inhibits maturation, mobility, and function to block syncytia formation. PLoS pathogens, San Francisco. v. 6, n. 7, p. 1-14, 2010.

GARNER, O. B.; BAUM, L. G. Galectin-glycan lattices regulate cell-surface glycoprotein organization and signalling. Biochemical Society transactions, London. v. 36, n. 6, p. 1472-7, 2008.

GASTEIGER, E. et al. Protein Identification and Analysis Tools on the ExPASy Server; (In) John M. Walker (ed): The Proteomics Protocols Handbook, Humana Press (2005). p. 571-607.

GIL, C. D.; GULLO, C. E.; OLIANI, S. M. Effect of exogenous galectin-1 on leukocyte migration: modulation of cytokine levels and adhesion molecules. International journal of clinical and experimental pathology, Madison. v. 4, n. 1, p.74-84, 2010.

GIORDANO, M.; CROCI. D. O.; RABINOVICH, G. A. Galectins in hematological malignancies. Current opinion in hematology, Philadelphia. v. 20, n. 4, p. 327-35, 2013.

GUIMARÃES, B.G. et al. The MX2 macromolecular crystallography beamline: a wiggler X-ray source at the LNLS. Journal of synchrotron radiation, Copenhagen. v. 16, p. 69-75, 2009.

HANNA, S., ETZIONI, A. Leukocyte adhesion deficiencies. Annals of the New York Academy of Sciences, New York. v. 1250, p.50-5, 2012.

HARLOW, E., LANE, D. Antibodies: A Laboratory Manual. New York: Cold Spring Harbor Laboratory Press, 1988. 726 p.

HAUDEK, K. C.; PATTERSON, R. J.; WANG, J. L. SR proteins and galectins: what's in a name? Glycobiology, Amsterdam. v. 20, n. 10, p. 1199-207, 2010.

HE, L. et al. Detection of ligand and solvent-induced shape alterations of cell-growthregulatory human lectin galectin-1 in solution by small angle neutron and X-ray scattering. Biophysical journal, New York. v. 85, p. 511-524, 2003.

HEIMBURG-MOLINARO, J.; SONG, X.; SMITH, D. F.; CUMMINGS, R. D. Preparation and analysis of glycan microarrays. Current protocols in protein science, Hoboken. capítulo 12, unidade12.10, 2011. 
HIRABAYASHI, J. et al. Oligosaccharide specificity of galectins: a search by frontal affinity chromatography. Biochimica et biophysica acta, Amsterdam. v. 1572, p. 232-54, 2002.

HIRAMATSU, $\mathrm{H}$. et al. Involvement of Histidine Residues in the $\mathrm{pH}$-Dependent $\beta$ Galactoside Binding Activity of Human Galectin-1. Biochemistry, Washington. v. 52, n. 13, p. 2371-80, 2013.

ILARREGUI, J. M. et al. Tolerogenic signals delivered by dendritic cells to $T$ cells through a galectin-1-driven immunoregulatory circuit involving interleukin 27 and interleukin 10. Nature immunology, New York. v. 10, n. 9, p. 981-91, 2009.

INAGAKI, Y. et al. Oxidized galectin-1 promotes axonal regeneration in peripheral nerves but does not possess lectin properties. European journal of biochemistry. Berlim. v. 267, p. 2955 $\pm 2964,2000$.

ISHIBASHI, S. et al. Galectin-1 regulates neurogenesis in the subventricular zone and promotes functional recovery after stroke. Experimental neurology, New York. v. 207, p. 302-313, 2007.

JANCARIK, J.; KIM, S. H. Sparse matrix sampling: a screening method for crystallization of proteins. Journal of Applied Crystallography, Copenhagen. v. 24, p. 409-411, 1991.

KAJITANI, K.; NOMARU, H.; IFUKU, M. et al. Galectin-1 promotes basal and kainate-induced proliferation of neural progenitors in the dentate gyrus of adult mouse hippocampus. Cell death and differentiation, London. v. 16, p. 417-427, 2009.

KARMAKAR, S.; CUMMINGS, R. D.; MCEVER, R. P. Contributions of Ca2+ to galectin-1-induced exposure of phosphatidylserine on activated neutrophils. The Journal of biological chemistry, Baltimore. v. 280, n. 31, p. 28623-31, 2005.

KARMAKAR, S.; STOWELL, S. R.; CUMMINGS, R. D.; MCEVER, R. P. Galectin-1 signaling in leukocytes requires expression of complex-type $\mathrm{N}$-glycans. Glycobiology, Oxford. v. 18, n. 10, p.770-8, 2008.

KAWASHIMA, H. Roles of Sulfated Glycans in Lymphocyte Homing. Biological \& pharmaceutical bulletin, Tóquio. v. 29, n. 12, p.2343-2349, 2006.

KELLY, S. M.; PRICE, N. C. The application of circular dichroism to studies of protein folding and unfolding. Biochimica et biophysica acta, Amsterdam. v.1338, n. 2, p.161-85, 1997. 
KURIHARA, D.; UENO, M.; TANAKA, T.; YAMASHITA, T. Expression of galectin-1 in immune cells and glial cells after spinal cord injury. Neuroscience research, Limerick. v. 66, n. 3, p. 265-70, 2010.

LA, M. et al. A novel biological activity for galectin-1: inhibition of leukocyteendothelial cell interactions in experimental inflammation. The American Journal of Pathology, Philadelphia, v. 163, n.4, p. 1505-15, 2003.

LEE R.T., ICHIKAWA Y., ALLEN H.J., LEE Y.C. Binding characteristics of galactoside-binding lectin (galaptin) from human spleen. The Journal of biological chemistry, Baltimore. v. 265, p. 7864- 7871, 1990.

LEFORT, C. T. et al. Outside-in signal transmission by conformational changes in integrin Mac-1. Journal of immunology, Baltimore. v. 183, n.10, p. 6460-8, 2009.

LEPPÄNEN, A.; STOWELL, S.; BLIXT, O.; CUMMINGS, R. D. Dimeric galectin-1 binds with high affinity to alpha2,3-sialylated and non-sialylated terminal $\mathrm{N}$ acetyllactosamine units on surface-bound extended glycans. The Journal of biological chemistry, Baltimore. v. 18, n. 7, p. 5549-62, 2005.

LESLIE, A.; POWELL, H.; READ, R.; SUSSMAN, J. Processing diffraction data with MOSFLM. Evolving Methods for Macromolecular Crystallography. v. 245, p. 41$51,2007$.

LIPSICK, J. S.; BEYER, E. C.; BARONDES, S. H.; KAPLAN, N. O. Lectins from chicken tissues are mitogenic for Thy-1 negative murine spleen cells. Biochemical and biophysical research communications, New York. v. 97, n.1, p. 56-61, 1980.

LIU, F. T.; RABINOVICH, G. A. Galectins as modulators of tumour progression. Nature reviews. Cancer, London. v. 5, n.1, p. 29-41, 2005.

LOHR, M. et al. Murine homodimeric adhesion/growth-regulatory galectins-1, -2 and 7: comparative profiling of gene/ promoter sequences by database mining, of expression by RT-PCR/immunohistochemistry and of contact sites for carbohydrate ligands by computational chemistry. Folia biologica, Praha. v. 53, n. 4, p.109-28, 2007.

LOKAR, M. et al. Agglutination of like-charged red blood cells induced by binding of beta2-glycoprotein I to outer cell surface. Bioelectrochemistry, London. v. 73, n. 2, p. 110-6, 2008.

LOPEZ-LUCENDO, M. F. et al. Growth-regulatory human galectin-1: crystallographic characterisation of the structural changes induced by single-site mutations and their impact on the thermodynamics of ligand binding. Journal of molecular biology, London. v. 343, n. 4, p. 957-70, 2004. 
MATTHEWS, B.W. Solvent content of protein crystals. Journal of molecular biology, London. v. 33, n. 2, p. 491-497, 1968.

MAYADAS, T.N.; CULLERE, X. Neutrophil beta2 integrins: moderators of life or death decisions. Trends in immunology, Oxford. v. 26, n.7, p. 388-95, 2005.

MCPHERSON, A. Introduction to macromolecular crystallography. 2nd edition. Hoboken: John Wiley \& Sons, Inc.2009.

MISHRA, B. B. et al. Galectin-3 functions as an alarmin: pathogenic role for sepsis development in murine respiratory tularemia. PLoS One, San Francisco. v. 8, n. 3, e59616, 2013.

MIURA, T. et al. Galectin-1beta, a natural monomeric form of galectin-1 lacking its six amino-terminal residues promotes axonal regeneration but not cell death. Cell death and differentiation, London. v. 11, n.10, p. 1076-83, 2004.

MOTRAN, C. C. et al. Galectin-1 functions as a Th2 cytokine that selectively induces Th1 apoptosis and promotes Th2 function. European journal of immunology, Weinheim. v. 38, n. 11, p. 3015-27, 2008.

NESMELOVA, I. V. et al. Lactose binding to galectin-1 modulates structural dynamics, increases conformational entropy, and occurs with apparent negative cooperativity. Journal of molecular biology, London. v. 397, n.5, p. 1209-30, 2010.

NISHI, N. et al. Galectin-8 modulates neutrophil function via interaction with integrin alphaM. Glycobiology, Oxford. v. 13, n. 11, p. 755-63, 2003.

NONAKA, M.; FUKUDA. M. Galectin-1 for neuroprotection? Immunity, Cambridge. v. 37, n. 2, p. 187-9, 2012.

ODOM, E. W.; VASTA, G. R. Characterization of a binary tandem domain F-type lectin from striped bass (Morone saxatilis). The Journal of biological chemistry, Baltimore. v. 281, n. 3, p. 1698-713. 2006.

OUYANG, J. et al. Galectin-1 serum levels reflect tumor burden and adverse clinical features in classical Hodgkin lymphoma. Blood, New York. v. 121, n. 17, p. 3431-3, 2013.

PATTERSON, R. J.; WANG, W.; WANG, J. L. Understanding the biochemical activities of galectin-1 and galectin-3 in the nucleus. Glycoconjugate journal, Lund. v. 19, n. 7-9, p. 499-506, 2004.

PERILLO, N. L.; PACE, K. E.; SEILHAMER, J. J.; BAUM, L. G. Apoptosis of T cells mediated by galectin-1. Nature, London. v. 378, p. 736-9, 1995. 
PERILLO, N. L.; UITTENBOGAART, C. H.; NGUYEN, J.T.; BAUM, L. G. Galectin-1, an endogenous lectin produced by thymic epithelial cells, induces apoptosis of human thymocytes. The Journal of experimental medicine, New York. v. 185, n.10, p. 1851-1858, 1997.

PLUSKOTA, E. et al. Expression, activation, and function of integrin alphaMbeta2 (Mac-1) on neutrophil-derived microparticles. Blood, New York. v. 112, n. 6, p. 232735, 2008.

POLIKARPOV, I. et al. Set-up and experimental parameters of the protein crystallography beamline at the Brazilian National Synchrotron Laboratory. Journal of Synchrotron Radiation, Copenhagen. v. 5, p. 72-76, 1998.

RABINOVICH, G. A.; TOSCANO, M. A.; JACKSON, S. S.; VASTA, G. R. Functions of cell surface galectin-glycoprotein lattices. Current opinion in structural biology, London. v. 17, n. 5, p. 513-20, 2007.

RABINOVICH, G. A.; TOSCANO, M. A. Turning 'sweet' on immunity: galectin-glycan interactions in immune tolerance and inflammation. Nature reviews. Immunology, London. v. 9, n. 5, p. 338-52, 2009.

RABINOVICH, G. A. Galectins: an evolutionarily conserved family of animal lectins with multifunctional properties; a trip from the gene to clinical therapy. Cell death and differentiation, London. v. 6, n. 8, p.711-21, 1999.

RABINOVICH, G. A. et al. Activated rat macrophages produce a galectin-1-like protein that induces apoptosis of $T$ cells: biochemical and functional characterization. Journal of immunology, Baltimore. v. 160, p. 4831-40, 1998.

RABINOVICH, G. A. et al. Induction of allogenic T-cell hyporesponsiveness by galectin-1-mediated apoptotic and non-apoptotic mechanisms. Cell death and differentiation, London. v. 9, n. 6, p. 661-70, 2002.

RILLAHAN, C. D.; PAULSON, J. C. Glycan microarrays for decoding the glycome. Annual review of biochemistry, Palo Alto. v. 80, p. 797-823, 2011.

ROMANIUK, M. A. et al. Binding of galectin-1 to $\alpha_{l l b} \beta_{3}$ integrin triggers "outside-in" signals, stimulates platelet activation, and controls primary hemostasis. FASEB journal: official publication of the Federation of American Societies for Experimental Biology, Bethesda. v. 26, p. 1-11, 2012.

ROSS, G. D. Regulation of the adhesion versus cytotoxic functions of the Mac1/CR3/a-m b-2 integrin glycoprotein. Critical reviews in immunology, Boca Raton. v. 20, p.197-222, 2000. 
RUBINSTEIN, N.; ILARREGUI, J. M.; TOSCANO, M. A.; RABINOVICH, G. A. The role of galectins in the initiation, amplification and resolution of the inflammatory response. Tissue Antigens, Copenhagen. v. 64, p.1-12, 2004.

SAKAGUCHI, M. et al. Regulation of adult neural progenitor cells by Galectin-1/ $\beta 1$ integrin interaction. Journal of neurochemistry, London. v. 113, p. 1515-1524, 2010.

SALOMONSSON, E. Monovalent Interactions of Galectin-1. Biochemistry, Washington. v. 49, n. 44, p. 9518-9532, 2010.

SANFORD, G. L.; OWENS, M. A.; ODUSANYA, B. M. Differential influence of dexamethasone on the activity and synthesis of beta-galactoside specific lectin (galaptin) during postnatal lung development. Experimental lung research, London. v. 19, n. 1, p. 91-104, 1993.

SANTUCCI, L. et al. Galectin-1 suppresses experimental colitis in mice. Gastroenterology, Philadelphia. v. 124, n. 5, p. 1381-94, 2003.

SATO, S.; OUELLET, M.; ST-PIERRE, C.; TREMBLAY, M. J. Glycans, galectins, and HIV-1 infection. Annals of the New York Academy of Sciences, New York. V. 1253, p. 133-48, 2012.

SATO, S.; ST-PIERRE, C.; BHAUMIK, P.; NIEMINEN, J. Galectins in innate immunity: dual functions of host soluble beta-galactoside-binding lectins as damageassociated molecular patterns (DAMPs) and as receptors for pathogen-associated molecular patterns (PAMPs). Immunological reviews, Copenhagen. v. 230, n. 1, p. 172-87, 2009.

SCOTT, S. A.; BUGARCIC, A.; BLANCHARD, H. Characterisation of oxidized recombinant human galectin-1. Protein and peptide letters, Schiphol v. 16, n. 10, p. 1249-55, 2009.

SCOTT, K.; WEINBERG, C. Galectin-1: A bifunctional regulator of cellular proliferation. Glycoconjugate Journal, Lund. v. 19, p. 467-477, 2004.

SCOTT, S. A.; SCOTT, K.; BLANCHARD, H. Crystallization and preliminary crystallographic analysis of recombinant human galectin-1. Acta crystallographica. Section F, Structural biology and crystallization communications, Chester. v. 1, n. 63(11), p. 967-71, 2007.

SCHATTNER, M.; RABINOVICH, G. A. Galectins: new agonists of platelet activation. Biological chemistry, Berlin. v. 94, n. 7, p. 857-63, 2013. 
SHARON, N.; LIS, H. Lectins: cell-agglutinating and sugar-specific proteins. Science, New York. v. 177, n. 4053, p. 949-59, 1972.

SHARON, N.; LIS, H. History of lectins: from hemagglutinins to biological recognition molecules. Glycobiology, Amsterdam. v. 14, n. 11, p. 53R-62R, 2004.

STOWELL, S. R. et al. Innate immune lectins kill bacteria expressing blood group antigen. Nature medicine, New York. v. 16, n. 3, p. 295-301, 2010.

STOWELL, S. R. et al. Ligand reduces galectin-1 sensitivity to oxidative inactivation by enhancing dimer formation. The Journal of biological chemistry, Baltimore. $v$. 284, n.8, p. 4989-99, 2009.

STOWELL, S. R. et al. Galectin-1 induces reversible phosphatidylserine exposure at the plasma membrane. Molecular biology of the cell, Bethesda. v. 20, n. 5, p.140818, 2009.

STOWELL, S. R. et al. Human galectin-1, -2, and -4 induce surface exposure of phosphatidylserine in activated human neutrophils but not in activated T cells. Blood, New York. v. 109, n. 1, p. 219-27, 2007.

STOWELL, S. R. et al. Differential roles of galectin-1 and galectin-3 in regulating leukocyte viability and cytokine secretion. Journal of immunology, Baltimore. v. 180, n. 5, p. 3091-102, 2008.

STOWELL, S. R. et al. Galectin-1, -2 , and -3 exhibit differential recognition of sialylated glycans and blood group antigens. The Journal of biological chemistry, Baltimore. v. 11, n.15, p. 10109-23, 2008.

STRASSER, A.; O'CONNOR, L.; AND DIXIT, V. M. Apoptosis signaling. Annual review of biochemistry, Palo Alto. v. 69, p. 217-245, 2000.

THIJSSEN, V. L. et al. Tumor cells secrete galectin-1 to enhance endothelial cell activity. Cancer research, Chicago. v. 1, n. 15, p.6216-24, 2010.

TOSCANO, M. A. et al. Nuclear factor (NF)-KB controls expression of the immunoregulatory glycan-binding protein galectin-1. Molecular immunology, Oxford. v. 48, n. 15-16, p. 1940-9, 2011.

TOSCANO, M. A. et al. Differential glycosylation of $\mathrm{TH} 1, \mathrm{TH} 2$ and $\mathrm{TH}-17$ effector cells selectively regulates susceptibility to cell death. Nature Immunology, New York. v. 8, n. 8, p. 825-834, 2007. 
VANCE, J. E. Phosphatidylserine and phosphatidylethanolamine in mammalian cells: two metabolically related aminophospholipids. Journal of lipid research, Memphis. v. 49 , n. 7 , p. 1377-87, 2008.

VARKI, A., CUMMINGS, R. D., ESKO, J. D., et al., editors. Essentials of Glycobiology. 2nd edition. New York: Cold Spring Harbor Laboratory Press, 2009.

VASTA, G. R. Roles of galectins in infection. Nature reviews. Microbiology, London. v. 7, n. 6, p. 424-38, 2009.

VASTA, G. R. Galectins as pattern recognition receptors: structure, function, and evolution. Advances in experimental medicine and biology, New York. v. 946, p. 21-36, 2012.

VILLALOBO, A.; GABIUS, H. Review Signaling pathways for transduction of the initial message of the glycocode into cellular responses. Acta anatomica, Basel. v. 161, p. 110-29, 1998.

VOSS, P. G. et al. Dissociation of the carbohydrate-binding and splicing activities of galectin-1. Archives of biochemistry and biophysics, New York. v. 478, n. 1, p. 18-25, 2008.

VYAKARNAM, A.; DAGHER, S. F.; WANG, J. L.; PATTERSON, R. J. Evidence for a role for galectin-1 in pre-mRNA splicing. Molecular and cellular biology, Washington, D.C. v. 17, n. 8, p. 4730-7, 1997.

WATANABE, M. Regeneration of optic nerve fibers of adult mammals. Development, growth \& differentiation, Nagoya. v.52, n. 7, p. 567-76, 2010.

WILSON, T. J.; FIRTH, M. N.; POWELL, J. T.; HARRISON, F. L. The sequence of the mouse $14 \mathrm{kDa}$ beta-galactoside-binding lectin and evidence for its synthesis on free cytoplasmic ribosomes. The Biochemical journal, London. v. 261, n. 3, p. 847$52,1989$.

YANG, R. Y.; RABINOVICH, G. A.; LIU, F. T. Galectins: structure, function and therapeutic potential. Expert reviews in molecular medicine, Cambridge. v. 10, $\mathrm{n}$. 17 , p. 1-24, 2008.

YAWATA, Y. Cell Membrane: The Red Blood Cell as a Model. Weinheim: WileyVHC, 2003. $454 \mathrm{p}$

ZHANG, B.; HIRAHASHI, J.; CULLERE, X.; MAYADAS, T.N. Elucidation of molecular events leading to neutrophil apoptosis following phagocytosis: cross-talk between caspase 8 , reactive oxygen species, and MAPK/ERK activation. The Journal of biological chemistry, Baltimore. v. 278, n. 31, p. 28443-54, 2003. 
ZHOU, Q.; CUMMINGS, R. D. L-14 lectin recognition of laminin and its promotion of in vitro cell adhesion. Archives of biochemistry and biophysics, New York. v. 300, p. 6-17, 1993. 